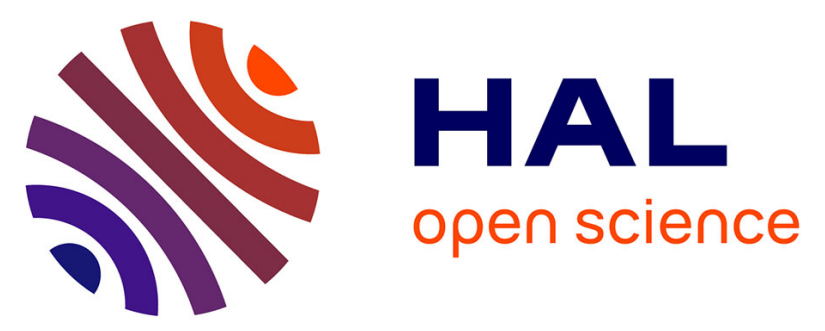

\title{
In silico studies, synthesis and binding evaluation of substituted 2-pyrrolidinones as peptidomimetics of RGD tripeptide sequence
}

Valérie Toum, Julie Bolley, Yoann Lalatonne, Carole Barbey, Laurence Motte, Marc Lecouvey, Jacques Royer, Nathalie Dupont, Joelle Pérard-Viret

\section{To cite this version:}

Valérie Toum, Julie Bolley, Yoann Lalatonne, Carole Barbey, Laurence Motte, et al.. In silico studies, synthesis and binding evaluation of substituted 2-pyrrolidinones as peptidomimetics of RGD tripeptide sequence. European Journal of Medicinal Chemistry, 2015, 93, pp.360. 10.1016/j.ejmech.2015.02.017 . hal-01904943

\section{HAL Id: hal-01904943 \\ https://hal.science/hal-01904943}

Submitted on 25 Oct 2018

HAL is a multi-disciplinary open access archive for the deposit and dissemination of scientific research documents, whether they are published or not. The documents may come from teaching and research institutions in France or abroad, or from public or private research centers.
L'archive ouverte pluridisciplinaire HAL, est destinée au dépôt et à la diffusion de documents scientifiques de niveau recherche, publiés ou non, émanant des établissements d'enseignement et de recherche français ou étrangers, des laboratoires publics ou privés. 


\title{
In silico studies, synthesis and binding evaluation of substituted 2- pyrrolidinones as peptidomimetics of RGD tripeptide sequence
}

\author{
Valérie Toum, ${ }^{a}$ Julie Bolley, ${ }^{b}$ Yoann Lalatonne, ${ }^{b}$ Carole Barbey, ${ }^{b}$ Laurence Motte, ${ }^{b}$ \\ Marc Lecouvey, Jacques Royer, ${ }^{a}$ Nathalie Dupont, ${ }^{b}$ Joëlle Pérard-Viret ${ }^{a}$ \\ ${ }^{a}$ Université Paris Descartes, Sorbonne Paris Cité, Faculté de Pharmacie, CNRS (UMR 8638), 4 avenue de l'observatoire \\ 75240 Paris cedex 06, France. \\ ${ }^{b}$ Université Paris 13, Sorbonne Paris Cité, Laboratoire CSPBAT, CNRS (UMR 7244) 74 avenue M. Cachin 93017 Bobigny, \\ France. \\ *corresponding author: E-mail: joelle.perard@parisdescartes.fr ; Fax: 331 43291403; Tel: 33153739749.
}

\begin{abstract}
In silico optimisation, synthesis and binding evaluation of $\alpha_{\mathrm{v}} \beta_{3}$ integrin's affinity for precursors of a new RGD peptidomimetics family are presented. The 2-pyrrolidinone building block was obtained by condensation of L-lysine with dimethoxydihydrofuran followed by reduction. The ring was functionalized with a carboxylic acid and a guanidinium appendage. On the pyrrolidinone heterocycle, the effects on affinity of position, length and relative geometry of the two acid or basic functionalized side chains introduced on the pyrrolidinone ring have been previously evaluated by docking studies. Peptidomimetics have finally been evaluated by competition binding assays for $\alpha v \beta 3$ integrin's affinity using radio-ligands.
\end{abstract}

Keywords: peptidomimetics, RGD, Integrin, docking, synthesis, binding.

\section{Introduction}

Integrins are heterodimeric transmembrane receptors which regulate cell attachment and response to the extracellular matrix. They are involved in many physiopathological processes: blood coagulation, tumorinduced angiogenesis, osteoporosis, restenosis, acute renal failure, ocular diseases, metastasis formation and sickle cell anaemia, and represent interesting targets for therapeutic and diagnosis purposes.[1-4]

Among the 24 known integrins, $\alpha_{v} \beta_{3}$ integrin is of particular interest since it plays a key role in angiogenesis, a process considered for cancer therapy by inhibiting vascularisation of tumors. [5, 6] It is also overexpressed in solid tumors such as glioblastomia, melanomas, and ovarian, breast and prostate cancers where it takes part in metastases formation.

The tripeptide Arg-Gly-Asp (RGD) is the motif of recognition for $\alpha_{v} \beta_{3}$ and seven other integrins on several matrix proteins (vitronectin $(\mathrm{VN})$, fibronectin $(\mathrm{FN})$ )... The specificity of each integrin depends on the conformation of this peptidic triad induced by the other residues.

Many studies have reported the development of linear and cyclic peptides, peptidomimetics or small molecules with affinity for RGD based integrins. Among them, a cyclic pentapeptide (c(-RGDf[NMe]V-) Cilengitide EMD 121974) presents a subnanomolar affinity for the $\alpha_{v} \beta_{3}$ integrin.[7]A Phase III study of Cilengitide is presently ongoing for glioblastoma, a very aggressive type of brain tumor.[8] However, recent studies showed that Cilengitide seemed unable to alter the pattern of glioblastoma progression. [9] Cilengitide also entered into Phase II trials for the treatment of several other types of cancers, such as prostate cancer, due to its capability to antagonize $\alpha_{\mathrm{v}} \beta_{3}, \alpha_{\mathrm{v}} \beta_{5}$ and $\alpha_{5} \beta_{1}$ integrins. [8]

Research efforts have been focused on changing the scaffold rigidity and the nature of the basic moiety. Peptidomimetics allow those modifications and also offer the possibility to incorporate unnatural amino acids and other building blocks to achieve a proper insertion of the molecule into the binding pocket.

A lot of studies describing access to peptidomimetics have recently been published.[10-16]

Few years ago, we described RGD mimics 1 based on indolizin-3-one skeleton.[17] Two of these mimics have shown moderate biological activity (Figure 1). The aim of this work is to develop new flexible structures having a single ring and of an additional amine function providing an anchor point for a drug or a carrier. in silico In order to increase the affinity for the integrin receptor (figure1). The synthesized peptidomimetics will evaluated by competition bindings assays to validate the docking studies 

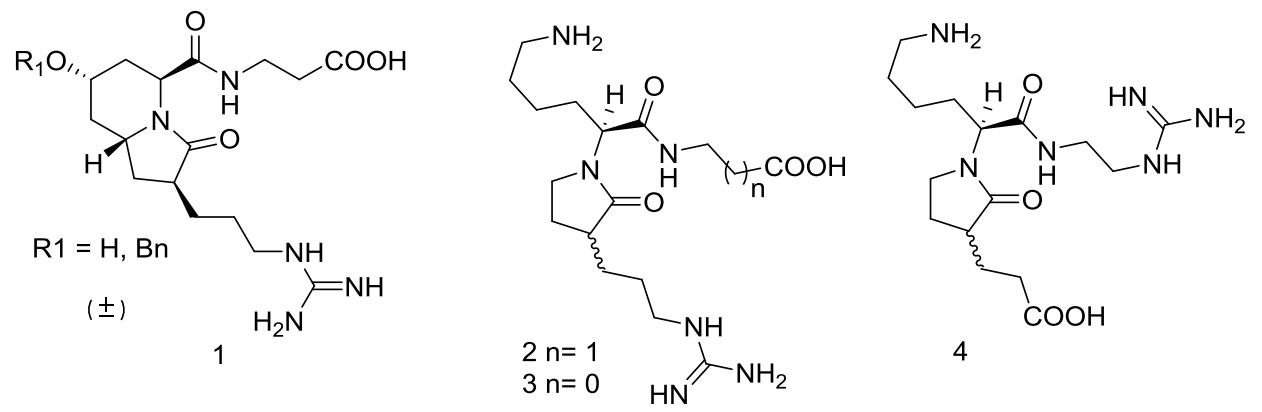

Figure 1: RGD peptidomimetics

\section{Results and discussion}

\subsection{In silico studies}

In order to evaluate and compare peptidomimetics's affinities for integrin before embarking on chemical experimental synthesis, molecular docking studies have been performed starting from the crystal structure of the human integrin alpha $\mathrm{V}$ beta 3 extracellular segment in complex with a cyclic pentapeptide ligand Arg-Gly-Asp- $\{\mathrm{d}-\mathrm{Phe}\}-\{N$-methyl-Val- $\}, \quad$ so-called $\quad$ cyclo(RGDF=N $\{\mathrm{Me}\} \mathrm{V}) \quad$ (PDB Accession code 1L5G)[18].

The binding mode of cyclo $(\mathrm{RGDF}=\mathrm{N}\{\mathrm{Me}\} \mathrm{V})$, taken into account for docking calculations, is best described as a three-points pharmacophore [19, 20] and is depicted using LigX [21] on Figure 2.
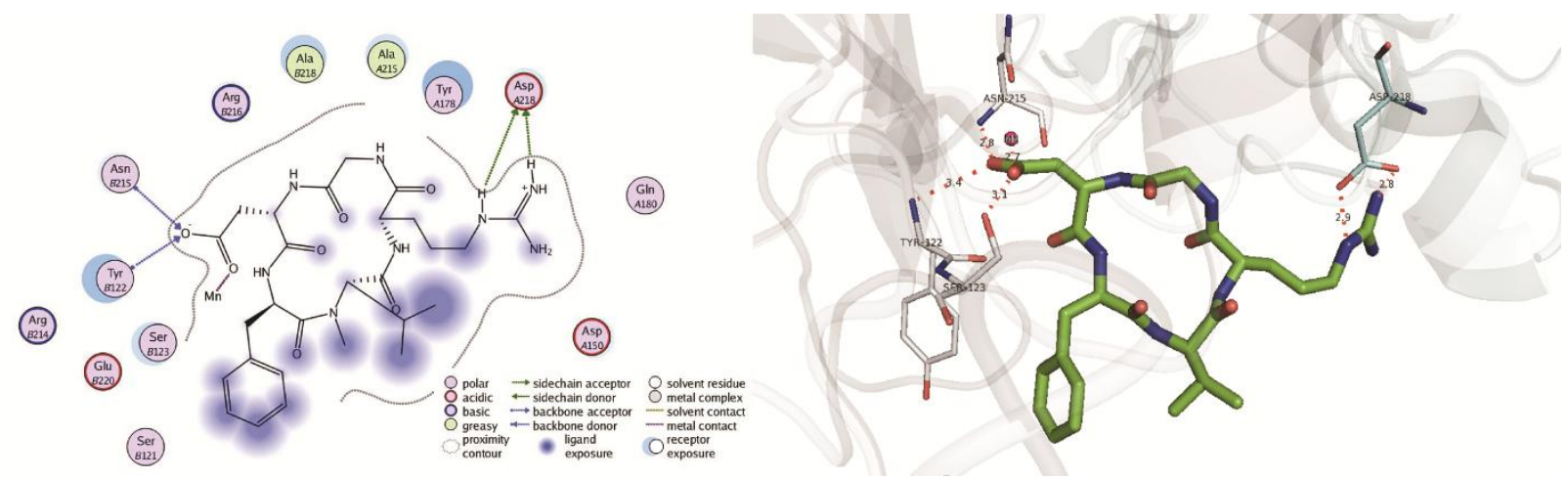

Figure 2 : LigX 2D-depiction (left side) and 3D-representation focused on Arg and Asp side chains (right side) of the binding mode of cyclo $(\mathrm{RGDF}=\mathrm{N}\{\mathrm{Me}\} \mathrm{V})$ to integrin alpha $\mathrm{V}$ beta 3 in PBD $1 \mathrm{~L} 5 \mathrm{G}$

The Arg and Asp side chains of the ligand, mimick the corresponding residues of the adhesive RGD sequence and point in opposite directions, respectively contacting A and B chains. Those two groups are determinants for receptor recognition, whereas the dPhe group, performing intra-ligand and extra-ligand hydrophobic contacts with Tyr122 (chain B), has been introduced to enhance pharmacological potency [22, 23]. The arginine guanidinium group is held in place by a bidentate salt bridge with Asp 218 and by an additional salt bridge with Asp150. One of the Asp carboxylate oxygen atom is in contact with a $\mathrm{Mn}^{2+}$ ion while the second Asp carboxyl oxygen forms hydrogen bonds with the backbone amides of Tyr122 and Asn215 and also contacts the aliphatic portion of the Arg214 side chain. The glycine residue, which completes the prototype RGD ligand sequence, lies at the interface between the A and B subunits and is involved in several hydrophobic interactions. The remaining two residues of the pentapeptide face away from the AB interface.

Peptidomimetics have been designed on the basis of cyclo(RGDF=N $\{\mathrm{Me}\} \mathrm{V})$ mainly with modulations includind chains' length, stereochemistry and some basic feature as mapped on Figure 3. For this first 
study, we did not consider the aromatic part of the three point pharmacophore. Further optimizations based upon aromatic insertion are ongoing.

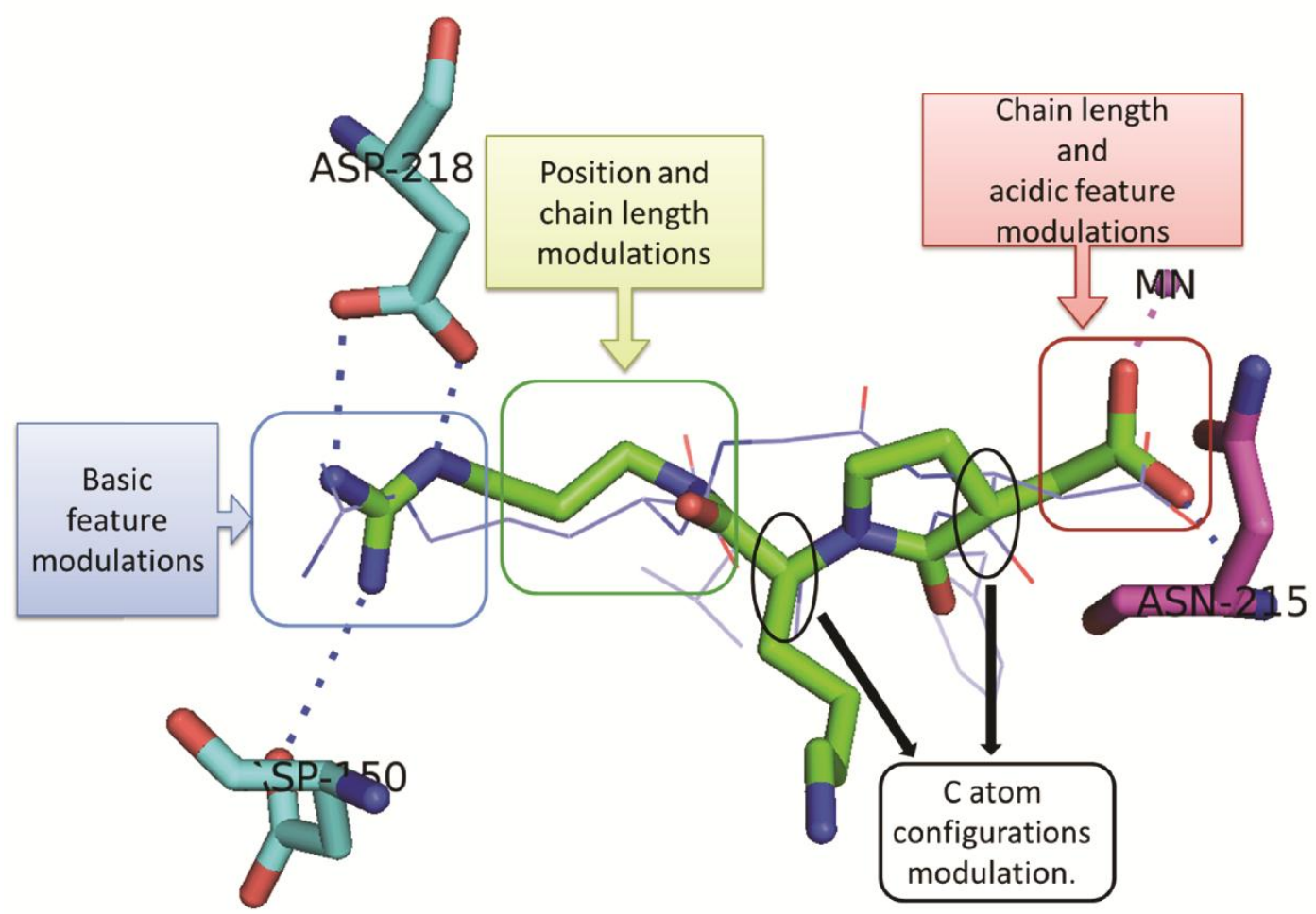

Figure 3 : Structural basis of in silico optimization of peptidomimetics

Docking calculations were performed with the minimized conformations using the GOLD suite version $5.1[24,25]$ into the active site initially containing the cyclo(RGDF=N $\{\mathrm{Me}\} \mathrm{V})$.

The best docking solutions were selected, first of all, on the basis of their attained fitness values and finally, after verification of the binding mode's preservation.

Best poses were obtained for derivates of compounds $\mathbf{2}$ and $\mathbf{4}$ with guanidinium as basic features and specific stereochemistries : $(2 \mathrm{~S}, 3 \mathrm{~S})$ configuration in compound $\mathbf{2}$ and $(3 \mathrm{~S}, 5 \mathrm{R})$ configuration in compound $\mathbf{4}$. Docking results analysis showed that the acidic chains' length in compounds $\mathbf{3}$ did not allow to correctly reach the proximity of $\mathrm{Mn}^{2+}$ ion and to form hydrogen bonds with Tyr122 and Asn215.

Table 1 sums up the most significant results. Overlay representations of cyclo $(\mathrm{RGDF}=\mathrm{NMeV})$ with the best docking poses for compounds 2, 3 and 4 with guanidinium feature are given as supplementary material (Figures S1,S2,S3).

Table 1 : Sum up of docking results. Compound references 1 to $\mathbf{4}$ are related to Figure 1 but calculations were done without any amine function to bind to a drug or a carrier.

\begin{tabular}{|c|c|c|c|}
\hline Parent Compounds & $\begin{array}{c}\text { Stereochemistry of pyrrolidinone C3 } \\
\text { carbon }\end{array}$ & Basic feature & $\begin{array}{l}\text { ChemPLP fitness } \\
\text { score }\end{array}$ \\
\hline $\begin{array}{c}\text { Reference redocked } \\
\text { cyclo }(\mathrm{RGDF}=\mathrm{N}\{\mathrm{Me}\} \mathrm{V})\end{array}$ & Not concerned & Guanidinium & 79.5 \\
\hline 1 & $(\mathrm{R} 1=\mathrm{H})$ & Guanidinium & 64.9 \\
\hline \multirow{4}{*}{2} & $\mathrm{R}$ & \multirow{2}{*}{ Amine } & 56.9 \\
\hline & $\mathrm{S}$ & & 56 \\
\hline & $\mathrm{R}$ & \multirow{2}{*}{ Guanidinium } & 63.7 \\
\hline & $\mathrm{S}$ & & 64.8 \\
\hline \multirow{3}{*}{3} & $\mathrm{R}$ & \multirow{2}{*}{ Amine } & No result \\
\hline & $\mathrm{S}$ & & 52,7 \\
\hline & $\mathrm{R}$ & Guanidinium & 61 \\
\hline
\end{tabular}




\begin{tabular}{|c|c|c|c|}
\hline & S & & 58,8 \\
\hline \multirow{4}{*}{4} & $\mathrm{R}$ & \multirow{2}{*}{ Amine } & 52 \\
\hline & $S$ & & 49.4 \\
\hline & $\mathrm{R}$ & \multirow{2}{*}{ Guanidinium } & 69 \\
\hline & S & & 56.6 \\
\hline
\end{tabular}

\subsection{Synthesis}

\subsubsection{Synthesis of the pyrolidinone building block}

The first step of the synthesis was the condensation of dimethoxydihydrofuran ${ }^{8}$ with L-CbzN ${ }^{\varepsilon}$ Lys-OMe $\mathbf{5}$ in acidic medium (Scheme 1). The resulting lactame 6 was directly hydrogenated. Using specific conditions $(5 \% \mathrm{Pd} / \mathrm{C}$ as a catalyst in ethyl acetate) $[26,27]$ the carbobenzoxy protection was preserved and only $10 \%$ of deprotected compound was observed. The saturated methyl ester was reduced with $\mathrm{NaBH}_{4}$ to afford alcohol $\mathbf{7}$ in 38\% yield over 3 steps. As direct allylation of $\mathbf{7}$ failed the alcohol group was protected as a tertbutyldimethylsilyl ester $(90 \%)$ using TBDMSCl. Then the side chain on the pyrolidinone skeleton had to be introduced with an appropriate relative configuration. An allyl group in position alpha with respect to the lactam carbonyl was chosen as it can be easily converted into various functions: alcohol, guanidine, carboxylic acid. This allylation was performed by treatment with allyl bromide after deprotonation using LDA in THF (scheme 2). The mixture of diastereoisomers obtained in 83/17 ratio was separated by chromatography on silica gel to give pure compounds $\mathbf{8 a}(62 \%)$ and $\mathbf{8 b}(13 \%)$. In order to modify the diastereoselectivity we turned towards less hindered protecting groups (allyl, MOM). The protected intermediates were obtained in moderate yield $(62 \%, 64 \%)$. When allyl ether was used a single diastereomer was obtained in $74 \%$ yield but unfortunately it couldn't be deprotected afterwards and only degradation products were observed certainly due to the presence of two double bonds. Using MOM ether the diastereoisomers were obtained in $40 \%$ and $11 \%$ yields, after deprotection with TFA, the major one being the same as with the TBDMS protecting group. Therefore the synthesis was carried on using the TBDMS protected compound. After cleavage of the silyl ether with tetrabubylammonium fluoride, the alcohol was oxidized by using Jones reagent to give acids 9a (72\%, from major diastereoisomer) and $\mathbf{9 b}$ (62\%, from minor diastereoisomer). Tags $\mathbf{a}$ (major) or $\mathbf{b}$ (minor) will be applied from now on to point out each diastereomer.
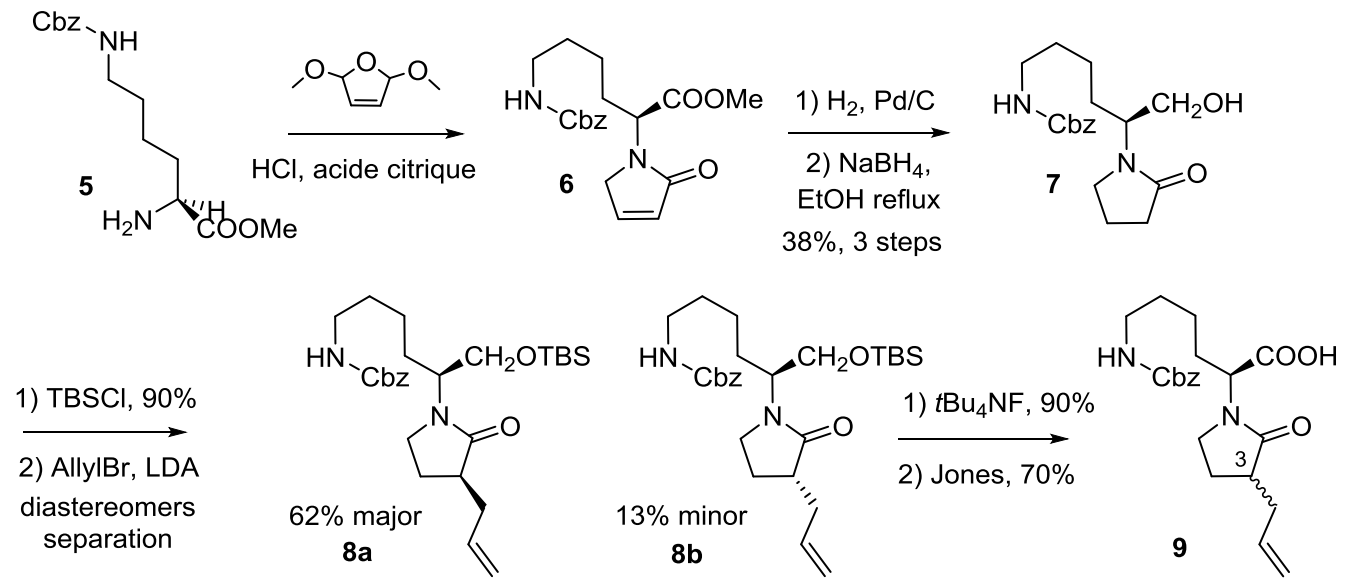

Scheme 1: synthesis of the key product 9

The absolute configuration of the $\mathrm{C} 3$ carbon atom bearing the allyl group on the diastereomers 9 could not be clearly inferred from spectroscopic data and only X-ray analysis of the major diastereoisomer 9a allowed us to unequivocally confirm its $S$ configuration. The ORTEP view reporting crystal structure of 9a is shown in Figure S4.

The acid compound 9 was the key intermediate for introduction of the critical acid and basic functions. The synthesis was performed successively on the two diastereoisomers,

\subsubsection{Introduction of acidic and basic functions}


Coupling reactions (EDC, NMM, HOBt) of carboxylic acids $9 \mathbf{a}$ and $\mathbf{9 b}$ with $\beta$-Alanine ter-butylester led to compounds 10a $(90 \%)$ and $\mathbf{1 0 b}(86 \%)$ and coupling reaction with glycine -ter-butylester gave $\mathbf{1 1}(89 \%)$. Hydroboration of the double bond was conducted with borabiclyclo-nonane followed by oxidation with $\mathrm{H}_{2} \mathrm{O}_{2}$ leading to the primary alcohol (70\% yield). Then substitution of the hydroxyl group by a guanidine through a Mitsunobu reaction with $\mathrm{DIAD} / \mathrm{PPh}_{3}$ and diBoc-guanidine afforded 12a (78\%), 12b $(85 \%)$ and 13a $(84 \%)$ in good yields. Deprotection by trifluoroacetic acid gave three mimics $\mathbf{1 5 a}(80 \%), \mathbf{1 6 a}$ and $\mathbf{1 6 b}$ (quantitative yield). The carbobenzoxy protecting group mimics the drug or the carrier which could be link to RGD peptidomimetics. Palladium/carbon treatment of $\mathbf{1 2 a}$ and $\mathbf{1 2 b}$ followed by trifluoroacetic acid hydrolysis also gave two analogues $14 \mathbf{a}$ and $14 \mathbf{b}$ (Scheme 2)..

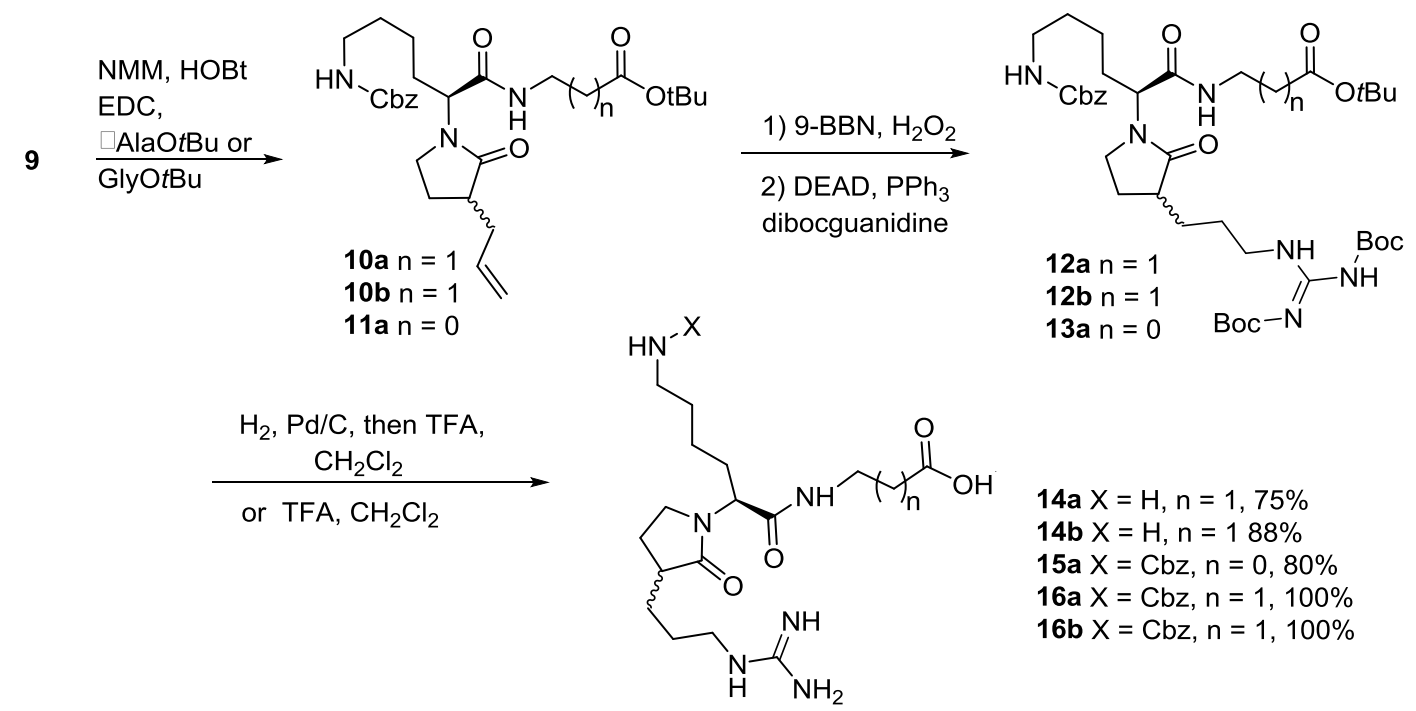

Scheme 2: introduction of acid and basic moiety

In a second sequence, we reversed the position of the carboxylic and guanidine groups (Scheme 3). The carboxylic acid 9a was coupled (EDC, NMM, HOBt) with $N$-Fmoc1,2-diaminoethane to give 17 (91\%). After an hydroboration step $(61 \%)$ oxydation of the alcohol $\mathbf{1 8}$ with Jones reagent gave access to acid 19 $(64 \%)$. After cleavage of the Fmoc group with piperidine the amino acid 20 was isolated in quantitative yield. The basic moiety (guanidine) was introduced via a substitution reaction with $N, N^{\prime}-$ diBoc- $1 H$ pyrazole-1-carboxamidine in a moderate yield (54\%). Deprotection with trifluoroacetic acid gave quantitatively the new mimic 22. 

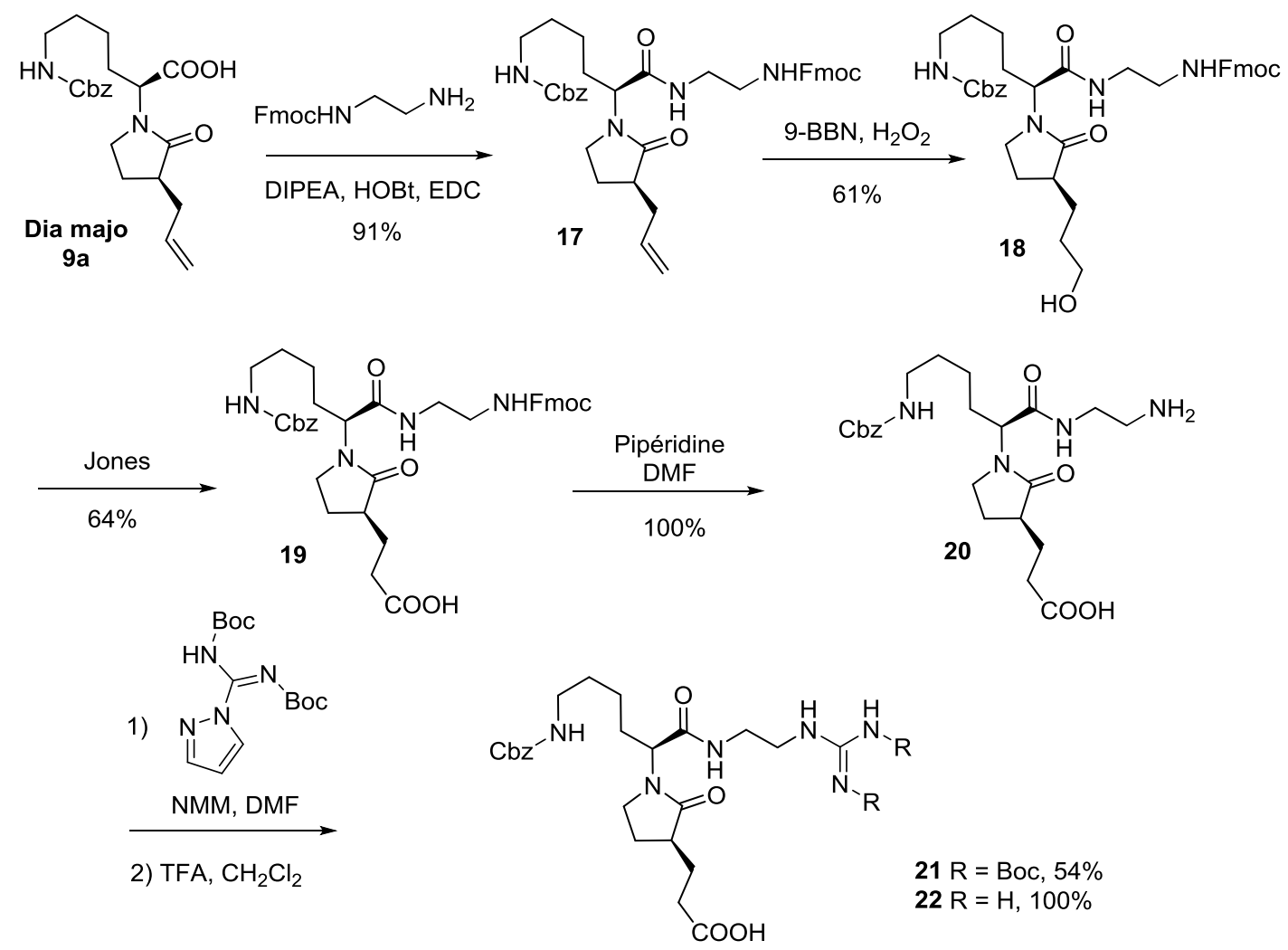

Scheme 3: introduction of acid and basic moiety with inversion position

\subsection{Competition Binding Assay for $\alpha_{v} \beta_{3}$ integrins affinity}

Compounds 14a and 14 b were previously tested by cell adhesion assay on S180 cells. The inhibition of adherence was quite the same as compounds 1 . To increase accuracy about their potential activity, we decided to test the new compounds by competition binding assay.

To accurately determine the affinity and specificity of our peptidomimetics for $\alpha_{\mathrm{v}} \beta_{3}$ integrins, we used radioactive ${ }^{125} \mathrm{I}$-labeled echistatin solid phase binding assay[28, 29]. Purified $\alpha_{\mathrm{v}} \beta_{3}$ receptor was coated onto Microlite-2+ plates at a concentration of $50 \mathrm{ng} /$ well as described in experimental section. ${ }^{125} \mathrm{I}-$ Echistatin was added into the wells to a final concentration $\mathrm{L}^{*}$ of $0.05 \mathrm{nM}$ in binding buffer $(50 \mu 1 /$ well $)$ in the presence of competing ligand. cRGDfK or peptidomimetics dissolved in binding buffer at the concentrations indicated were added before the addition of radio-ligand.

After a $3 \mathrm{~h}$ incubation at room temperature, the wells were washed and radioactivity was determined with a gamma counter (wizard 1470, Perkin Elmer). All measurements were done in triplicate with standard deviations of less than $10 \%$. The results are presented in Table 2.

\begin{tabular}{|c|c|}
\hline mimics & IC50 $(\mu \mathrm{M})$ \\
\hline c(RGDfK $)$ & 0.093 \\
\hline $\mathbf{1 4 a}$ & $\#$ \\
\hline $\mathbf{1 4 b}$ & 50 \\
\hline $\mathbf{1 5 a}$ & $\#$ \\
\hline $\mathbf{1 6 a}$ & $\#$ \\
\hline $\mathbf{1 6 b}$ & 100 \\
\hline $\mathbf{2 0}$ & $\#$ \\
\hline $\mathbf{2 2}$ & $>100\left(30\right.$ on $\left.\alpha_{\mathrm{v}} \beta_{5}\right)$ \\
\hline
\end{tabular}

Table 2: IC50 towards $\alpha_{\mathrm{v}} \beta_{3}$, obtained by competition binding assay

Measured affinities for $\alpha_{\mathrm{v}} \beta_{3}$ and $\alpha_{\mathrm{v}} \beta_{5}$ integrins are quite low compared to c(RGDfK) affinity. Compounds 14b and 16b differ only from the presence of $\mathrm{NH}_{2}$ appendage protective moiety and both present a measurable affinity for integrin $\alpha_{v} \beta_{3}$, that indicates that activity must be induced by the right pharmacophoric acidic and basic functions. It is noticeable that inversed compound 22 presents more 
affinity for $\alpha_{\mathrm{v}} \beta_{5}$ than for $\alpha_{\mathrm{v}} \beta_{3}$. Compounds $\mathbf{1 4 b}, \mathbf{1 6 b}$ and 22 present low but measurable affinities for integrins $\alpha_{\mathrm{v}} \beta_{3}$ and $\alpha_{\mathrm{v}} \beta_{5}$ and correspond to the best docking scores. These compounds turned out to be promising compounds for further optimizations including insertion of an aromatic pharmacophoric function.

\section{Conclusion}

New series of peptidomimetics starting from in silico studies up to their binding evaluation after complete synthesis and characterization were designed. It turned out that these molecules had low activities compare to the cyclopentapeptide. Nevertheless active mimics matched best docking scores with the right scaffold length, the right stereochemistry and guanidinium function as basic feature. We can lean on them for the design of more successful structures. As previously described [30] and in silico predicted, compounds with an amine function as basic feature have less affinity for $\alpha_{v} \beta_{3}$ integrins. The introduction of a hydrophobic groups on the basis of a three-point pharmacophore should be improve the affinity of these ligands. In silico studies are in progress

We aim to link peptidomimetics to nanoparticles for diagnosis application in order to improve their affinity as it has been already demonstrated for c(RGDfK).[31]

\section{Experimental section}

\subsection{General experimental methods}

All commercially available reagents were used without further purification unless otherwise noted. Tetrahydrofuran was freshly distilled from benzophenone ketyl radical under argon prior to use. Column chromatography was performed with silica gel (35-70 mesh).

NMR spectra were recorded on 300 and $400 \mathrm{MHz}$ Bruker Avance spectrometers. Chemical shifts are reported in ppm. Coupling constants ( $J$ values) are reported in Hertz. ${ }^{13} \mathrm{C}$ and ${ }^{1} \mathrm{H}$ peak assignments were made based on DEPT, HMQC, HSQC, HSBC data and IR spectra were recorded on a FT-IR spectrometer Perkin Elmer 1600. MS experiments were performed on a Z-Q- Micromass spectrometer. HRMS were performed on a LCT premier Waters. Specific rotations were measured at $20^{\circ} \mathrm{C}$ with a Perkin Elmer 341 polarimeter at $589 \mathrm{~nm}$.

\subsection{1 (2S)-6-Benzyloxycarbonylamino-2-(2-oxo-2,5-dihydro-pyrrol-1-yl)-hexanoic acid methyl ester} 6

To a solution of $\mathrm{N}^{\varepsilon}$-Z-L-lysine methyl ester hydrochloride $(20 \mathrm{~g}, 60 \mathrm{mmol})$ in $220 \mathrm{~mL}$ of water at $50{ }^{\circ} \mathrm{C}$ was added $11.52 \mathrm{~g}$ of citric acid and $7.26 \mathrm{~mL}(60 \mathrm{mmol})$ of dimethoxydihydrofuran. The reaction was stirred $10 \mathrm{~min}$, then put in an ice bath and $32 \mathrm{~g}$ of sodium acetate were added by portion. The solution was stirred for 1 hour and extracted by $\mathrm{CH}_{2} \mathrm{Cl}_{2}$ (3 times) the organic layers was dried $\left(\mathrm{MgSO}_{4}\right)$ and concentrated under vacuum. A redbrown oil was obtained and filtered over vegetal charcoal (7 spoons) in $\mathrm{CH}_{2} \mathrm{Cl}_{2}$. After filtration and evaporation of the solvent $14.35 \mathrm{~g}(66 \%)$ of red-brown oil was obtained. The crude product was used without further purification.

${ }^{1} \mathrm{H}$ NMR $\left(300 \mathrm{MHz}, \mathrm{CDCl}_{3}\right): \delta_{\mathrm{H}} 1.15\left(\mathrm{~m}, 2 \mathrm{H}, \mathrm{H}_{4}\right) ; 1.42\left(\mathrm{~m}, 2 \mathrm{H}, \mathrm{H}_{5}\right) ; 1.61-1.69\left(\mathrm{~m}, 1 \mathrm{H}, \mathrm{H}_{3}\right) ; 1.82-1.91(\mathrm{~m}, 1 \mathrm{H}$, $\left.\mathrm{H}_{3}\right) ; 3.02\left(\mathrm{dd}, 2 \mathrm{H}, J=12.8,6.7 \mathrm{~Hz}, \mathrm{H}_{6}\right) ; 3.56(\mathrm{~s}, 3 \mathrm{H}, \mathrm{COOMe}) ; 3.81\left(\mathrm{~d}, 1 \mathrm{H}, J=9 \mathrm{~Hz}, \mathrm{H}_{5}\right) ; 4.10(\mathrm{~d}, 1 \mathrm{H}, J=9 \mathrm{~Hz}$, $\left.\mathrm{H}_{5}\right) ; 4.73\left(\mathrm{dd}, 1 \mathrm{H}, J=10.6,4.8 \mathrm{~Hz}, \mathrm{H}_{2}\right) ; 4.96\left(\mathrm{~s}, 2 \mathrm{H}, \mathrm{PhCH}_{2}\right) ; 5.51(\mathrm{t}, 1 \mathrm{H}, J=5.4 \mathrm{~Hz}, \mathrm{NH}) ; 6.02(\mathrm{~d}, 1 \mathrm{H}, J=5.9$ $\left.\mathrm{Hz}, \mathrm{H}_{4}\right) ; 6.99\left(\mathrm{~d}, 1 \mathrm{H}, J=5.9 \mathrm{~Hz}, \mathrm{H}_{3}\right) ; 7.18(\mathrm{~m}, 5 \mathrm{H}, \mathrm{Ar}) .{ }^{13} \mathrm{C} \mathrm{NMR}\left(75 \mathrm{MHz}, \mathrm{CDCl}_{3}\right) \delta_{\mathrm{C}} 23.0\left(\mathrm{C}_{4}\right) ; 29.0\left(\mathrm{C}_{5}\right) ; 29.5$ $\left(\mathrm{C}_{3}\right) ; 40.4\left(\mathrm{C}_{6}\right) ; 49.7\left(\mathrm{C}_{5}\right) ; 52.2$ (COOMe); $53.0\left(\mathrm{C}_{2}\right) ; 66.2\left(\mathrm{PhCH}_{2}\right) ; 126.84\left(\mathrm{C}_{4}\right) ; 127.9\left(\mathrm{C}_{\mathrm{Ar}}\right) ; 136.7\left(\mathrm{C}_{\text {Arquat }}\right)$; $144.3\left(\mathrm{C}_{3}\right) ; 156.6(\mathrm{CO}) ; 171.8-172.0(2 \mathrm{CO})$.

\subsection{2 (2S)-6-Benzyloxycarbonylamino-2-(2-oxo-pyrrolidin-1-yl)-hexanoic acid methyl ester}

Ester (13.4 g, $37 \mathrm{mmol}$ ) was dissolved in $150 \mathrm{~mL}$ of ethyl acetate, $1.3 \mathrm{~g}$ of Pd/C 5\% was added. The mixture was hydrogenated at atmospheric pressure for 16 hours. After filtration of the catalyst, washing with ethyl acetate, the solvant was removed under vacuum to yield $11.4 \mathrm{~g}(85 \%)$ of a brown oil. The crude product was used without further purification.

NMR ${ }^{1} \mathrm{H}\left(300 \mathrm{MHz}, \mathrm{CDCl}_{3}\right): \delta_{\mathrm{H}} 1.32\left(\mathrm{~m}, 2 \mathrm{H}, \mathrm{H}_{4}\right) ; 1.48-1.56\left(\mathrm{~m}, 2 \mathrm{H}, \mathrm{H}_{5}\right) ; 1.70-1.71\left(\mathrm{~m}, 1 \mathrm{H}, \mathrm{H}_{3}\right) ; 1.92-2.05(\mathrm{~m}$, $\left.3 \mathrm{H}, \mathrm{H}_{3} \mathrm{H}_{4}\right) ; 2.39\left(\mathrm{t}, 2 \mathrm{H}, J=9 \mathrm{~Hz}, \mathrm{H}_{3}\right) ; 3.17\left(\mathrm{dd}, 2 \mathrm{H}, J=6.5,13 \mathrm{~Hz}, \mathrm{H}_{6}\right) ; 3.29\left(\mathrm{dd}, 1 \mathrm{H}, J=8.5,14 \mathrm{~Hz}, \mathrm{H}_{5}\right) ; 3.47$ $\left(\mathrm{dd}, 1 \mathrm{H}, J=9,15 \mathrm{~Hz}, \mathrm{H}_{5}\right) ; 3.69$ (s, 3H, COOMe); $4.76\left(\mathrm{dd}, 1 \mathrm{H}, J=10.9 ; \mathrm{J}=4.8 \mathrm{~Hz}, \mathrm{H}_{2}\right) ; 5.08\left(\mathrm{~s}, 2 \mathrm{H}, \mathrm{PhCH}_{2}\right)$; $5.2(\mathrm{bs}, 1 \mathrm{H}, \mathrm{NH}) ; 7.31(\mathrm{~m}, 5 \mathrm{H}, \mathrm{Ar}) . \mathrm{NMR}{ }^{13} \mathrm{C}\left(75 \mathrm{MHz}, \mathrm{CDCl}_{3}\right): \delta_{\mathrm{C}} 18.2\left(\mathrm{C}_{4}\right) ; 23.1\left(\mathrm{C}_{4}\right) ; 28.2-29.1\left(\mathrm{C}_{3} / \mathrm{C}_{5}\right)$; $30.80\left(\mathrm{C}_{3}\right)$; $40.6\left(\mathrm{C}_{6}\right) ; 43.5\left(\mathrm{C}_{5}\right) ; 52.2$ (COOMe); $53.3\left(\mathrm{C}_{2}\right) ; 66.5\left(\mathrm{PhCH}_{2}\right) ; 128.1-128.5\left(\mathrm{C}_{\mathrm{Ar}}\right) ; 136.7\left(\mathrm{C}_{\text {Arquat }}\right)$; $156.5(\mathrm{CO}) ; 171.4-175.97(\mathrm{CO})$. 


\subsection{3 (5S)-6-Hydroxy-5-(2-oxo-pyrrolidin-1-yl)-hexyl]-carbamic acid benzyl ester 7}

To the methyl ester $(15 \mathrm{~g}, 41.4 \mathrm{mmol})$ dissolved in $500 \mathrm{~mL}$ of absolute alcohol, sodium borohydride (16.1 $\mathrm{g}, 414 \mathrm{mmol}, 10$ equiv) was added. The mixture was refluxed for 3 hours. After cooling, the solution was reduced under vacuum, borane precipitates were filtrated and washed with $\mathrm{CH}_{2} \mathrm{Cl}_{2}$. The filtrate was concentrated under reduced pressure and the residue was diluted with $\mathrm{CH}_{2} \mathrm{Cl}_{2}$ and $\mathrm{HCl} 1 \mathrm{M}$, extracted twice by $\mathrm{CH}_{2} \mathrm{Cl}_{2}$. The organic phase was dried with $\mathrm{MgSO}_{4}$ and evaporated to dryness, thereafter the residue was purified by flash chromatography on silica gel (EtOAc/MeOH, 95/5) to afford $9.3 \mathrm{~g}$ of 7 as light yellow oil $(67 \%)$.

$\mathrm{R}_{\mathrm{f}}=0.24(\mathrm{AcOEt} / \mathrm{MeOH}: 95 / 5) \mathrm{NMR}{ }^{1} \mathrm{H}\left(300 \mathrm{MHz}, \mathrm{CDCl}_{3}\right): \delta_{\mathrm{H}}(\mathrm{ppm}): 1.31\left(\mathrm{~m}, 2 \mathrm{H}, \mathrm{H}_{3}\right) ; 1.46-1.58\left(\mathrm{~m}, 4 \mathrm{H}, \mathrm{H}_{4}\right.$ $\left.\mathrm{H}_{2}\right) ; 2.02\left(\mathrm{~m}, 2 \mathrm{H}, \mathrm{H}_{4}\right) ; 2.42\left(\mathrm{t}, 2 \mathrm{H}, J=7.6 \mathrm{~Hz}, \mathrm{H}_{3}\right) ; 3.07(\mathrm{bs}, 1 \mathrm{H}, \mathrm{OH}) ; 3.19\left(\mathrm{~m}, 2 \mathrm{H}, 2 \mathrm{H}_{1}\right) ; 3.30(\mathrm{dd}, 1 \mathrm{H}, J=8.1$, $\left.13.4 \mathrm{~Hz}, \mathrm{H}_{5}\right) ; 3.41\left(\mathrm{dd}, 1 \mathrm{H}, J=7.8,14.9 \mathrm{~Hz}, \mathrm{H}_{5}\right) ; 3.57\left(\mathrm{dd}, 1 \mathrm{H}, J=11.5,20 \mathrm{~Hz}, \mathrm{H}_{6}\right) ; 3.66(\mathrm{dd}, 1 \mathrm{H}, J=4,11.6$ $\left.\mathrm{Hz}, \mathrm{H}_{6}\right) ; 4.05\left(\mathrm{~m}, 1 \mathrm{H}, \mathrm{H}_{5}\right) ; 5.11\left(\mathrm{~s}, 2 \mathrm{H}, \mathrm{PhCH} \mathbf{H}_{2}\right) ; 5.21(\mathrm{~m}, 1 \mathrm{H}, \mathrm{NH}) ; 7.34\left(\mathrm{~m}, 5 \mathrm{H}, \mathrm{H}_{\mathrm{Ar}}\right) . \mathrm{NMR}{ }^{13} \mathrm{C}(75 \mathrm{MHz}$, $\left.\mathrm{CDCl}_{3}\right): \delta_{\mathrm{C}} 18.1\left(\mathrm{C}_{4}\right) ; 22.1\left(\mathrm{C}_{3}\right) ; 27.4-29.3\left(\mathrm{C}_{4} / \mathrm{C}_{2}\right) ; 31.5\left(\mathrm{C}_{3}\right) ; 40.6\left(\mathrm{C}_{1}\right) ; 43.1\left(\mathrm{C}_{5}\right) ; 53.5\left(\mathrm{C}_{5}\right) ; 62.5\left(\mathrm{C}_{6}\right) ; 66.4$ $\left(\mathrm{PhCH}_{2}\right) ; 127.9-128.4\left(\mathrm{C}_{\mathrm{Ar}}\right) ; 136.7\left(\mathrm{C}_{\text {Arquat }}\right) ; 156.7(\mathrm{CO}) ; 176.6(\mathrm{CO}) .[\alpha]_{\mathrm{D}}{ }^{20}:-10.5\left(\mathrm{c}=1.1 ; \mathrm{CH}_{2} \mathrm{Cl}_{2}\right)$. IR (neat): $v_{\max } 3310,2933,1696,1656,1248,697 \mathrm{~cm}^{-1}$. HRMS $\left(\mathrm{ES}^{+} .[\mathrm{M}+\mathrm{Na}]^{+}\right)$: Calcd for $\mathrm{C}_{18} \mathrm{H}_{26} \mathrm{~N}_{2} \mathrm{O}_{4} \mathrm{Na} 357.1790$ Found 357.1780 .

\subsection{4 (5S)-[6-(tert-Butyl-dimethyl-silanyloxy)-5-(2-oxo-pyrrolidin-1-yl)-hexyl]-carbamic acid} benzyl ester

Alcohol 7 (740 mg; $2.2 \mathrm{mmol})$ was dissolved in $\mathrm{CH}_{2} \mathrm{Cl}_{2}(10 \mathrm{~mL})$ and tert-butyldiméthylsilyl chloride (400 $\mathrm{mg}, 2.6 \mathrm{mmol} ; 1.2$ equiv.) was added under argon. The solution was stirred for 14 hours and an aqueous saturated $\mathrm{NH}_{4} \mathrm{Cl}$ solution was added. The aqueous layer was extracted with $\mathrm{CH}_{2} \mathrm{Cl}_{2}$. The organic phase was dried with $\mathrm{MgSO}_{4}$ and the solvent removed under vacuum. The residue was purified by flashchromatography on silica gel (ethyl acetate/cyclohexane, 60/40). Silyl ether was obtained as a pale beige oil in $90 \%$ yield $(890 \mathrm{mg})$.

$\mathrm{R}_{\mathrm{f}}=0.4\left(\right.$ AcOEt/cyclohexane: 65/35). NMR ${ }^{1} \mathrm{H}\left(300 \mathrm{MHz}, \mathrm{CDCl}_{3}\right): \delta_{\mathrm{H}} 0.06$ (s, 2H, 2SiMe); 0.90 (s, 3H, SitBu); $1.28\left(\mathrm{~m}, 2 \mathrm{H}, 2 \mathrm{H}_{3}\right) ; 1.50-1.58\left(\mathrm{~m}, 4 \mathrm{H}, \mathrm{H}_{4} \mathrm{H}_{2}\right) ; 1.97\left(\mathrm{~m}, 2 \mathrm{H}, \mathrm{H}_{4}\right) ; 2.38\left(\mathrm{t}, 2 \mathrm{H}, J=8 \mathrm{~Hz}, 2 \mathrm{H}_{3}\right) ; 3.20\left(\mathrm{~m}, 2 \mathrm{H}, \mathrm{H}_{1}\right)$; $3.32\left(\mathrm{~m}, 1 \mathrm{H}, \mathrm{H}_{5}\right) ; 3.42\left(\mathrm{~m}, 1 \mathrm{H}, \mathrm{H}_{5}\right) ; 3.64\left(\mathrm{~m}, 2 \mathrm{H}, \mathrm{H}_{6}\right) ; 4.12-4.13\left(\mathrm{~m}, 1 \mathrm{H}, \mathrm{H}_{5}\right) ; 5.08(\mathrm{bs}, 1 \mathrm{H}, \mathrm{NH}) ; 5.11(\mathrm{~s}, 2 \mathrm{H}$, $\left.\mathrm{PhCH}_{2}\right) ; 7.32-7.38\left(\mathrm{~m}, 5 \mathrm{H}, \mathrm{H}_{\mathrm{Ar}}\right)$. NMR ${ }^{13} \mathrm{C}\left(75 \mathrm{MHz}, \mathrm{CDCl}_{3}\right): \delta_{\mathrm{C}}-5.6(\mathrm{SiMe}) ;-5.5(\mathrm{SiMe}) ; 18.1\left(\mathrm{C}_{4}\right) ; 18.5$ $\left(\mathrm{SiC}_{\text {quat }}\right) ; 23.1\left(\mathrm{C}_{3}\right) ; 25.8(\mathrm{Sit} \mathbf{B u}) ; 27.5-29.5\left(\mathrm{C}_{4} / \mathrm{C}_{2}\right) ; 31.4\left(\mathrm{C}_{3}\right) ; 40.8\left(\mathrm{C}_{1}\right) ; 43.8\left(\mathrm{C}_{5}\right) ; 52.5\left(\mathrm{C}_{5}\right) ; 63.9\left(\mathrm{C}_{6}\right) ; 66.5$ $\left(\mathrm{PhCH}_{2}\right) ; 128.0-128.1-128.5\left(\mathrm{C}_{\mathrm{Ar}}\right) ; 136.7\left(\mathrm{C}_{\text {Arquat }}\right) ; 156.5(\mathrm{CO}) ; 175.5(\mathrm{CO}) .[\alpha]_{\mathrm{D}}{ }^{20}:-18.0\left(\mathrm{c}=0.8 ; \mathrm{CH}_{2} \mathrm{Cl}_{2}\right) . \mathrm{IR}$ (neat): $v_{\max } 3320,2928,1667,1248,1112,834 \mathrm{~cm}^{-1}$. HRMS (ES ${ }^{+}$. [M + H] $\left.]^{+}\right]$): Calcd for $\mathrm{C}_{24} \mathrm{H}_{41} \mathrm{~N}_{2} \mathrm{O}_{4} \mathrm{Si} 449.2830$ Found 449.2830 .

\subsection{5 (3S, 5S)-[5-(3-Allyl-2-oxo-pyrrolidin-1-yl)-6-(tert-butyl-dimethyl-silanyloxy)-hexyl]-carbamic acid benzyl ester $8 \mathrm{a}$}

A $30 \mathrm{~mL}$ LDA solution in THF was prepared from diisopropylamine ( $25.6 \mathrm{mmol} ; 3.6 \mathrm{~mL} ; 2$. éq.) and $\mathrm{n}$-BuLi 1.6 $\mathrm{M}$ in hexane $(25.6 \mathrm{mmol} ; 16 \mathrm{~mL})$ cooled to $-78^{\circ} \mathrm{C}$ and was cannulated to amide $7(12.7 \mathrm{mmol} ; 5.7 \mathrm{~g})$ in THF (90 $\mathrm{mL}$ ) maintained at $-78^{\circ} \mathrm{C}$ under argon. The solution was stirred at the same temperature for 20 min and allyl bromide $\left(25.4 \mathrm{mmol} ; 2.2 \mathrm{~mL} ; 2\right.$ equiv.) was slowly added. The mixture was stirred at $-78^{\circ} \mathrm{C}$ for $2 \mathrm{~h}$ and then treated with an aqueous saturated $\mathrm{NH}_{4} \mathrm{Cl}$ solution $(60 \mathrm{~mL})$. The aqueous phase was extracted several times with $\mathrm{CH}_{2} \mathrm{Cl}_{2}$. The organic phase was then dried with $\mathrm{MgSO}_{4}$ and the solvent removed in vacuum. The residue was purified by flash chromatography on silica gel (AcOEt/cyclohexane: 80/20) to give the two diastereoisomers 8a and $8 \mathbf{b}$ in a 83/17 ratio and a 75\% global yield. (3.9 g of pure $8 \mathbf{a}$ as a pale yellow oil, $0.78 \mathrm{~g}$ of pure $8 \mathbf{b}$ as a pale yellow oil.

$\mathrm{R}_{\mathrm{f}}=0.46\left(\right.$ AcOEt/cyclohexane: 50/50). NMR ${ }^{1} \mathrm{H}\left(400 \mathrm{MHz}, \mathrm{CDCl}_{3}\right): \delta_{\mathrm{H}}: 0.08$ (s, 6H, SiMe); $0.92(\mathrm{~s}, 9 \mathrm{H}, \mathrm{SitBu}) ;$ $1.31\left(\mathrm{~m}, 2 \mathrm{H}, \mathrm{H}_{3}\right) ; 1.48-1.63\left(\mathrm{~m}, 4 \mathrm{H}, \mathrm{H}_{4} \mathrm{H}_{2}\right) ; 1.73\left(\mathrm{~m}, 1 \mathrm{H}, \mathrm{H}_{4}\right) ; 2.09-2.25\left(\mathrm{~m}, 2 \mathrm{H}, \mathrm{H}_{4} \mathbf{C H}_{2}-\mathrm{CH} \mathrm{CH}_{2}\right) ; 2.49-2.66$ $\left(\mathrm{m}, 2 \mathrm{H}, \mathrm{H}_{3} \mathbf{C H 2}-\mathrm{CH}=\mathrm{CH}_{2}\right) ; 3.22\left(\mathrm{~m}, 3 \mathrm{H}, \mathrm{H}_{1} \mathrm{H}_{5}\right) ; 3.42\left(\mathrm{dddd}, 1 \mathrm{H}, J=9.2,3.6,3.6,3.6 \mathrm{~Hz}, \mathrm{H}_{5}\right) ; 3.66(\mathrm{~d}, 2 \mathrm{H} ; J=$ 5.4, $\left.\mathrm{H}_{6}\right) ; 4.14$ (dddd, $\left.1 \mathrm{H}, J=10.9,5.3,5.3,5.3 \mathrm{~Hz}, 1 \mathrm{H}_{5}\right) ; 4.89$ (bs, $\left.1 \mathrm{H}, \mathrm{NH}\right) ; 5.05\left(\mathrm{~m}, 4 \mathrm{H}, \mathrm{PhCH}_{2} \mathrm{CH}=\mathrm{CH} 2\right)$; $5.80(\mathrm{~m}, 1 \mathrm{H}, \mathrm{CH}=\mathrm{CH} 2) ; 7.34-7.44(\mathrm{~m}, 5 \mathrm{H}, \mathrm{Ar}) . \mathrm{NMR}{ }^{13} \mathrm{C}\left(75 \mathrm{MHz}, \mathrm{CDCl}_{3}\right): \delta_{\mathrm{C}}-5.6(\mathrm{SiMe}) ;-5.5(\mathrm{SiMe}) ; 18.1$ $\left(\mathrm{SiC}_{\text {quat }}\right) ; 23.0\left(\mathrm{C}_{3}\right) ; 24.3\left(\mathrm{C}_{4}\right) ; 25.8(\mathrm{Sit} \mathbf{B u}) ; 27.5-29.4\left(\mathrm{C}_{4} / \mathrm{C}_{2}\right) ; 35.4\left(\mathbf{C H}_{2}-\mathrm{CH}=\mathrm{CH}_{2}\right) ; 40.8\left(\mathrm{C}_{1}\right) ; 41.8\left(\mathrm{C}_{3}\right) ; 41.7$ $\left(\mathrm{C}_{5}\right) ; 52.6\left(\mathrm{C}_{5}\right) ; 64.0\left(\mathrm{C}_{6}\right) ; 66.5\left(\mathrm{PhCH}_{2}\right) ; 116.7\left(\mathrm{CH}=\mathbf{C H}_{2}\right) ; 128.0-128.05-128.5\left(\mathrm{C}_{\mathrm{Ar}}\right) ; 135.8\left(\mathbf{C H}=\mathrm{CH}_{2}\right) ; 136.7$ $\left(\mathrm{C}_{\text {Arquat }}\right) ; 156.5(\mathrm{CO}) ; 176.5(\mathrm{CO})$. [ $\left.\alpha\right]_{\mathrm{D}}{ }^{20}:-20.2\left(\mathrm{c}=0.5 ; \mathrm{CH}_{2} \mathrm{Cl}_{2}\right.$ ). IR (neat): $v_{\max } 3317,2928,2856,1696,1662$, $1249,833 \mathrm{~cm}^{-1}$. HRMS (ES- [M - H]'): Calcd for $\mathrm{C}_{27} \mathrm{H}_{43} \mathrm{~N}_{2} \mathrm{O}_{4} \mathrm{Si} 487.2992$ Found 487.2969. 
4.1.6 (3R, 5S)-[5-(3-Allyl-2-oxo-pyrrolidin-1-yl)-6-(tert-butyl-dimethyl-silanyloxy)-hexyl]-carbamic acid benzyl ester $8 b$

$\mathrm{R}_{\mathrm{f}}=0.57(\mathrm{AcOEt} / \mathrm{cyclohexane:} 50 / 50) . \mathrm{NMR}{ }^{1} \mathrm{H}\left(400 \mathrm{MHz}, \mathrm{CDCl}_{3}\right): \delta_{\mathrm{H}}: 0.08$ (s, 6H, SiMe); $0.92(\mathrm{~s}, 9 \mathrm{H}, \mathrm{SitBu}) ;$ $1.31\left(\mathrm{~m}, 2 \mathrm{H}, \mathrm{H}_{3}\right) ; 1.48-1.63\left(\mathrm{~m}, 4 \mathrm{H}, \mathrm{H}_{4} \mathrm{H}_{2}\right) ; 1.69\left(\mathrm{~m}, 1 \mathrm{H}, \mathrm{H}_{4}\right) ; 2.13-2.24\left(\mathrm{~m}, 2 \mathrm{H}, \mathrm{H}_{4} \mathbf{C H}_{2}-\mathrm{CH} \mathrm{CH}_{2}\right) ; 2.51-2.69$ $\left(\mathrm{m}, 2 \mathrm{H}, \mathrm{H}_{3} \mathbf{C H 2}-\mathrm{CH}=\mathrm{CH}_{2}\right) ; 3.22\left(\mathrm{~m}, 3 \mathrm{H}, \mathrm{H}_{1} 1 \mathrm{H}_{5}\right) ; 3.32$ (dddd, $\left.1 \mathrm{H}, J=17.89 .6 .8 .38 .3 \mathrm{~Hz}, \mathrm{H}_{5}\right) ; 3.62-3.69(\mathrm{~m}$, $\left.2 \mathrm{H}, \mathrm{H}_{6}\right) ; 4.15$ (dddd, $\left.1 \mathrm{H}, J=10.9,5.3,5.3,5.3 \mathrm{~Hz}, \mathrm{H}_{5}\right) ; 4.89$ (bs, $\left.1 \mathrm{H}, \mathrm{NH}\right) ; 5.08\left(\mathrm{~m}, 4 \mathrm{H}, \mathrm{PhCH}_{2} \mathrm{CH}=\mathrm{CH} 2\right) ; 5.80$ $(\mathrm{m}, 1 \mathrm{H}, \mathrm{CH}=\mathrm{CH} 2) ; 7.34-7.44\left(\mathrm{~m}, 5 \mathrm{H}, \mathrm{Ar} . \mathrm{NMR}{ }^{13} \mathrm{C}\left(75 \mathrm{MHz}, \mathrm{CDCl}_{3}\right): \delta_{\mathrm{C}}-5.6(\mathrm{SiMe}) ;-5.5(\mathrm{SiMe}) ; 18.05\right.$ $\left(\mathrm{SiC}_{\text {quat }}\right) ; 23.0\left(\mathrm{C}_{3}\right) ; 24.5\left(\mathrm{C}_{4}\right) ; 25.8(\mathrm{Sit} \mathbf{B u}) ; 27.3-29.4\left(\mathrm{C}_{4} / \mathrm{C}_{2}\right) ; 35.4\left(\mathbf{C H 2}-\mathrm{CH}=\mathrm{CH}_{2}\right) ; 40.8\left(\mathrm{C}_{1}\right) ; 41.8\left(\mathrm{C}_{3}\right) ; 41.9$ $\left(\mathrm{C}_{5}\right) ; 52.6\left(\mathrm{C}_{5}\right) ; 63.8\left(\mathrm{C}_{6}\right) ; 66.5\left(\mathrm{PhCH}_{2}\right) ; 116.7\left(\mathrm{CH}=\mathbf{C H}_{2}\right) ; 128.0-128.05-128.5\left(\mathrm{C}_{\mathrm{Ar}}\right) ; 135.7\left(\mathbf{C H}=\mathrm{CH}_{2}\right) ; 136.7$ $\left(\mathrm{C}_{\text {Arquat }}\right) ; 156.5(\mathrm{CO}) ; 176.5(\mathrm{CO})$. $[\alpha]_{\mathrm{D}}^{20}:-5.2\left(\mathrm{c}=0.5 ; \mathrm{CH}_{2} \mathrm{Cl}_{2}\right)$.). IR (neat): $v_{\max } 3291,2928,2856,1718,1667$, 1247, 1095, 834, 776. HRMS (ES. [M - H] ): Calcd for $\mathrm{C}_{27} \mathrm{H}_{43} \mathrm{~N}_{2} \mathrm{O}_{4} \mathrm{Si} 487.2992$ Found 487.2973.

\subsection{7 (3S, 5S)-[5-(3-Allyl-2-oxo-pyrrolidin-1-yl)-6-hydroxy-hexyl]-carbamic acid benzyl ester}

To silyl compound $8 \mathbf{8 a}(203 \mathrm{mg} ; 0.42 \mathrm{mmol}$ ) dissolved in $7 \mathrm{~mL}$ of anhydrous THF was added slowly a solution 1 $\mathrm{M}$ of tetrabutylammonium fluoride in THF $\left(1.3 \mathrm{~mL} ; 1.3 \mathrm{mmol} ; 3.1\right.$ equiv) at $0{ }^{\circ} \mathrm{C}$. Stirring was continued $45 \mathrm{~min}$ after removal of the ice bath. At $0{ }^{\circ} \mathrm{C} 7 \mathrm{~mL}$ of water was added, the mixture was extracted 3 times with dichloromethane. The organic layer was dried with $\mathrm{MgSO}_{4}$ and the solvent removed in vacuum. The residue was purified by flash chromatography (AcOEt/MeOH: 95/5) to give the alcohol as a pale yellow oil (131 mg, 84\%).

$\mathrm{R}_{\mathrm{f}}=0.48(\mathrm{AcOEt} / \mathrm{MeOH}: 95 / 5) . \mathrm{NMR}{ }^{1} \mathrm{H}\left(300 \mathrm{MHz}, \mathrm{CDCl}_{3}\right): \delta_{\mathrm{H}}: 1.26\left(\mathrm{~m}, 2 \mathrm{H}, \mathrm{H}_{3}\right) ; 1.37-1.56\left(\mathrm{~m}, 4 \mathrm{H}_{1} \mathrm{H}_{4} \mathrm{H}_{2}\right)$; 1.69, (dddd, $\left.1 \mathrm{H} J=15.4,7.7,7.7,7.7 \mathrm{~Hz}, \mathrm{H}_{4}\right) ; 1.99-2.18\left(\mathrm{~m}, 2 \mathrm{H}, \mathrm{H}_{4} \mathbf{C H}_{2}-\mathrm{CH}=\mathrm{CH}_{2}\right) ; 2.49\left(\mathrm{~m}, 2 \mathrm{H}, \mathrm{H}_{3} \mathbf{C H}_{2^{-}}\right.$ $\left.\mathrm{CH}=\mathrm{CH}_{2}\right) ; 3.14\left(\mathrm{~m}, 3 \mathrm{H}, \mathrm{H}_{1} \mathrm{H}_{5}\right) ; 3.28\left(\mathrm{~m}, 1 \mathrm{H}, \mathrm{H}_{5}\right) ; 3.41-3.55(\mathrm{bm}, 1 \mathrm{H}, \mathrm{OH}) ; 3.59\left(\mathrm{~m}, 2 \mathrm{H}, \mathrm{H}_{6}\right) ; 3.90-4.05(\mathrm{~m}, 1 \mathrm{H}$, $\left.\mathrm{H}_{5}\right) ; 5.01\left(\mathrm{~m}, 4 \mathrm{H}, \mathrm{PhCH}_{2} 2 \mathrm{CH}=\mathrm{CH}_{2}\right) ; 5.39(\mathrm{bs}, 1 \mathrm{H}, \mathrm{NH}) ; 5.70\left(\mathrm{~m}, 1 \mathrm{H}, \mathrm{CH}=\mathrm{CH}_{2}\right) ; 7.26-7.30(\mathrm{~m}, 5 \mathrm{H}, \mathrm{Ar})$. NMR ${ }^{13} \mathrm{C}\left(75 \mathrm{MHz}, \mathrm{CDCl}_{3}\right): \delta_{\mathrm{C}}: 23.0\left(\mathrm{C}_{3}\right) ; 24.0\left(\mathrm{C}_{4}\right) ; 27.5-29.3\left(\mathrm{C}_{4} / \mathrm{C}_{2}\right) ; 35.2\left(\mathbf{C H}_{2}-\mathrm{CH}=\mathrm{CH}_{2}\right) ; 40.6\left(\mathrm{C}_{1}\right) ; 41.8\left(\mathrm{C}_{5}\right)$; $41.9\left(\mathrm{C}_{3}\right) ; 53.9\left(\mathrm{C}_{5}\right) ; 62.7\left(\mathrm{C}_{6}\right) ; 66.4\left(\mathrm{PhCH}_{2}\right) ; 116.9\left(\mathrm{CH}=\mathbf{C H}_{2}\right) ; 128.0-128.4\left(\mathrm{C}_{\mathrm{Ar}}\right) ; 135.5\left(\mathbf{C H}=\mathrm{CH}_{2}\right) ; 136.7$ $\left(\mathrm{C}_{\text {Arquat }}\right) ; 156.7(\mathrm{CO}) ; 177.6(\mathrm{CO}) .[\alpha]_{\mathrm{D}}{ }^{20}:+5.3\left(\mathrm{c}=0.6 ; \mathrm{CH}_{2} \mathrm{Cl}_{2}\right)$. IR (neat): $v_{\max } 3311,2936,2864,1697,1657$, 1248, 1001, 736, 696. HRMS (ES. [M - H] ): Calcd for $\mathrm{C}_{21} \mathrm{H}_{29} \mathrm{~N}_{2} \mathrm{O}_{4} 373.2127$ Found 373.2121.

\subsection{8 (3R, 5S)-[5-(3-Allyl-2-oxo-pyrrolidin-1-yl)-6-hydroxy-hexyl]-carbamic acid benzyl ester}

The same experimental procedure as described for deprotection of previous alcohol (220 mg; $0.45 \mathrm{mmol})$ using a solution $1 \mathrm{M}$ of tetrabutylammonium fluoride in THF (1.4 mL, $1.4 \mathrm{mmol}, 3.1$ equiv). Flash chromatography on silica gel (AcOEt/MeOH: 95/5) allowed the isolation of a colorless oil $(90 \%, 152 \mathrm{mg}$.

$\mathrm{R}_{\mathrm{f}}=0.58(\mathrm{AcOEt} / \mathrm{MeOH}: 95 / 5) . \mathrm{NMR}{ }^{1} \mathrm{H}\left(300 \mathrm{MHz}, \mathrm{CDCl}_{3}\right): \delta_{\mathrm{H}}: 1.24\left(\mathrm{~m}, 2 \mathrm{H}, \mathrm{H}_{3}\right) ; 1.45\left(\mathrm{~m}, 4 \mathrm{H}, \mathrm{H}_{4} \mathrm{H}_{2}\right) ; 1.69$, (dddd, $\left.1 \mathrm{H} J=12.9,8.6,8.6,8.6 \mathrm{~Hz}, \mathrm{H}_{4}\right) ; 2.08-2.23\left(\mathrm{~m}, 2 \mathrm{H}, \mathrm{H}_{4} \mathbf{C H}_{2}-\mathrm{CH}=\mathrm{CH}_{2}\right) ; 2.26$ (bs, $\left.\mathrm{NH}\right) ; 2.43-2.58(\mathrm{~m}, 2 \mathrm{H}$, $\left.\mathrm{H}_{17} \mathbf{C H}_{2}-\mathrm{CH}=\mathrm{CH}_{2}\right) ; 3.18\left(\mathrm{~m}, 3 \mathrm{H}, \mathrm{H}_{1} \mathrm{H}_{5}\right) ; 3.31\left(\mathrm{~m}, 1 \mathrm{H}, \mathrm{H}_{5}\right) ; 3.44-3.61(\mathrm{bm}, 1 \mathrm{H}, \mathrm{OH}) ; 3.61-3.71\left(\mathrm{~m}, 2 \mathrm{H}, \mathrm{H}_{6}\right)$; 3.94-4.05 (m, $\left.1 \mathrm{H}, \mathrm{H}_{5}\right) ; 5.08\left(\mathrm{~m}, 4 \mathrm{H}, \mathrm{PhCH}_{2} \mathrm{CH}=\mathrm{CH}_{2}\right) ; 5.70\left(\mathrm{~m}, 1 \mathrm{H}, \mathrm{CH}=\mathrm{CH}_{2}\right) ; 7.31-7.40(\mathrm{~m}, 5 \mathrm{H}, \mathrm{Ar})$. NMR ${ }^{13} \mathrm{C}\left(75 \mathrm{MHz}, \mathrm{CDCl}_{3}\right): \delta_{\mathrm{C}}: 23.0\left(\mathrm{C}_{3}\right) ; 24.0\left(\mathrm{C}_{4}\right) ; 27.2-29.3\left(\mathrm{C}_{4} / \mathrm{C}_{2}\right) ; 35.2\left(\mathbf{C H}_{2}-\mathrm{CH}=\mathrm{CH}_{2}\right) ; 40.6\left(\mathrm{C}_{1}\right) ; 41.4\left(\mathrm{C}_{5}\right)$; $41.9\left(\mathrm{C}_{3}\right) ; 53.7\left(\mathrm{C}_{5}\right) ; 62.7\left(\mathrm{C}_{6}\right) ; 66.4\left(\mathrm{PhCH}_{2}\right) ; 117.1\left(\mathrm{CH}=\mathbf{C H}_{2}\right) ; 128.0-128.4\left(\mathrm{C}_{\mathrm{Ar}}\right) ; 135.3\left(\mathbf{C H}=\mathrm{CH}_{2}\right) ; 136.7$ $\left(\mathrm{C}_{\text {Arquat }}\right) ; 156.7(\mathrm{CO}) ; 177.6(\mathrm{CO})$. [ $[\alpha]_{\mathrm{D}}{ }^{20}:-24.8\left(\mathrm{c}=0.8 ; \mathrm{CH}_{2} \mathrm{Cl}_{2}\right)$. IR (neat): $v_{\max } 3314,2935,2865,1694,1658$, 1248, 1002, 736, 696. HRMS (ES. [M-H]): Calcd for $\mathrm{C}_{21} \mathrm{H}_{29} \mathrm{~N}_{2} \mathrm{O}_{4} 373.2127$ Found 373.2130.

\subsection{9 (3S, 2S)-2-(3-Allyl-2-oxo-pyrrolidin-1-yl)-6-benzyloxycarbonylamino-hexanoic acid 9a}

To previous alcohol $(570 \mathrm{mg} ; 1.5 \mathrm{mmol})$ dissolved in $15 \mathrm{~mL}$ of acetone was added dropwise Jones reagent $2.67 \mathrm{M}\left(0.85 \mathrm{~mL} ; 2.3 \mathrm{mmol} ; 1.5\right.$ equiv) at $0{ }^{\circ} \mathrm{C}$. Stirring was continued for $40 \mathrm{~min} .8 \mathrm{~mL}$ of isopropanol was added; the mixture was stirred for $20 \mathrm{~min}$ at $0{ }^{\circ} \mathrm{C}$. After addition of $5 \mathrm{~mL}$ of water, the mixture was extracted 3 times with dichloromethane. The organic phase was extracted 3 times by $\mathrm{NaHCO}_{3} 5 \%$ solution. The aqueous phase was acidified with concentrated $\mathrm{HCl}$ and extracted 3 times with dichloromethane. The organic phase was dried with $\mathrm{MgSO}_{4}$ and the solvent removed in vacuum. The carboxylic acid 9a was obtained as a pale yellow oil $(72 \% ; 430 \mathrm{mg})$. Suitable crystals for X-ray analysis were obtained in acetonitrile.

$\mathrm{R}_{\mathrm{f}}=0.55\left(\right.$ AcOEt/cyclohexane/AcOH: 90/10/1). NMR ${ }^{1} \mathrm{H}\left(300 \mathrm{MHz}, \mathrm{CDCl}_{3}\right): \delta_{\mathrm{H}}: 1.37\left(\mathrm{~m}, 2 \mathrm{H}, \mathrm{H}_{4}\right) ; 1.59(\mathrm{~m}, 2 \mathrm{H}$, $\left.\mathrm{H}_{5}\right) ; 1.84\left(\mathrm{~m}, 2 \mathrm{H}, \mathrm{H}_{3}\right) ; 1.96-2.12\left(\mathrm{~m}, 2 \mathrm{H}, \mathrm{H}_{4} \mathbf{C H 2}-\mathrm{CH}=\mathrm{CH}_{2}\right) ; 2.21\left(\mathrm{~m}, 1 \mathrm{H}, \mathrm{H}_{4}\right) ; 2.62\left(\mathrm{~m}, 2 \mathrm{H}, \mathrm{H}_{3} \mathbf{C H}_{2}-\mathrm{CH}=\mathrm{CH}_{2}\right)$;

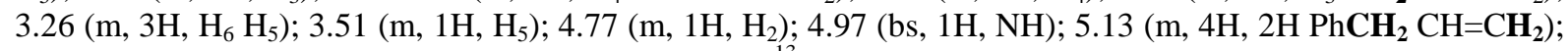
); $5.81\left(\mathrm{~m}, 1 \mathrm{H}, \mathbf{C H}=\mathrm{CH}_{2}\right) ; 7.40(\mathrm{~m}, 5 \mathrm{H}, \mathrm{Ar}) . \mathrm{NMR}{ }^{13} \mathrm{C}\left(75 \mathrm{MHz}, \mathrm{CDCl}_{3}\right): \delta_{\mathrm{C}}: 23.2\left(\mathrm{C}_{4}\right) ; 24.1\left(\mathrm{C}_{4}\right) ; 28.1-3$ $\left(\mathrm{C}_{3} / \mathrm{C}_{5}\right) ; 35.0\left(\mathbf{C H}_{2}-\mathrm{CH}=\mathrm{CH}_{2}\right) ; 40.6\left(\mathrm{C}_{3}\right) ; 41.3\left(\mathrm{C}_{6}\right) ; 42.1\left(\mathrm{C}_{5}\right) ; 53.7\left(\mathrm{C}_{2}\right) ; 66.6\left(\mathrm{PhCH}_{2}\right) ; 117.0\left(\mathrm{CH}=\mathbf{C H}_{2}\right) ; 128.1-$ 
$128.5\left(\mathrm{C}_{\mathrm{Ar}}\right) ; 135.4\left(\mathbf{C H}=\mathrm{CH}_{2}\right) ; 136.6\left(\mathrm{C}_{\text {Arquat }}\right) ; 156.7(\mathrm{CO}) ; 173.7-177.9(2 \mathrm{CO}) .[\alpha]_{\mathrm{D}}{ }^{20}:-0.9\left(\mathrm{c}=0.5 ; \mathrm{CH}_{2} \mathrm{Cl}_{2}\right)$. $)$. IR (neat): $v_{\max }$ 3190, 2948, 1732, 1654, 1184, $699 \mathrm{~cm}^{-1}$. HRMS $\left(\mathrm{ES}^{+}\right.$. $\left.[\mathrm{M}+\mathrm{Na}]^{+}\right)$: Calcd for $\mathrm{C}_{21} \mathrm{H}_{28} \mathrm{~N}_{2} \mathrm{O}_{5} \mathrm{Na}$ 411.1896 Found 411.1891.

\subsubsection{0 (3R, 2S)2-(3-Allyl-2-oxo-pyrrolidin-1-yl)-6-benzyloxycarbonylamino-hexanoic acid 9b}

The same experimental procedure as described for oxidation of alcohol (140 mg; $0.37 \mathrm{mmol}$ ) using Jones reagent $2.67 \mathrm{M}(0.2 \mathrm{~mL} ; 0.53 \mathrm{mmol} ; 1.5$ equiv) was applied. The carboxylic acid $\mathbf{9 b}$ was obtained as a pale yellow oil $(62 \% ; 90 \mathrm{mg})$.

$\left.\delta_{\mathrm{H}}: 1.37\left(\mathrm{~m}, 2 \mathrm{H}, \mathrm{H}_{4}\right) ; 1.59\left(\mathrm{~m}, 2 \mathrm{H}, \mathrm{H}_{5}\right) ; 1.78\left(\mathrm{~m}, 2 \mathrm{H}, \mathrm{H}_{3}\right) ; 1.99-2.12\left(\mathrm{~m}, 2 \mathrm{H}, \mathrm{H}_{4} \mathbf{C H} 2-\mathrm{CH}=\mathrm{CH}_{2}\right) ;\right) ; 2.24(\mathrm{~m}, 1 \mathrm{H}$, $\left.\mathrm{H}_{4}\right) ; 2.64\left(\mathrm{~m}, 2 \mathrm{H}, \mathrm{H}_{2} \mathbf{C H}_{2}-\mathrm{CH}=\mathrm{CH}_{2}\right) ; 3.24\left(\mathrm{~m}, 2 \mathrm{H}, \mathrm{H}_{6}\right) ; 3.33\left(\mathrm{t}, 1 \mathrm{H}, J=8.0 \mathrm{~Hz}, \mathrm{H}_{5}\right) ; 3.49$ (ddd, 1H, J = 17.0 8.0 $\left.8.0 \mathrm{~Hz}, \mathrm{H}_{5}\right) ; 4.71$ (ddd, $\left.1 \mathrm{H}, J=10.45 .05 .0 \mathrm{~Hz}, \mathrm{H}_{2}\right) ; 4.90(\mathrm{bs}, 1 \mathrm{H}, \mathrm{NH}) ; 5.13\left(\mathrm{~m}, 4 \mathrm{H}, \mathrm{PhCH} \mathbf{C H}=\mathrm{CH}_{2}\right) ; 5.79$ $\left(\mathrm{m}, 1 \mathrm{H}, \mathrm{CH}=\mathrm{CH}_{2}\right) ; 7.40(\mathrm{~m}, 5 \mathrm{H}, \mathrm{Ar}) . \mathrm{NMR}{ }^{13} \mathrm{C}\left(75 \mathrm{MHz}, \mathrm{CDCl}_{3}\right): \delta_{\mathrm{C}}: 23.2\left(\mathrm{C}_{4}\right) ; 24.0\left(\mathrm{C}_{4}\right) ; 27.7-29.0\left(\mathrm{C}_{3} / \mathrm{C}_{5}\right)$; $35.0\left(\mathbf{C H}_{2}-\mathrm{CH}=\mathrm{CH}_{2}\right) ; 40.6\left(\mathrm{C}_{3}\right) ; 41.6\left(\mathrm{C}_{6}\right) ; 42.4\left(\mathrm{C}_{5}\right) ; 53.7\left(\mathrm{C}_{2}\right) ; 66.6\left(\mathrm{PhCH}_{2}\right) ; 117.3\left(\mathrm{CH}=\mathbf{C H}_{2}\right) ; 128.1-128.5$ $\left(\mathrm{C}_{\mathrm{Ar}}\right) ; 135.1\left(\mathbf{C H}=\mathrm{CH}_{2}\right) ; 136.6\left(\mathrm{C}_{\text {Arquat }}\right) ; 156.7(\mathrm{CO}) ; 173.3-178.0(2 \mathrm{CO}) .[\alpha]_{\mathrm{D}}{ }^{20}:-18.6\left(\mathrm{c}=0.2 ; \mathrm{CH}_{2} \mathrm{Cl}_{2}\right) . \mathrm{IR}$ (neat): $\left.v_{\max } 3323,2932,2869,1728,1666,1246,915,735,696 . \mathrm{HRMS}_{(\mathrm{ES}}^{+} .[\mathrm{M}+\mathrm{Na}]^{+}\right)$: Calcd for $\mathrm{C}_{21} \mathrm{H}_{28} \mathrm{~N}_{2} \mathrm{O}_{5} \mathrm{Na} 411.1896$ Found 411.1885.

\subsubsection{3-[(3S,2S)-2-(3-Allyl-2-oxo-pyrrolidin-1-yl)-6-benzyloxycarbonylamino-hexanoylamino]- propionic acid tert-butyl ester 10a}

To carboxylic acid 9a (304 mg; $0.78 \mathrm{mmol})$ dissolved in $15 \mathrm{~mL}$ of anhydrous dichloromethane was added the amino acid (0.86 mmol, 1.1 equiv), N-methylmorpholine (NMM) (257 $\mu \mathrm{L}, 2.34 \mathrm{mmol}, 3$ equiv), hydroxybenzotriazole (HOBt) (158 mg, $1.17 \mathrm{mmol}, 1.5$ equiv), then EDC (165mg, 0.86mmol, 1.1 equiv) at $0{ }^{\circ} \mathrm{C}$. Stirring was continued for $20 \mathrm{~h}$ at $\mathrm{rt}$. The residue was taken off with $10 \mathrm{~mL}$ of dichloromethane, washed with $10 \mathrm{~mL}$ of $10 \% \mathrm{Na}_{2} \mathrm{CO}_{3}$ solution, $10 \mathrm{~mL}$ of $10 \% \mathrm{KHSO}_{4}$ solution and $10 \mathrm{~mL}$ of brine. The organic phase was dried over $\mathrm{Na}_{2} \mathrm{SO}_{4}$ and the solvent removed in vacuum. The compound was isolated as a colourless oil $(90 \%, 361 \mathrm{mg})$.

$\mathrm{R}_{\mathrm{f}}=0.38\left(\right.$ AcOEt/cyclohexane: 70/30). NMR ${ }^{1} \mathrm{H}\left(300 \mathrm{MHz}, \mathrm{CDCl}_{3}\right): \delta_{\mathrm{H}}: 1.22\left(\mathrm{~m}, 2 \mathrm{H}, \mathrm{H}_{4}\right) ; 1.42(\mathrm{~s}, 9 \mathrm{H}, t \mathrm{Bu})$; 1.48-1.50 (m, 2H, $\left.\mathrm{H}_{5}\right)$; 1.63-1.75 (m, 2H, H $\left.\mathrm{H}_{4}\right) ; 1.93\left(\mathrm{~m}, 1 \mathrm{H}, \mathrm{H}_{3}\right) ; 2.14\left(\mathrm{~m}, 2 \mathrm{H}, \mathbf{C H}_{2}-\mathrm{CH}=\mathrm{CH}_{2} \mathrm{H}_{4}\right) ; 2.38(\mathrm{t}, 2 \mathrm{H}$, $\left.J=6.3 \mathrm{~Hz}, \mathbf{C H}_{2} \mathrm{COO} t \mathrm{Bu}\right) ; 2.52\left(\mathrm{~m}, 2 \mathrm{H}, \mathrm{H}_{3} \mathbf{C H}_{2}-\mathrm{CH}=\mathrm{CH}_{2}\right) ; 3.14\left(\mathrm{~m}, 2 \mathrm{H}, \mathrm{H}_{6}\right) ; 3.19\left(\mathrm{~m}, 1 \mathrm{H}, \mathrm{H}_{5}\right) ; 3.30(\mathrm{~m}, 1 \mathrm{H}$, $\left.\mathrm{H}_{5}\right) ; 3.39\left(\mathrm{~m}, 2 \mathrm{H}, \mathrm{NHCH}_{2} \mathrm{CH}_{2} \mathrm{COO} t \mathrm{Bu}\right) ; 4.50\left(\mathrm{dd}, 1 \mathrm{H}, J=9.76 .3 \mathrm{~Hz}, \mathrm{H}_{2}\right) ; 5.05\left(\mathrm{~m}, 5 \mathrm{H}, \mathrm{PhCH} \mathbf{C H}_{2} \mathrm{CH}_{2} \mathbf{C H}_{2} \mathrm{NH}\right)$; $5.72\left(\mathrm{~m}, 1 \mathrm{H}, \mathrm{CH}=\mathrm{CH}_{2}\right) ; 6.78(\mathrm{bt}, 1 \mathrm{H}, \mathrm{NH}) ; 7.27-7.33(\mathrm{~m}, 5 \mathrm{H}, \mathrm{Ar}) . \mathrm{NMR}{ }^{13} \mathrm{C}\left(75 \mathrm{MHz}, \mathrm{CDCl}_{3}\right): \delta_{\mathrm{C}}: 23.0\left(\mathrm{C}_{4}\right)$; $24.2\left(\mathrm{C}_{4}\right) ; 27.4-28.0\left(\mathrm{C}_{3} / \mathrm{C}_{5}\right) ; 35.0\left(\mathbf{C H}_{2}-\mathrm{CH}=\mathrm{CH}_{2}\right) ; 35.05\left(\mathrm{NHCH}_{2} \mathrm{CH}_{2} \mathrm{COO} t \mathrm{Bu}\right) ; 35.1\left(\mathbf{C H}_{2} \mathrm{COO} t \mathrm{Bu}\right) ; 40.6$ $\left(\mathrm{C}_{6}\right) ; 41.7\left(\mathrm{C}_{3}\right) ; 42.1\left(\mathrm{C}_{5}\right) ; 54.7\left(\mathrm{C}_{2}\right) ; 66.5\left(\mathrm{PhCH}_{2}\right) ; 81.0\left(\mathrm{C}_{\text {Arquat }} t \mathrm{Bu}\right) ; 117.1\left(\mathrm{CH}=\mathbf{C H}_{2}\right) ; 128.0-128.1-128.4$ $\left(\mathrm{C}_{\mathrm{Ar}}\right) ; 135.1\left(\mathbf{C H}=\mathrm{CH}_{2}\right) ; 136.6\left(\mathrm{C}_{\text {Arquat }}\right) ; 156.5(\mathrm{O}-\mathrm{CONH}), 169.8-171.4-177.0(\mathrm{CO}) .[\alpha]_{\mathrm{D}}^{20}:-37.1(\mathrm{c}=0.6$; $\mathrm{CH}_{2} \mathrm{Cl}_{2}$ ). IR (neat): $v_{\max } 3317,2932,1721,1658,1247,1152,697 \mathrm{~cm}^{-1}$. HRMS $\left(\mathrm{ES}^{+} .[\mathrm{M}+\mathrm{H}]^{+}\right)$: Calcd for $\mathrm{C}_{28} \mathrm{H}_{42} \mathrm{~N}_{3} \mathrm{O}_{6}$ 516.3068 Found 516.3067.

\subsubsection{3-[(3R, 2S)-2-(3-Allyl-2-oxo-pyrrolidin-1-yl)-6-benzyloxycarbonylamino-hexanoylamino]-} propionic acid tert-butyl ester $10 \mathrm{~b}$

The same experimental procedure as described for peptide coupling was applied to carboxylic acid 9b (226 $\mathrm{mg} ; 0.58 \mathrm{mmol})$ using amino acid $(0.58 \mathrm{mmol}, 1$ equiv), $\mathrm{N}$-methylmorpholine (NMM) $(191 \mu \mathrm{L}, 1.74 \mathrm{mmol}$, 3 equiv), hydroxybenzotriazole (HOBt) $(117 \mathrm{mg}, 0.87 \mathrm{mmol}, 1.5$ equiv), then EDC (122mg, $0.64 \mathrm{mmol}, 1.1$ equiv). This allowed the isolation of an oil $(86 \%, 259 \mathrm{mg})$.

$\mathrm{R}_{\mathrm{f}}=0.49(\mathrm{AcOEt} / \mathrm{cyclohexane}: 75 / 25) . \mathrm{NMR}{ }^{1} \mathrm{H}\left(300 \mathrm{MHz}, \mathrm{CDCl}_{3}\right): \delta_{\mathrm{H}}: 1.22\left(\mathrm{~m}, 2 \mathrm{H}, \mathrm{H}_{4}\right) ; 1.42(\mathrm{~s}, 9 \mathrm{H}, t \mathrm{Bu})$; 1.48-1.50 (m, 2H, $\left.\mathrm{H}_{5}\right) ; 1.63-1.75\left(\mathrm{~m}, 2 \mathrm{H}, \mathrm{H}_{3} \mathrm{H}_{4}\right) ; 1.93\left(\mathrm{~m}, 1 \mathrm{H}, \mathrm{H}_{3}\right) ; 2.14\left(\mathrm{~m}, 2 \mathrm{H}, \mathbf{C H}_{2}-\mathrm{CH}=\mathrm{CH}_{2} \mathrm{H}_{4}\right) ; 2.38(\mathrm{t}, 2 \mathrm{H}$, $\left.J=6.3 \mathrm{~Hz}, \mathbf{C H}_{2} \mathrm{COO} \mathrm{Bu}\right) ; 2.52\left(\mathrm{~m}, 2 \mathrm{H}, \mathrm{H}_{3} \mathbf{C H}_{2}-\mathrm{CH}=\mathrm{CH}_{2}\right) ; 3.16\left(\mathrm{~m}, 2 \mathrm{H}, \mathrm{H}_{6}\right) ; 3.27\left(\mathrm{t}, 2 \mathrm{H}, J=6.3 \mathrm{~Hz}, \mathrm{H}_{5}\right) ; 3.41$ $\left(\mathrm{m}, 2 \mathrm{H}, \mathrm{NHCH}_{2} \mathrm{CH}_{2} \mathrm{COO} t \mathrm{Bu}\right) ; 4.47$ (bt, $\left.1 \mathrm{H}, J=7.6 \mathrm{~Hz}, 1 \mathrm{H}_{2}\right) ; 5.05\left(\mathrm{~m}, 5 \mathrm{H}, \mathrm{PhCH}_{2} \mathrm{CH}=\mathbf{C H} \mathbf{C H}_{2} \mathrm{NH}\right) ; 5.72(\mathrm{~m}, 1 \mathrm{H}$, $\left.\mathrm{CH}=\mathrm{CH}_{2}\right) ; 6.75$ (bt, $\left.1 \mathrm{H}, \mathrm{NH}\right) ; 7.27-7.33(\mathrm{~m}, 5 \mathrm{H}, \mathrm{Ar})$.

$\mathrm{NMR}{ }^{13} \mathrm{C}\left(75 \mathrm{MHz}, \mathrm{CDCl}_{3}\right): \delta_{\mathrm{C}}: 22.9 \quad\left(\mathrm{C}_{4}\right) ; 24.0 \quad\left(\mathrm{C}_{4}\right) ; 27.2-28.0 \quad\left(\mathrm{C}_{3} / \mathrm{C}_{5}\right) ; 35.1 \quad\left(2 \mathrm{C}, \quad \mathbf{C H}_{2}-\mathrm{CH}_{=} \mathrm{CH}_{2}\right.$ $\left.\mathrm{NHCH}_{2} \mathrm{CH}_{2} \mathrm{COO} t \mathrm{Bu}\right) ; 35.2\left(\mathbf{C H}_{2} \mathrm{COO} t \mathrm{Bu}\right) ; 40.6\left(\mathrm{C}_{6}\right) ; 41.3\left(\mathrm{C}_{3}\right) ; 42.1\left(\mathrm{C}_{5}\right) ; 54.7\left(\mathrm{C}_{2}\right) ; 66.5\left(\mathrm{PhCH}_{2}\right) ; 81.0\left(\mathrm{C}_{\mathrm{q}}\right.$ $t \mathrm{Bu}) ; 117.2\left(\mathrm{CH}=\mathbf{C H}_{2}\right) ; 128.0-128.1-128.4\left(\mathrm{C}_{\mathrm{Ar}}\right) ; 135.2\left(\mathbf{C H}=\mathrm{CH}_{2}\right) ; 136.6\left(\mathrm{C}_{\text {Arquat }}\right) ; 156.5(\mathrm{O}-\mathbf{C O N H}), 169.7-$ 171.5-177.0 (CO). $[\alpha]_{\mathrm{D}}{ }^{20}:-61.4\left(\mathrm{c}=0.9 ; \mathrm{CH}_{2} \mathrm{Cl}_{2}\right)$. IR (neat): $v_{\max } 3317,2976,2933,1720,1657,1530,1366$, $1248,1152,697 \mathrm{~cm}^{-1}$. HRMS $\left(\mathrm{ES}^{+}\right.$. $\left.[\mathrm{M}+\mathrm{H}]^{+}\right)$: Calcd for $\mathrm{C}_{28} \mathrm{H}_{42} \mathrm{~N}_{3} \mathrm{O}_{6} 516.3068$ Found 516.3066. 


\subsubsection{3-\{(3S,2S)-6-Benzyloxycarbonylamino-2-[3-(3-hydroxy-propyl)-2-oxo-pyrrolidin-1-yl]- hexanoylamino\}-propionic acid tert-butyl ester}

To alkene 10a (374 $\mathrm{mg} ; 0.73 \mathrm{mmol})$ dissolved in $12 \mathrm{~mL}$ of anhydrous tetrahydrofuran was added 9-BBN as a $0.5 \mathrm{M}$ solution in THF $\left(5.4 \mathrm{~mL} ; 2.7 \mathrm{mmol} ; 3.7\right.$ equiv). At $0{ }^{\circ} \mathrm{C}$ under argon, the mixture was stirred for $30 \mathrm{~min}$ at the same temperature. Stirring was continued for $16 \mathrm{~h}$ at $\mathrm{rt}$. After addition of sodium acetate $5 \mathrm{M}$ ( $1.8 \mathrm{~mL}, 9 \mathrm{mmol}, 12$ equiv) and a $30 \% \mathrm{H}_{2} \mathrm{O}_{2}$ solution $\left(1.2 \mathrm{~mL} ; 14.5\right.$ equiv) at $0{ }^{\circ} \mathrm{C}$ the mixture was stirred $7 \mathrm{~h}$ at $\mathrm{rt} .5 \mathrm{~mL}$ of $\mathrm{H}_{2} \mathrm{O}$ was added and the mixture was extracted 3 times with ethyl acetate. The organic phase was washed with brine. The organic phase was dried with $\mathrm{MgSO}_{4}$ and the solvent removed in vacuum. Flash chromatography on silica gel (AcOEt/MeOH: 99/1) allowed the isolation of a yellow oil $(71 \%, 270 \mathrm{mg})$.

$\mathrm{R}_{\mathrm{f}}=0.17$ (AcOEt). NMR ${ }^{1} \mathrm{H}\left(300 \mathrm{MHz}, \mathrm{CDCl}_{3}\right): \delta_{\mathrm{H}}: 1.23-1.33\left(\mathrm{~m}, 2 \mathrm{H}, \mathrm{H}_{4}\right) ; 1.45(\mathrm{~s}, 9 \mathrm{H}, t \mathrm{Bu}) ; 1.53-1.60(\mathrm{~m}, 3 \mathrm{H}$, $\left.\mathrm{H}_{5} \mathbf{C H}_{2} \mathrm{CH}_{2} \mathrm{CH}_{2}-\mathrm{OH}\right) ; 1.62-1.77$ (m, 4H, H3 $\left.\mathrm{CH}_{2} \mathbf{C H}_{2} \mathrm{CH}_{2}-\mathrm{OH} \mathrm{H}_{4}\right) ; 1.81-2.25$ (m, 3H, $\mathrm{H}_{4} \mathbf{C H}_{2} \mathrm{CH}_{2} \mathrm{CH}_{2}-\mathrm{OH}$ $\left.\mathrm{H}_{3}\right) ; 2.42\left(\mathrm{t}, 2 \mathrm{H}, J=6 \mathrm{~Hz}, \mathbf{C H}_{2} \mathrm{COO} t \mathrm{Bu}\right) ; 2.50\left(\mathrm{~m}, 1 \mathrm{H}, \mathrm{H}_{3}\right) ; 3.17\left(\mathrm{dd}, 2 \mathrm{H}, J=6.5,13 \mathrm{~Hz}, \mathrm{H}_{6}\right) ; 3.25\left(\mathrm{~m}, 1 \mathrm{H}, \mathrm{H}_{5}\right)$; $3.36\left(\mathrm{~m}, 1 \mathrm{H}, \mathrm{H}_{5}\right) ; 3.43\left(\mathrm{~m}, 2 \mathrm{H}, \mathrm{NHCH}_{2} \mathrm{CH}_{2} \mathrm{COO} t \mathrm{Bu}\right) ; 3.65\left(\mathrm{t}, 2 \mathrm{H}, \mathrm{J}=6 \mathrm{~Hz}, \mathrm{CH}_{2} \mathrm{CH}_{2} \mathbf{C H}-\mathrm{OH}\right) ; 4.50(\mathrm{dd}, 1 \mathrm{H}$, $\left.\mathrm{J}=6.5,9 \mathrm{~Hz}, \mathrm{H}_{2}\right) ; 4.96(\mathrm{bs}, 1 \mathrm{H}, \mathrm{NH}) ; 5.09(\mathrm{~s}, 2 \mathrm{H}, \mathrm{PhCH}) ; 6.76(\mathrm{sl}, 1 \mathrm{H}, \mathrm{NH}) ; 7.31(\mathrm{~m}, 5 \mathrm{H}, \mathrm{Ar}) . \mathrm{NMR}{ }^{13} \mathrm{C}(75$ $\left.\mathrm{MHz}, \mathrm{CDCl}_{3}\right): \delta_{\mathrm{C}}: 23.0\left(\mathrm{C}_{4}\right) ; 25.0\left(\mathrm{C}_{4}\right) ; 27.1\left(\mathbf{C H}_{2} \mathrm{CH}_{2} \mathrm{CH}_{2}-\mathrm{OH}\right) ; 27.6\left(\mathrm{C}_{3}\right) ; 28.0\left(\mathrm{C}_{\mathrm{tBu}}\right) ; 29.2\left(\mathrm{C}_{5}\right) ; 29.9$ $\left(\mathrm{CH}_{2} \mathbf{C H}_{2} \mathrm{CH}_{2}-\mathrm{OH}\right) ; 35.0-35.1\left(\mathrm{NHCH}_{2} \mathbf{C H}_{2} \mathrm{COO} t \mathrm{Bu}\right) ; 40.6\left(\mathrm{C}_{6}\right) ; 41.4\left(\mathrm{C}_{3}\right) ; 42.2\left(\mathrm{C}_{5}\right) ; 54.7\left(\mathrm{C}_{2}\right) ; 62.1\left(\mathrm{CH}_{2} \mathrm{CH}_{2}\right.$ $\left.\mathbf{C H}_{2}-\mathrm{OH}\right)$; $66.4\left(\mathrm{PhCH}_{2}\right) ; 81.11\left(\mathrm{C}_{\text {quattBu }}\right) ; 128.05-128.4\left(\mathrm{C}_{\mathrm{Ar}}\right) ; 136.6\left(\mathrm{C}_{\text {Arquat }}\right) ; 156.5(\mathrm{CO}) ; 169.9-171.5-177.8$ (3 CO). $[\alpha]_{\mathrm{D}}{ }^{20}:-40.3\left(\mathrm{c}=1 ; \mathrm{CH}_{2} \mathrm{Cl}_{2}\right)$. IR (neat): $v_{\max } 3315,2931,2865,1719,1656,1252,1152,738,697$. HRMS $\left(\mathrm{ES}^{+} .[\mathrm{M}+\mathrm{Na}]^{+}\right)$: Calcd for $\mathrm{C}_{28} \mathrm{H}_{43} \mathrm{~N}_{3} \mathrm{O}_{7} \mathrm{Na}$ 556.2999 Found 556.2985.

\subsubsection{3-\{(3R,2S)-6-Benzyloxycarbonylamino-2-[3-(3-hydroxy-propyl)-2-oxo-pyrrolidin-1-yl]- hexanoylamino\}-propionic acid tert-butyl ester}

The same experimental procedure as described for hydroboration was applied to alkene $\mathbf{1 0 b}(259 \mathrm{mg} ; 0.5$ mmol) using a $0.5 \mathrm{M}$ solution of $9-\mathrm{BBN}$ in THF $(3.7 \mathrm{~mL} ; 1.8 \mathrm{mmol} ; 3.7$ equiv). Stirring was maintained 16 $\mathrm{h}$ after addition of sodium acetate $5 \mathrm{M}\left(1.2 \mathrm{~mL}, 6 \mathrm{mmol}, 12\right.$ equiv) and a $30 \% \mathrm{H}_{2} \mathrm{O}_{2}$ solution $(0.84 \mathrm{~mL} ; 14$ equiv). Flash chromatography on silica gel (AcOEt/MeOH: 99/1) allowed the isolation of a yellow oil $(64 \%, 165 \mathrm{mg})$.

$\mathrm{R}_{\mathrm{f}}=0.07$ (AcOEt). NMR ${ }^{1} \mathrm{H}\left(300 \mathrm{MHz}, \mathrm{CDCl}_{3}\right): \delta_{\mathrm{H}}: 1.17-1.27\left(\mathrm{~m}, 2 \mathrm{H}, \mathrm{H}_{4}\right) ; 1.42(\mathrm{~s}, 9 \mathrm{H}, t \mathrm{Bu}) ; 1.41-1.52(\mathrm{~m}, 3 \mathrm{H}$, $\left.\mathrm{H}_{5} \mathbf{C H}_{2} \mathrm{CH}_{2} \mathrm{CH}_{2}-\mathrm{OH}\right) ; 1.49-1.71\left(\mathrm{~m}, 4 \mathrm{H}, \mathrm{H}_{3} \mathrm{CH}_{2} \mathbf{C H}_{2} \mathrm{CH}_{2}-\mathrm{OH} \mathrm{H}\right.$ ); 1.72-1.92 (m, 2H, $\left.\mathbf{C H}_{2} \mathrm{CH}_{2} \mathrm{CH}_{2}-\mathrm{OH} \mathrm{H}_{3}\right)$; $2.18\left(\mathrm{~m}, 1 \mathrm{H}, \mathrm{H}_{4}\right) ; 2.39\left(\mathrm{t}, 2 \mathrm{H}, J=6.3 \mathrm{~Hz}, \mathbf{C H}_{2} \mathrm{COO} t \mathrm{Bu}\right) ; 2.45\left(\mathrm{~m}, 1 \mathrm{H}, \mathrm{H}_{3}\right) ; 3.13\left(\mathrm{dd}, 2 \mathrm{H}, J=6.4,12.5 \mathrm{~Hz}, \mathrm{H}_{6}\right)$; $3.29\left(\mathrm{~m}, 2 \mathrm{H}, \mathrm{H}_{5}\right) ; 3.39\left(\mathrm{~m}, 2 \mathrm{H}, \mathrm{NHCH}_{2} \mathrm{CH}_{2} \mathrm{COO} t \mathrm{Bu}\right) ; 3.59\left(\mathrm{t}, 2 \mathrm{H}, J=6.1 \mathrm{~Hz}, \mathrm{CH}_{2} \mathrm{CH}_{2} \mathbf{C H}_{2}-\mathrm{OH}\right) ; 4.49$ (dd, $1 \mathrm{H}$, $\left.J=6.3,10.8 \mathrm{~Hz}, \mathrm{H}_{2}\right) ; 5.25\left(\mathrm{~s}, 2 \mathrm{H}, \mathrm{PhCH}_{2}\right) ; 5.25(\mathrm{bt}, 1 \mathrm{H}, \mathrm{NH}) ; 6.88(\mathrm{bt}, 1 \mathrm{H}, J=5.8 \mathrm{~Hz}, \mathrm{NH}) ; 7.31(\mathrm{~m}, 5 \mathrm{H}$, Ar).NMR ${ }^{13} \mathrm{C}\left(75 \mathrm{MHz}, \mathrm{CDCl}_{3}\right): \delta_{\mathrm{C}}: 22.9\left(\mathrm{C}_{4}\right) ; 24.9\left(\mathrm{C}_{4}\right) ; 27.2\left(\mathbf{C H}_{2} \mathrm{CH}_{2} \mathrm{CH}_{2}-\mathrm{OH}\right) ; 27.4\left(\mathrm{C}_{3}\right) ; 28.0\left(\mathrm{C}_{t \mathrm{Bu}}\right) ; 29.2$ $\left(\mathrm{C}_{5}\right) ; 29.9\left(\mathrm{CH}_{2} \mathbf{C H}_{2} \mathrm{CH}_{2}-\mathrm{OH}\right) ; 35.0-35.1\left(\mathrm{NHCH}_{2} \mathbf{C H}_{2} \mathrm{COO} t \mathrm{Bu}\right) ; 40.6\left(\mathrm{C}_{6}\right) ; 41.8\left(\mathrm{C}_{3}\right) ; 42.1\left(\mathrm{C}_{5}\right) ; 54.5\left(\mathrm{C}_{2}\right) ; 62.1$ $\left(\mathrm{CH}_{2} \mathrm{CH}_{2} \mathbf{C H}_{2}-\mathrm{OH}\right) ; 66.4\left(\mathrm{PhCH}_{2}\right) ; 81.11\left(\mathrm{C}_{\text {quat } t \mathrm{Bu}}\right) ; 128.05-128.4\left(\mathrm{C}_{\mathrm{Ar}}\right) ; 136.6\left(\mathrm{C}_{\text {Arquat }}\right) ; 156.5(\mathrm{CO})$; $169.8-$ 171.4-177.8 (3 CO). $[\alpha]_{\mathrm{D}}{ }^{20}:-49.3\left(\mathrm{c}=0.7 ; \mathrm{CH}_{2} \mathrm{Cl}_{2}\right)$. IR (neat): $v_{\max } 3307,2930,2865,1719,1658,1266,1154$, 695. HRMS $\left(\mathrm{ES}^{+}\right.$. $\left.[\mathrm{M}+\mathrm{H}]^{+}\right)$: Calcd for $\mathrm{C}_{28} \mathrm{H}_{44} \mathrm{~N}_{3} \mathrm{O}_{7} 534.3173$ Found 516.3171.

\subsubsection{3-\{(3S, 2S)-6-Benzyloxycarbonylamino-2-[3-(3-guanidin-diboc-propyl)-2-oxo-pyrrolidin-1-yl]- hexanoylamino\}-propionic acid tert-butyl ester 12a}

Previous alcohol (155 mg, $0.29 \mathrm{mmol})$ and 1,3-bis(tert-butoxycarbonyl) guanidine (150 $\mathrm{mg}, 0.58 \mathrm{mmol}, 2$ equiv) were dried under vacuum and then dissolved in $6 \mathrm{~mL}$ of anhydrous THF under argon. Triphenylphosphine (152 mg, $0.58 \mathrm{mmol}, 2$ equiv) was added to the solution at room temperature, then a $40 \%$ solution of diethylazodicarboxylate (DEAD) in toluene $(0.1 \mathrm{~mL}, 0.58 \mathrm{mmol}, 2$ equiv) was added dropwise at $0{ }^{\circ} \mathrm{C}$. The mixture was stirred for 3 days at room temperature. Solvents were removed in vacuum. The residue was purified by flash chromatography on silica gel $\left(\mathrm{Et}_{2} \mathrm{O} /\right.$ cyclohexane: $\left.99 / 1\right)$ to give a colourless oil (175 mg, 78\%).

$\mathrm{R}_{\mathrm{f}}=0.17\left(\mathrm{Et}_{2} \mathrm{O} /\right.$ cyclohexane: 90/10). $\mathrm{NMR}{ }^{1} \mathrm{H}\left(300 \mathrm{MHz}, \mathrm{CDCl}_{3}\right): \delta_{\mathrm{H}}: 1.23-1.29\left(\mathrm{~m}, 2 \mathrm{H}, \mathrm{H}_{4}\right) ; 1.36-1.38-1.40(3 \mathrm{~s}$, $27 \mathrm{H}, t \mathrm{Bu}) ; 1.36-1.40\left(\mathrm{~m}, 3 \mathrm{H}, \mathrm{H}_{5} \mathbf{C H}_{2} \mathrm{CH}_{2} \mathrm{CH}_{2}-\mathrm{NH}\right) ; 1.63-178\left(\mathrm{~m}, 5 \mathrm{H}, \mathrm{H}_{3} \mathrm{CH}_{2} \mathbf{C H}_{2} \mathrm{CH}_{2}-\mathrm{NH} \mathrm{H}_{4}\right) ; 1.92-1.98$ (m, $\left.1 \mathrm{H}, \mathbf{C H}_{2} \mathrm{CH}_{2} \mathrm{CH}_{2}-\mathrm{NH}\right) ; 1.99-2.04\left(\mathrm{~m}, 1 \mathrm{H}, \mathrm{H}_{3}\right) ; 2.42\left(\mathrm{t}, 2 \mathrm{H}, J=6 \mathrm{~Hz}, \mathbf{C H}_{2} \mathrm{COO} t \mathrm{Bu}\right) ; 2.53\left(\mathrm{~m}, 1 \mathrm{H}, \mathrm{H}_{3}\right) ; 3.21$ (dd, $\left.2 \mathrm{H}, J=6,16 \mathrm{~Hz}, \mathrm{H}_{6}\right) ; 3.27\left(\mathrm{~m}, 1 \mathrm{H}, \mathrm{H}_{5}\right) ; 3.39\left(\mathrm{~m}, 1 \mathrm{H}, \mathrm{H}_{5}\right) ; 3.47\left(\mathrm{~m}, 2 \mathrm{H}, \mathrm{NHCH}_{2} \mathrm{CH}_{2} \mathrm{COO} t \mathrm{Bu}\right) ; 3.81(\mathrm{~m}, 1 \mathrm{H}$, $\left.\mathrm{CH}_{2} \mathrm{CH}_{2} \mathbf{C H}_{2}-\mathrm{NH}\right) ; 4.01\left(\mathrm{~m}, 1 \mathrm{H}, \mathrm{CH}_{2} \mathrm{CH}_{2} \mathbf{C H}_{2}-\mathrm{NH}\right) ; 4.51$ (dd, $\left.1 \mathrm{H}, J=9.76 .3 \mathrm{~Hz}, \mathrm{H}_{2}\right) ; 4.92(\mathrm{bs}, 1 \mathrm{H}, \mathrm{NH}) ; 5.13$ (s, 2H, PhCH $\mathbf{C H}_{2}$ ) 6.73 (bt, 1H, NH); 7.31-7.4 (m, 5H, Ar); 9.24 (bs, $\left.1 \mathrm{H}, \mathrm{NH}\right) . \mathrm{NMR}{ }^{13} \mathrm{C}\left(75 \mathrm{MHz}, \mathrm{CDCl}_{3}\right): \delta_{\mathrm{C}}$ : 
$23.1\left(\mathrm{C}_{4}\right) ; 25.0\left(\mathrm{C}_{4}\right) ; 26.1\left(\mathrm{CH}_{2} \mathbf{C H}_{2} \mathrm{CH}_{2}-\mathrm{NH}\right) ; 27.4\left(\mathrm{C}_{3}\right) ; 27.7\left(\mathbf{C H}_{2} \mathrm{CH}_{2} \mathrm{CH}_{2}-\mathrm{NH}\right) ; 28.0-28.1-28.3\left(\mathrm{C}_{t B u}\right) ; 29.3$ $\left(\mathrm{C}_{5}\right)$; 34.9-35.0 ( $\left.\mathrm{NHCH}_{2} \mathbf{C H}_{2} \mathrm{COO} t \mathrm{Bu}\right) ; 40.6\left(\mathrm{C}_{6}\right) ; 41.7\left(\mathrm{C}_{3}\right) ; 42.1\left(\mathrm{C}_{5}\right) ; 44.2\left(\mathrm{CH}_{2} \mathrm{CH}_{2} \mathbf{C H}_{2}-\mathrm{NH}\right) ; 54.7\left(\mathrm{C}_{2}\right) ; 66.5$ $\left(\mathrm{PhCH}_{2}\right)$; 78.6-81.0-83.7 ( $\left.\mathrm{C}_{\text {quattBu}}\right)$; 128.0-128.4 ( $\left.\mathrm{C}_{\mathrm{Ar}}\right)$; $136.6\left(\mathrm{C}_{\text {Arquat }}\right)$; 154.9-156.4-160.5-163.7 (4 CO); 169.9$171.5(2 \mathrm{CO}) .[\alpha]_{\mathrm{D}}{ }^{20}:+22.2\left(\mathrm{c}=0.6 ; \mathrm{CH}_{2} \mathrm{Cl}_{2}\right)$. IR (neat): $v_{\max } 3374,2928,1709,1661,1248,1142,1098,696$. $\operatorname{MS}\left(\mathrm{ES}^{+}\right): m / z=797\left([\mathrm{MNa}]^{+}\right)$. HRMS $\left(\mathrm{ES}^{+} .[\mathrm{MH}]^{+}\right)$: Calcd for $\mathrm{C}_{39} \mathrm{H}_{63} \mathrm{~N}_{6} \mathrm{O}_{10} 775.4600$ Found 775.4593.

\subsubsection{3-\{(3R,2S)-6-Benzyloxycarbonylamino-2-[3-(3-guanidin-diboc-propyl)-2-oxo-pyrrolidin-1-yl]- hexanoylamino\}-propionic acid tert-butyl ester $12 \mathrm{~b}$}

The same experimental procedure as described for 12a was applied to minor distereoisomer (47 mg; 0.088 mmol) using and 1,3-bis(tert-butoxycarbonyl) guanidine (46 mg, $0.18 \mathrm{mmol}, 2$ equiv), triphenylphosphine (46 $\mathrm{mg}, 0.18 \mathrm{mmol}, 2$ equiv), $40 \%$ solution of diethylazodicarboxylate (DEAD) in toluene $(0.08 \mathrm{~mL}, 0.18 \mathrm{mmol}, 2$ equiv). Stirring was continued for $44 \mathrm{~h}$. Flash chromatography on silica gel $\left(\mathrm{Et}_{2} \mathrm{O}\right.$ to $\mathrm{Et}_{2} \mathrm{O} / \mathrm{MeOH}$ : 99/1) allowed the isolation of $\mathbf{1 2 b}$ as a colourless oil (58 $\mathrm{mg}, 85 \%)$.

$\mathrm{NMR}{ }^{1} \mathrm{H}\left(300 \mathrm{MHz}, \mathrm{CDCl}_{3}\right): \delta_{\mathrm{H}}: 1.23-1.29\left(\mathrm{~m}, 2 \mathrm{H}, \mathrm{H}_{4}\right) ; 1.36-1.38-1.40(3 \mathrm{~s}, 27 \mathrm{H}, t \mathrm{Bu}) ; 1.36-1.40\left(\mathrm{~m}, 3 \mathrm{H}, \mathrm{H}_{5}\right.$ $\left.\mathbf{C H}_{2} \mathrm{CH}_{2} \mathrm{CH}_{2}-\mathrm{NH}\right) ; 1.63-178\left(\mathrm{~m}, 5 \mathrm{H}, \mathrm{H}_{3} \mathrm{CH}_{2} \mathbf{C H}_{2} \mathrm{CH}_{2}-\mathrm{NH} \mathrm{H}_{4}\right) ; 1.92-1.98\left(\mathrm{~m}, 1 \mathrm{H}, \mathbf{C H}_{2} \mathrm{CH}_{2} \mathrm{CH}_{2}-\mathrm{NH}\right) ; 1.99-$ $2.04\left(\mathrm{~m}, 1 \mathrm{H}, \mathrm{H}_{3}\right) ; 2.42\left(\mathrm{t}, 2 \mathrm{H}, J=6 \mathrm{~Hz}, \mathbf{C H}_{2} \mathrm{COO} t \mathrm{Bu}\right) ; 2.53\left(\mathrm{~m}, 1 \mathrm{H}, \mathrm{H}_{3}\right) ; 3.21\left(\mathrm{dd}, 2 \mathrm{H}, J=6,16 \mathrm{~Hz}, \mathrm{H}_{6}\right) ; 3.27$ $\left(\mathrm{m}, 1 \mathrm{H}, \mathrm{H}_{5}\right) ; 3.39\left(\mathrm{~m}, 1 \mathrm{H}, \mathrm{H}_{5}\right) ; 3.47\left(\mathrm{~m}, 2 \mathrm{H}, \mathrm{NHCH}_{2} \mathrm{CH}_{2} \mathrm{COO} t \mathrm{Bu}\right) ; 3.81\left(\mathrm{~m}, 1 \mathrm{H}, \mathrm{CH}_{2} \mathrm{CH}_{2} \mathbf{C H}_{2}-\mathrm{NH}\right) ; 4.01(\mathrm{~m}$, $1 \mathrm{H}, \mathrm{CH}_{2} \mathrm{CH}_{2} \mathbf{C H}_{2}-\mathrm{NH}$ ); 4.45 bt, $\left.1 \mathrm{H}, J=7.5 \mathrm{~Hz}, \mathrm{H}_{2}\right) ; 4.91$ (bs, $\left.1 \mathrm{H}, \mathrm{NH}\right) ; 5.13$ (s, 2H, PhCH $) ; 6.50$ (bt, $\left.1 \mathrm{H}, \mathrm{NH}\right)$; 7.31-7.4 (m, 5H, Ar); 9.24 (bs, 2H, NH). NMR ${ }^{13} \mathrm{C}\left(100 \mathrm{MHz}, \mathrm{CDCl}_{3}\right): \delta_{\mathrm{C}}: 23.0\left(\mathrm{C}_{4}\right) ; 25.0\left(\mathrm{C}_{4}\right) ; 26.2\left(\mathrm{CH}_{2} \mathbf{C H}_{2}\right.$ $\left.\mathrm{CH}_{2}-\mathrm{NH}\right) ; \quad 27.2 \quad\left(\mathrm{C}_{3}\right) ; \quad 28.0 \quad\left(\mathbf{C H}_{2} \mathrm{CH}_{2} \quad \mathrm{CH}_{2}-\mathrm{NH}\right) ; \quad 28.0-28.1-28.3 \quad\left(\mathrm{C}_{t B u}\right) ; \quad 29.4 \quad\left(\mathrm{C}_{5}\right) ; \quad 35.1-35.2$ $\left(\mathrm{NHCH}_{2} \mathbf{C H}_{2} \mathrm{COO} t \mathrm{Bu}\right) ; 40.7\left(\mathrm{C}_{6}\right) ; 41.7\left(\mathrm{C}_{3}\right) ; 42.1\left(\mathrm{C}_{5}\right) ; 44.3\left(\mathrm{CH}_{2} \mathrm{CH}_{2} \mathbf{C H}_{2}-\mathrm{NH}\right) 54.8\left(\mathrm{C}_{2}\right) ; 66.5\left(\mathrm{PhCH}_{2}\right)$; 78.681.0-83.7 ( $\left.\mathrm{C}_{\text {quat } \mathrm{Bu}}\right)$; 128.0-128.5 ( $\left.\mathrm{C}_{\mathrm{Ar}}\right)$; 136.7 ( $\left.\mathrm{C}_{\text {Arquat }}\right)$; 155.0-156.5-160.5-163.8 (3 CO, $\left.\mathrm{N}=\mathrm{C}\right) ; 169.7-171.3-177.6$ (3 CO). $[\alpha]_{D}{ }^{20}:-41.6\left(\mathrm{c}=1.8 ; \mathrm{CH}_{2} \mathrm{Cl}_{2}\right)$. IR (neat): $v_{\max } 3381,2976,2930,1710,1661,1248,1143,1098,695$. HRMS $\left(\mathrm{ES}^{+} .[\mathrm{M}+\mathrm{Na}]^{+}\right)$: Calcd for $\mathrm{C}_{39} \mathrm{H}_{62} \mathrm{~N}_{6} \mathrm{O}_{10} \mathrm{Na}$ 797.4425 Found 797.4396.

\subsubsection{2-((3S,2S)-6-(((benzyloxy)carbonyl)amino)-2-(3-(3-guanidinopropyl)-2-oxopyrrolidin-1- yl)hexanamido)propanoic acid 16a}

TFA $(0.3 \mathrm{~mL} ; 3.3 \mathrm{mmol})$ was added to a cooled $\left(0{ }^{\circ} \mathrm{C}\right)$ solution of compound 12a $(16 \mathrm{mg} ; 0.021 \mathrm{mmol})$ dissolved in $\mathrm{CH}_{2} \mathrm{Cl}_{2}(1.5 \mathrm{~mL})$ with a droplet of water. The mixture was stirred at room temperature for $4 \mathrm{~h}$. The mixture was concentrated in vacuo after addition of toluene $(2 \mathrm{~mL})$. Two more additions and evaporations of toluene were done and finally the residue was taken up in ether $(1 \mathrm{~mL})$ and extracted with water (3 times). The aqueous layer was lyophilised to yield 16a as a foam in a quantitative yield (13 $\mathrm{mg}$ ).

NMR ${ }^{1} \mathrm{H}(400 \mathrm{MHz}, \mathrm{MeOD}): \delta_{\mathrm{H}}: 1.21-1.35\left(\mathrm{~m}, 2 \mathrm{H}, \mathrm{H}_{4}\right) ; 1.41-1.61\left(\mathrm{~m}, 3 \mathrm{H}, \mathrm{H}_{5} \mathbf{C H}_{2} \mathrm{CH}_{2} \mathrm{CH}_{2}-\mathrm{NH}\right) ; 1.68(\mathrm{~m}, 2 \mathrm{H}$, $\left.\mathrm{CH}_{2} \mathbf{C H}_{2} \mathrm{CH}_{2}-\mathrm{NH}\right) ; 1.70-1.90\left(\mathrm{~m}, 4 \mathrm{H}, \mathrm{H}_{3} \mathrm{H}_{4} \mathbf{C H}_{2} \mathrm{CH}_{2} \mathrm{CH}_{2}-\mathrm{NH}\right) ; 2.22\left(\mathrm{~m}, 1 \mathrm{H}, \mathrm{H}_{3}\right) ; 2.52(\mathrm{t}, 3 \mathrm{H}, J=6.6 \mathrm{~Hz}$, $\left.\mathbf{C H}_{2} \mathrm{COOH}, \mathrm{H}_{3}\right) ; 3.13\left(\mathrm{t}, 2 \mathrm{H}, J=6.6, \mathrm{H}_{6}\right) ; 3.21\left(\mathrm{t}, 2 \mathrm{H}, J=7, \mathrm{CH}_{2} \mathrm{CH}_{2} \mathbf{C H}_{2}-\mathrm{NH}\right) ; 3.34-3.40\left(\mathrm{~m}, 1 \mathrm{H}, \mathrm{H}_{5}\right) ; 3.43(\mathrm{t}$, $\left.2 \mathrm{H}, J=6.1 \mathrm{~Hz}, \mathrm{NHCH}_{2} \mathrm{CH}_{2} \mathrm{COO} t \mathrm{Bu}\right) ; 3.57\left(\mathrm{~m}, 1 \mathrm{H}, \mathrm{H}_{5}\right) ; 4.52\left(\mathrm{dd}, 1 \mathrm{H}, J=9.75 .8 \mathrm{~Hz}, \mathrm{H}_{2}\right) ; 5.07(\mathrm{~s}, 2 \mathrm{H}, \mathrm{PhCH})$; 7.31-7.5 (m, 5H, Ar).. NMR ${ }^{13} \mathrm{C}(75 \mathrm{MHz}, \mathrm{MeOD}): \delta_{\mathrm{C}}: 23.0\left(\mathrm{C}_{4}\right) ; 24.6\left(\mathrm{C}_{4}\right) ; 26.0\left(\mathrm{CH}_{2} \mathbf{C H}_{2} \mathrm{CH}_{2}-\mathrm{NH}\right) ; 27.5$ $\left(\mathbf{C H}_{2} \mathrm{CH}_{2} \mathrm{CH}_{2}-\mathrm{NH}\right) ; 28.2\left(\mathrm{C}_{3}\right) ; 29.0\left(\mathrm{C}_{5}\right) ; 33.2\left(\mathbf{C H}_{2} \mathrm{COOH}\right) ; 35.1 \quad\left(\mathrm{NHCH}_{2} \mathrm{CH}_{2} \mathrm{COOH}\right) ; 40.1 \quad\left(\mathrm{C}_{6}\right) ; 41.0$ $\left(\mathrm{CH}_{2} \mathrm{CH}_{2} \mathbf{C H}_{2}-\mathrm{NH}\right) ; 41.4\left(\mathrm{C}_{3}\right) ; 42.4\left(\mathrm{C}_{5}\right) ; 54.9\left(\mathrm{C}_{2}\right) ; 66.0\left(\mathrm{PhCH}_{2}\right) ; 127.4-127.6-128.1\left(\mathrm{C}_{\mathrm{Ar}}\right) ; 137.2\left(\mathrm{C}_{\text {Arquat }}\right)$; 157.2-157.5 (CO, C=N); $171.7(\mathrm{CO}) ; 178.1(2 \mathrm{CO}) .[\alpha]_{\mathrm{D}}{ }^{20}:-16.9\left(\mathrm{c}=1 ; \mathrm{H}_{2} \mathrm{O}\right)$. IR (neat): $v_{\max } 3340,3190,2948$, 1659, 1544, 1436, 1267, 1186, 1200, 1134, 722. HRMS (ES- [M - H] ${ }^{-}$): Calcd for $\mathrm{C}_{25} \mathrm{H}_{37} \mathrm{~N}_{6} \mathrm{O}_{8} 517.2775$ Found 517.2772 .

\subsubsection{3-((3R,2S)-6-(((benzyloxy)carbonyl)amino)-2-(3-(3-guanidinopropyl)-2-oxopyrrolidin-1- yl)hexanamido)propanoic acid 16b}

The same protocol for TFA deprotection was applied to minor diastereoisomer as described above (19 mg; 0.024 mmol). Guanidyl compound $\mathbf{1 6} \mathbf{b}$ was obtained as a foam in a quantitative yield $(13 \mathrm{mg})$.

NMR ${ }^{1} \mathrm{H}\left(400 \mathrm{MHz}, \mathrm{D}_{2} \mathrm{O}\right): \delta_{\mathrm{H}}$ : 0.95-1.12 (m, 2H, H4); 1.15-1.46 (m, 5H, $\mathrm{H}_{5} \mathbf{C H}_{2} \mathrm{CH}_{2} \mathrm{CH}_{2}-\mathrm{NH} \mathrm{CH}_{2} \mathbf{C H}_{2} \mathrm{CH}_{2}-$ $\mathrm{NH}) ; 1.46-1.70\left(\mathrm{~m}, 4 \mathrm{H}, \mathrm{H}_{3} \mathrm{H}_{4} \mathbf{C H}_{2} \mathrm{CH}_{2} \mathrm{CH}_{2}-\mathrm{NH}\right) ; 2.08\left(\mathrm{~m}, 1 \mathrm{H}, \mathrm{H}_{3}\right) ; 2.52\left(\mathrm{t}, 3 \mathrm{H}, J=6.3 \mathrm{~Hz}, \mathbf{C H}_{2} \mathrm{COOH}_{3} \mathrm{H}_{3}\right)$; $2.94\left(\mathrm{~m}, 4 \mathrm{H}, \mathrm{H}_{6} \mathrm{CH}_{2} \mathrm{CH}_{2} \mathbf{C H}_{2}-\mathrm{NH}\right) ; 3.11-3.24\left(\mathrm{~m}, 2 \mathrm{H}, \mathrm{H}_{5}\right) ; 3.29\left(\mathrm{~m}, 2 \mathrm{H}, \mathrm{NHCH}_{2} \mathrm{CH}_{2} \mathrm{COO} t \mathrm{Bu}\right) ; 4.33(\mathrm{t}, 1 \mathrm{H}, J=$ $\left.8 \mathrm{~Hz}, \mathrm{H}_{2}\right) ; 4.95(\mathrm{~m}, 2 \mathrm{H}, \mathrm{PhCH}) ; 7.28(\mathrm{~m}, 5 \mathrm{H}, \mathrm{Ar}) . . \mathrm{NMR}{ }^{13} \mathrm{C}\left(75 \mathrm{MHz}, \mathrm{D}_{2} \mathrm{O}\right): \delta_{\mathrm{C}}: 22.1\left(\mathrm{C}_{4}\right) ; 23.7\left(\mathrm{C}_{4}\right) ; 25.1$ $\left(\begin{array}{lllllllll}\mathrm{CH}_{2} \mathbf{C H}_{2} & \mathrm{CH}_{2}-\mathrm{NH}\end{array}\right) ; \quad 26.8 \quad\left(\mathrm{C}_{3}\right) ; \quad 27.1 \quad\left(\mathbf{C H}_{2} \mathrm{CH}_{2} \quad \mathrm{CH}_{2}-\mathrm{NH}\right) ; \quad 27.9 \quad\left(\mathrm{C}_{5}\right) ; \quad 33.3 \quad\left(\mathbf{C H}_{2} \mathrm{COOH}\right) ; \quad 35.1$ $\left(\mathrm{NHCH}_{2} \mathrm{CH}_{2} \mathrm{COOH}\right) ; 39.9\left(\mathrm{CH}_{2} \mathrm{CH}_{2} \mathbf{C H}_{2}-\mathrm{NH}\right) ; 40.8\left(\mathrm{C}_{6}\right) ; 41.5\left(\mathrm{C}_{3}\right) ; 42.6\left(\mathrm{C}_{5}\right) ; 54.8\left(\mathrm{C}_{2}\right) ; 66.6\left(\mathrm{PhCH}_{2}\right) ; 127.4-$ 128.2-128.6 $\left(\mathrm{C}_{\mathrm{Ar}}\right)$; $136.5\left(\mathrm{C}_{\text {Arquat }}\right) ; 156.5-158.3(\mathrm{CO}, \mathrm{C}=\mathrm{N}) ; 171.8-175.9-179.9(3 \mathrm{CO}) .[\alpha]_{\mathrm{D}}{ }^{20}:-29.5(\mathrm{c}=0.7$; 
$\mathrm{H}_{2} \mathrm{O}$ ). IR (neat): $\left.v_{\max } 3326,3191,2941,1651,1532,1262,1178,1130,720 . \mathrm{HRMS}_{(\mathrm{ES}}^{+} .[\mathrm{M}+\mathrm{Na}]^{+}\right)$: Calcd for $\mathrm{C}_{25} \mathrm{H}_{38} \mathrm{~N}_{6} \mathrm{O}_{6} \mathrm{Na}$ 541.2751 Found 541.2747.

\subsubsection{3-\{(3S,2S)-6-amino-2-[3-(3-guanidin-diboc-propyl)-2-oxo-pyrrolidin-1-yl]-hexanoylamino $\}-$ propionic acid tert-butyl ester}

To benzyloxycarbonyl 12a (300 mg, $0.38 \mathrm{mmol})$ dissolved in $17 \mathrm{~mL}$ of methanol was added $100 \mathrm{mg}$ of hydroxide palladium on activated carbon $(20 \% \mathrm{Pd})$. The mixture was stirred for $5 \mathrm{~h}$ under hydrogen atmosphere. After filtration, washing with $\mathrm{MeOH}$, the solvent was removed under vaccuum. The residue was purified by flash chromatography on silica gel (Ethyl acetate/MeOH/ $\mathrm{Et}_{3} \mathrm{~N}$ : $80 / 20 / 1.5$ ) to give a colourless oil (180 mg, 75\%).

$\mathrm{R}_{\mathrm{f}}=0.10$ (Ethyl acetate/MeOH/ $\left.\mathrm{EtN}_{3}: 80 / 20 / 1.5\right) . \mathrm{NMR}{ }^{1} \mathrm{H}\left(300 \mathrm{MHz}, \mathrm{CDCl}_{3}\right): \delta_{\mathrm{H}}: 1.25-1.41\left(\mathrm{~m}, 2 \mathrm{H}, \mathrm{H}_{4}\right) ; 1.48-$ 1.52-1.56 (3s, 27H, $t \mathrm{Bu}) ; 1.58-1.79\left(\mathrm{~m}, 7 \mathrm{H}, \mathrm{H}_{5} \mathrm{H}_{3} \mathrm{H}_{4} \mathrm{CH}_{2} \mathbf{C H}_{2} \mathrm{CH}_{2} \mathrm{NH}_{\mathbf{C H}} \mathbf{C H}_{2} \mathrm{CH}_{2} \mathrm{NH}\right) ; 1.91-1.94\left(\mathrm{~m}, 1 \mathrm{H}, \mathrm{H}_{3}\right)$; 1.95-1.97 (m, 1H, $\left.\mathbf{C H}_{2} \mathrm{CH}_{2} \mathrm{CH}_{2}-\mathrm{NH}\right) ; 2.38\left(\mathrm{~m}, 1 \mathrm{H}, \mathrm{H}_{4}\right) ; 2.46\left(\mathrm{t}, 2 \mathrm{H}, J=6.0 \mathrm{~Hz}, \mathbf{C H}_{2} \mathrm{COO} t \mathrm{Bu}\right) ; 2.56(\mathrm{~m}, 1 \mathrm{H}$, $\left.\mathrm{H}_{3}\right) ; 2.80\left(\mathrm{t}, 2 \mathrm{H}, J=6.8 \mathrm{~Hz}, \mathrm{H}_{6}\right) ; 3.09\left(\mathrm{bs}, 2 \mathrm{H}, \mathrm{NH}_{2}\right) ; 3.3\left(\mathrm{dd}, 1 \mathrm{H}, J=8.516 .5 \mathrm{~Hz}, \mathrm{H}_{5}\right) ; 3.45-3.53\left(\mathrm{~m}, 3 \mathrm{H}, \mathrm{H}_{5}\right.$ $\left.\mathrm{NHCH}_{2} \mathrm{CH}_{2} \mathrm{COO} t \mathrm{Bu}\right) ; 3.82\left(\mathrm{~m}, 1 \mathrm{H}, \mathrm{CH}_{2} \mathrm{CH}_{2} \mathbf{C H}_{2}-\mathrm{NH}\right) ; 4.04\left(\mathrm{~m}, 1 \mathrm{H}, \mathrm{CH}_{2} \mathrm{CH}_{2} \mathbf{C H}_{2}-\mathrm{NH}\right) ; 4.55(\mathrm{dd}, 1 \mathrm{H}, J=6.3$ $\left.8.6 \mathrm{~Hz}, \mathrm{H}_{2}\right) ; 6.95$ (bt, $\left.1 \mathrm{H}, \mathrm{NH}\right) ; 9.3(\mathrm{bd}, 2 \mathrm{H}, \mathrm{NH}=\mathrm{C}-\mathrm{NHBoc}) . \mathrm{NMR}{ }^{13} \mathrm{C}\left(75 \mathrm{MHz}, \mathrm{CDCl}_{3}\right): \delta_{\mathrm{C}}: 23.2\left(\mathrm{C}_{4}\right) ; 25.1$ $\left(\mathrm{C}_{4}\right) ; 26.2\left(\mathrm{C}_{3}\right) ; 27.8\left(\mathbf{C H}_{2} \mathbf{C H}_{2} \mathrm{CH}_{2}-\mathrm{NH}\right) ; 28.0528 .128 .3\left(3 \mathrm{C}_{t b u}\right) ; 31.1\left(\mathrm{C}_{5}\right) ; 35.1\left(2 \mathrm{C}, \mathrm{NHCH}_{2} \mathbf{C H}_{2} \mathbf{C O O} t \mathrm{Bu}\right)$; $41.0\left(\mathrm{C}_{6}\right) ; 41.2\left(\mathrm{C}_{3}\right) ; 42.3\left(\mathrm{C}_{5}\right) ; 44.2\left(\mathrm{CH}_{2} \mathrm{CH}_{2} \mathbf{C H}_{2}-\mathrm{NH}\right) ; 54.7\left(\mathrm{C}_{2}\right) ; 78.6-81.0-83.7\left(3 \mathrm{C}, \mathrm{C}_{\text {quattBu }}\right) ; 155.0-160 ; 5$ (2CO); $163.8(\mathrm{C}=\mathrm{N}) ; 170.1-171.4-177.5(3 \mathrm{CO}) .[\alpha]_{\mathrm{D}}{ }^{20}:-14.2\left(\mathrm{c}=0.5 ; \mathrm{CH}_{2} \mathrm{Cl}_{2}\right)$. IR (neat): $v_{\max } 3383,2976$, 1712, 1661, 1366, 1250, 1145, 1100. MS $\left(\mathrm{ES}^{+}\right): \mathrm{m} / z=641\left([\mathrm{MH}]^{+}\right)$. HRMS (ES.$\left[\mathrm{M}-\mathrm{H}^{-}\right)$: Calcd for $\mathrm{C}_{31} \mathrm{H}_{56} \mathrm{~N}_{6} \mathrm{O}_{8}$ 639.4087 Found 639.4054.

\subsubsection{3-\{(3R,2S)-6-amino-2-[3-(3-guanidin-diboc-propyl)-2-oxo-pyrrolidin-1-yl]-hexanoylamino\}- propionic acid tert-butyl ester}

The same protocol for deprotection of benzyloxycarbonyl was applied to minor diastereoisomer $\mathbf{1 2 b}$ (58 $\mathrm{mg}$; $0.074 \mathrm{mmol})$. Guanidyl compound was obtained as an oil (42 $\mathrm{mg}, 88 \%)$.

NMR ${ }^{1} \mathrm{H}\left(300 \mathrm{MHz}, \mathrm{CDCl}_{3}\right): \delta_{\mathrm{H}}: 1.24-1.36\left(\mathrm{~m}, 2 \mathrm{H}, \mathrm{H}_{4}\right) ; 1.46-1.50-1.55(3 \mathrm{~s}, 27 \mathrm{H}, t \mathrm{Bu}) ; 1.50-1.80\left(\mathrm{~m}, 7 \mathrm{H}, \mathrm{H}_{5} \mathrm{H}_{3}\right.$ $\left.\mathrm{H}_{4} \quad \mathrm{CH}_{2} \mathbf{C H}_{2} \mathrm{CH}_{2} \mathrm{NH} \quad \mathbf{C H}_{2} \mathrm{CH}_{2} \mathrm{CH}_{2} \mathrm{NH}\right) ; 1.81-2.01\left(\mathrm{~m}, 2 \mathrm{H}, \mathrm{H}_{3} \quad \mathbf{C H}_{2} \mathrm{CH}_{2} \mathrm{CH}_{2}-\mathrm{NH}\right) ; 2.30-2.60\left(\mathrm{~m}, 6 \mathrm{H}, \mathrm{H}_{4}\right.$ $\left.\mathbf{C H}_{2} \mathrm{COO} t \mathrm{Bu} \mathrm{H} \mathrm{H}_{6}\right) ; 3.31-3.53\left(\mathrm{~m}, 4 \mathrm{H}, \mathrm{H}_{5} \mathrm{NHCH}_{2} \mathrm{CH}_{2} \mathrm{COO} t \mathrm{Bu}\right) ; 3.82\left(\mathrm{~m}, 1 \mathrm{H}, \mathrm{CH}_{2} \mathrm{CH}_{2} \mathbf{C H}_{2}-\mathrm{NH}\right) ; 4.0(\mathrm{~m}, 1 \mathrm{H}$, $\left.\mathrm{CH}_{2} \mathrm{CH}_{2} \mathbf{C H}_{2}-\mathrm{NH}\right) ; 4.50\left(\mathrm{t}, 1 \mathrm{H}, J=7.3, \mathrm{H}_{2}\right) ; 6.9$ (bt, $\left.1 \mathrm{H}, \mathrm{NH}\right) ; 9.20$ (bd, 2H, NH=C-NHBoc).NMR ${ }^{13} \mathrm{C}(75$ $\left.\mathrm{MHz}, \mathrm{CDCl}_{3}\right): \delta_{\mathrm{C}}: 23.9\left(\mathrm{C}_{4}\right) ; 25.1\left(\mathrm{C}_{4}\right) ; 26.2\left(\mathrm{C}_{3}\right) ; 27.0\left(\mathbf{C H}_{\mathbf{2}} \mathbf{C H}_{2} \mathrm{CH}_{2}-\mathrm{NH}\right) ; 27.7\left(\mathrm{C}_{5}\right) ; 28.1-28.3\left(3 C_{t \mathrm{bu}}\right)$; $35.1 / 35.3$ (3 C, NHCH $\left.\mathbf{C H}_{2} \mathrm{COO} t \mathrm{Bu} \mathrm{C}_{6}\right) ; 41.8\left(\mathrm{C}_{3}\right) ; 42.2\left(\mathrm{C}_{5}\right) ; 44.3\left(\mathrm{CH}_{2} \mathrm{CH}_{2} \mathbf{C H}_{2}-\mathrm{NH}\right) ; 54.9\left(\mathrm{C}_{2}\right) ; 78.6-81.0-$ $83.7\left(3 \mathrm{C}, \mathrm{C}_{\text {quattBu }}\right) ; 155.0-160 ; 5(2 \mathrm{CO}) ; 163.8(\mathrm{C}=\mathrm{N}) ; 170.0-171.2-177.5(3 \mathrm{CO}) .[\alpha]_{\mathrm{D}}^{20}:-44.9\left(\mathrm{c}=1 ; \mathrm{CH}_{2} \mathrm{Cl}_{2}\right) . \mathrm{IR}$ (neat): $v_{\max } 3382,2977,1713,1663,1251,1147,1100$.

\subsubsection{3-\{(3S,2S)-6-amino-2-[3-(3-guanidino-propyl)-2-oxo-pyrrolidin-1-yl]-hexanoylamino\}- propionic acid 14a}

The same protocol for deprotection with TFA was applied to compound as described above (28 mg; 0.043 mmol). Guanidyl compound $\mathbf{1 4 a}$ was obtained as a foam in a quantitative yield (24 $\mathrm{mg})$.

NMR ${ }^{1} \mathrm{H}\left(300 \mathrm{MHz}, \mathrm{D}_{2} \mathrm{O}\right): \delta_{\mathrm{H}}: 1.02-1.22\left(\mathrm{~m}, 2 \mathrm{H}, \mathrm{H}_{4}\right) ; 1.22-1.38\left(\mathrm{~m}, 1 \mathrm{H}, \mathbf{C H}_{2} \mathrm{CH}_{2} \mathrm{CH}_{2} \mathrm{NH} ;\right)$ 1.39-.1.81 (m, 8H, $\left.\mathbf{C H}_{2} \mathrm{CH}_{2} \mathrm{CH}_{2} \mathrm{NH}, \mathrm{CH}_{2} \mathbf{C H}_{2} \mathrm{CH}_{2} \mathrm{NH}, \mathrm{H}_{5} \mathrm{H}_{3} \mathrm{H}_{4}\right) ; 2.14\left(\mathrm{~m}, 1 \mathrm{H}, \mathrm{H}_{4}\right) ; 2.45\left(\mathrm{~m}, 3 \mathrm{H}, \mathbf{C H}_{2} \mathrm{COO} t \mathrm{Bu} \mathrm{H}\right) ; 2.83(\mathrm{t}, 2 \mathrm{H}, J=$ $\left.7.2 \mathrm{~Hz}, \mathrm{CH}_{2} \mathrm{CH}_{2} \mathbf{C H}_{2}-\mathrm{NH}\right) ; 3.07\left(\mathrm{t}, 2 \mathrm{H}, J=6.5 \mathrm{~Hz}, \mathrm{H}_{6}\right) ; 3.35\left(\mathrm{~m}, 4 \mathrm{H}, \mathrm{H}_{5} \mathrm{NHCH}_{2} \mathrm{CH}_{2} \mathrm{COO} t \mathrm{Bu}\right) ; 4.36(\mathrm{t}, 1 \mathrm{H}, J=$ $\left.7.5 \mathrm{~Hz}, \mathrm{H}_{2}\right)$. NMR ${ }^{13} \mathrm{C}\left(75 \mathrm{MHz}, \mathrm{D}_{2} \mathrm{O}\right): \delta_{\mathrm{C}}: 22.2\left(\mathrm{C}_{4}\right) ; 24.0\left(\mathrm{C}_{4}\right) ; 25.2\left(\mathrm{C}_{5}\right) ; 26.2\left(\mathrm{CH}_{2} \mathbf{C H}_{2} \mathrm{CH}_{2}-\mathrm{NH}\right) ; 27.2$ $\left(\mathbf{C H}_{2} \mathrm{CH}_{2} \mathrm{CH}_{2}-\mathrm{NH} \mathrm{C}\right)$; $33.5\left(\mathbf{C H}_{2} \mathrm{COOH}\right) ; 35.2\left(\mathrm{NHCH}_{2} \mathrm{CH}_{2} \mathrm{COOH}\right) ; 39.2\left(\mathrm{CH}_{2} \mathrm{CH}_{2} \mathbf{C H}-\mathrm{NH}\right) ; 40.9\left(\mathrm{C}_{6}\right) ; 40.9$ $\left(\mathrm{C}_{3}\right) ; 43.0\left(\mathrm{C}_{5}\right) ; 55.1\left(\mathrm{C}_{2}\right) ; 156.7(\mathrm{C}=\mathrm{N}) ; 171.9-176.1-179.9(\mathrm{CO}) .[\alpha]_{\mathrm{D}}{ }^{20}:-28.8\left(\mathrm{c}=0.5 ; \mathrm{H}_{2} \mathrm{O}\right)$. IR $($ neat $): v_{\max }$ 3336, 3180, 2944, 1645, 1536, 1437, 1266, 1184, 1198, 720. HRMS (ES ${ }^{+}$[M + H]+): Calcd for $\mathrm{C}_{17} \mathrm{H}_{32} \mathrm{~N}_{6} \mathrm{O}_{4}$ 385.2558 Found 385.2551.

\subsubsection{3-\{(3R,2S)-6-amino-2-[3-(3-guanidino-propyl)-2-oxo-pyrrolidin-1-yl]-hexanoylamino\}- propionic acid $14 \mathrm{~b}$}

The same protocol for deprotection with TFA was applied to compound described above (28 mg; 0.043 mmol). Guanidyl compound $\mathbf{1 4 b}$ was obtained as a foam in a quantitative yield (22 $\mathrm{mg})$. 
NMR ${ }^{1} \mathrm{H}\left(300 \mathrm{MHz}, \mathrm{D}_{2} \mathrm{O}\right): \delta_{\mathrm{H}}: 1.07-1.22\left(\mathrm{~m}, 2 \mathrm{H}, \mathrm{H}_{4}\right) ; 1.22-1.38\left(\mathrm{~m}, 1 \mathrm{H}, \mathbf{C H}_{2} \mathrm{CH}_{2} \mathrm{CH}_{2} \mathrm{NH}\right)$ 1.39-1.70 (m, 7H, $\left.\mathbf{C H}_{2} \mathrm{CH}_{2} \mathrm{CH}_{2} \mathrm{NH}, \mathrm{CH}_{2} \mathbf{C H}_{2} \mathrm{CH}_{2} \mathrm{NH}, \mathrm{H}_{5} \mathrm{H}_{3} \mathrm{H}_{4}\right) ; 1.69-1.81\left(\mathrm{~m}, 1 \mathrm{H}, \mathrm{H}_{3}\right) ; 2.14\left(\mathrm{~m}, 1 \mathrm{H}, \mathrm{H}_{4}\right) ; 2.45(\mathrm{~m}, 3 \mathrm{H}$, $\mathbf{C H}_{2} \mathrm{COO} t \mathrm{Bu} \mathrm{H}$ ); $2.83\left(\mathrm{t}, 2 \mathrm{H}, J=7.3 \mathrm{~Hz}, \mathrm{CH}_{2} \mathrm{CH}_{2} \mathbf{C H}_{2}-\mathrm{NH}\right) ; 3.06\left(\mathrm{t}, 2 \mathrm{H}, J=6.7 \mathrm{~Hz}, \mathrm{H}_{6}\right) ; 3.22\left(\mathrm{~m}, 1 \mathrm{H}, \mathrm{H}_{5}\right) ; 3.33$ $\left(\mathrm{m}, 3 \mathrm{H}, \mathrm{H}_{5} \mathrm{NHCH}_{2} \mathrm{CH}_{2} \mathrm{COO} t \mathrm{Bu}\right) ; 4.36\left(\mathrm{t}, 1 \mathrm{H}, J=7.7 \mathrm{~Hz}, \mathrm{H}_{2}\right) .{ }^{13} \mathrm{C}\left(75 \mathrm{MHz}, \mathrm{D}_{2} \mathrm{O}\right): \delta_{\mathrm{C}}: 22.2\left(\mathrm{C}_{4}\right) ; 24.0\left(\mathrm{C}_{4}\right) ; 25.4$ $\left(\mathrm{C}_{5}\right) ; 26.3\left(\mathrm{CH}_{2} \mathbf{C H}_{2} \mathrm{CH}_{2}-\mathrm{NH}\right) ; 27.0-27.3\left(\mathbf{C H}_{2} \mathrm{CH}_{2} \mathrm{CH}_{2}-\mathrm{NH} \mathrm{C}\right)_{3}$; $33.5\left(\mathbf{C H}_{2} \mathrm{COOH}\right) ; 35.2\left(\mathrm{NHCH}_{2} \mathrm{CH}_{2} \mathrm{COOH}\right)$; $39.1\left(\mathrm{CH}_{2} \mathrm{CH}_{2} \mathbf{C H}_{2}-\mathrm{NH}\right) ; 40.9\left(\mathrm{C}_{6}\right) ; 41.7\left(\mathrm{C}_{3}\right) ; 43.0\left(\mathrm{C}_{5}\right) ; 55.1\left(\mathrm{C}_{2}\right) ; 171.6-176.1-180.0(\mathrm{CO}) .[\alpha]_{\mathrm{D}}{ }^{20}:-35.0(\mathrm{c}=$ $\left.0.3 ; \mathrm{H}_{2} \mathrm{O}\right)$. IR (neat): $v_{\max } 3339,3179,2943,1643,1537,1437,1282,1184,1072$. HRMS $\left.\left(\mathrm{ES}^{+} \text {. [M + H] }\right]^{+}\right): \mathrm{Calcd}$ for $\mathrm{C}_{17} \mathrm{H}_{32} \mathrm{~N}_{6} \mathrm{O}_{4} 385.2558$ Found 385.2564 .

4.1.23 (3S, 2S)-[2-(3-Allyl-2-oxo-pyrrolidin-1-yl)-6-benzyloxycarbonylamino-hexanoylamino]-acetic acid tert-butyl ester 11a

The same experimental procedure as described for peptide coupling was applied to carboxylic acid 9a (200 $\mathrm{mg}$; $0.52 \mathrm{mmol})$ using amino acid (0.52 mmol, 1 equiv), $\mathrm{N}$-methylmorpholine (NMM) (171 $\mu \mathrm{L}, 1.56 \mathrm{mmol}$, 3 equiv), hydroxybenzotriazole (HOBt) $(113 \mathrm{mg}, 0.83 \mathrm{mmol}, 1.6$ equiv), then EDC (150mg, $0.78 \mathrm{mmol}, 1.5$ equiv). This allowed the isolation of an oil $(89 \%, 232 \mathrm{mg})$.

NMR ${ }^{1} \mathrm{H}\left(400 \mathrm{MHz}, \mathrm{CDCl}_{3}\right): \delta_{\mathrm{H}}: 1.21-1.31\left(\mathrm{~m}, 2 \mathrm{H}, \mathrm{H}_{4}\right) ; 1.41(\mathrm{~s}, 9 \mathrm{H}, t \mathrm{Bu}) ; 1.48-1.49\left(\mathrm{~m}, 2 \mathrm{H}, \mathrm{H}_{5}\right) ; 1.60-1.80(\mathrm{~m}$, $\left.2 \mathrm{H}, \mathrm{H}_{3} \mathrm{H}_{4}\right) ; 1.85-2.00\left(\mathrm{~m}, 1 \mathrm{H}, \mathrm{H}_{3}\right) ; 2.00-2.20\left(\mathrm{~m}, 2 \mathrm{H}, \mathbf{C H}_{2}-\mathrm{CH}=\mathrm{CH}_{2} \mathrm{H}_{4}\right) ; 2.50\left(\mathrm{~m}, 2 \mathrm{H}, \mathrm{H}_{3} \mathbf{C} \mathbf{H}_{2}-\mathrm{CH}_{2} \mathrm{CH}_{2}\right) ; 3.12$ $\left(\mathrm{m}, 2 \mathrm{H}, \mathrm{H}_{6}\right) ; 3.21\left(\mathrm{~m}, 1 \mathrm{H}, \mathrm{H}_{5}\right) ; 3.44\left(\mathrm{~m}, 1 \mathrm{H}, \mathrm{H}_{5}\right) ; 3.80\left(\mathrm{dd}, 1 \mathrm{H}, J=14.83 .3 \mathrm{~Hz}, 2 \mathrm{H}, \mathrm{NHCH}_{2} \mathrm{COO} t \mathrm{Bu}\right) ; 4.61(\mathrm{~m}$, $\left.1 \mathrm{H}, \mathrm{H}_{2}\right) ; 4.95-5.10\left(\mathrm{~m}, 4 \mathrm{H}, \mathrm{Ph} \mathbf{C H}_{2} \mathbf{C H}=\mathbf{C H}_{2}\right) ; 5.43$ (bt, $\left.1 \mathrm{H}, \mathrm{OCONH}\right) 5.71\left(\mathrm{~m}, 1 \mathrm{H}, \mathrm{CH}=\mathrm{CH}_{2}\right) ; 7.07$ (bt, $1 \mathrm{H}$, $\mathrm{NH}) ; 7.27-7.33(\mathrm{~m}, 5 \mathrm{H}, \mathrm{Ar}) . \mathrm{NMR}{ }^{13} \mathrm{C}\left(75 \mathrm{MHz}, \mathrm{CDCl}_{3}\right): \delta_{\mathrm{C}}: 23.0\left(\mathrm{C}_{4}\right) ; 24.2\left(\mathrm{C}_{4}\right) ; 27.5\left(\mathrm{C}_{3}\right) ; 28.0(t \mathrm{Bu}) ; 29.2$ $\left(\mathrm{C}_{5}\right) ; 35.0\left(\mathbf{C H}_{2}-\mathrm{CH}=\mathrm{CH}_{2}\right) ; 40.6\left(\mathrm{C}_{6}\right) ; 41.3\left(\mathrm{C}_{3}\right) ; 41.7\left(\mathbf{C H}_{2} \mathrm{COO} t \mathrm{Bu}\right) ; 42.2\left(\mathrm{C}_{5}\right) ; 54.5\left(\mathrm{C}_{2}\right) ; 66.4(\mathrm{PhCH}) ; 81.9$ $\left(\mathrm{C}_{\text {ArquattBu }}\right) ; 117.0\left(\mathrm{CH}=\mathbf{C H}_{2}\right) ; 128.0-128.1-128.4\left(\mathrm{C}_{\mathrm{Ar}}\right) ; 135.4\left(\mathbf{C H}=\mathrm{CH}_{2}\right) ; 136.7\left(\mathrm{C}_{\text {Arquat }}\right) ; 156.5(\mathrm{O}-\mathbf{C O N H})$, 168.6-170.4-177.1 (CO). $[\alpha]_{\mathrm{D}}{ }^{20}:-41.5\left(\mathrm{c}=0.7 ; \mathrm{CH}_{2} \mathrm{Cl}_{2}\right)$. IR (neat): $v_{\max } 3316,2977,2933,1739,1660,1525$, 1245, 1223, 1152, 736, 697. HRMS (ES ${ }^{+}$. $\left[\mathrm{M}+\mathrm{Na}^{+}\right)$: Calcd for $\mathrm{C}_{27} \mathrm{H}_{29} \mathrm{~N}_{3} \mathrm{O}_{6} \mathrm{Na}$ 524.2737 Found 524.2727.

\subsubsection{4 (3S, 2S)-\{6-Benzyloxycarbonylamino-2-[3-(3-hydroxy-propyl)-2-oxo-pyrrolidin-1-yl]-} hexanoylamino\}-acetic acid tert-butyl ester

The same experimental procedure as described for hydroboration was applied to alkene 11a (147 mg; 0.29 mmol) using a $0.5 \mathrm{M}$ solution of 9-BBN in THF (2.2 mL; $1.1 \mathrm{mmol} ; 3.8$ equiv). Stirring was maintained for $16 \mathrm{~h}$ after addition of sodium acetate $5 \mathrm{M}\left(0.71 \mathrm{~mL}, 3.55 \mathrm{mmol}, 12\right.$ equiv) and a $30 \% \mathrm{H}_{2} \mathrm{O}_{2}$ solution $(0.5$ $\mathrm{mL} ; 14$ equiv). Flash chromatography on silica gel (AcOEt) allowed the isolation of a yellow oil (76\%, 115 $\mathrm{mg})$.

$\mathrm{R}_{\mathrm{f}}=0.17$ (AcOEt). NMR ${ }^{1} \mathrm{H}\left(300 \mathrm{MHz}, \mathrm{CDCl}_{3}\right): \delta_{\mathrm{H}}: 1.23-1.34\left(\mathrm{~m}, 2 \mathrm{H}, \mathrm{H}_{4}\right) ; 1.45(\mathrm{~s}, 9 \mathrm{H}, t \mathrm{Bu}) ; 1.48-1.59(\mathrm{~m}, 3 \mathrm{H}$, $\left.\mathrm{H}_{5} \mathbf{C H}_{2} \mathrm{CH}_{2} \mathrm{CH}_{2}-\mathrm{OH}\right) ; 1.60-1.81\left(\mathrm{~m}, 4 \mathrm{H}, \mathrm{H}_{3} \mathrm{CH}_{2} \mathbf{C H}_{2} \mathrm{CH}_{2}-\mathrm{OH} \mathrm{H}\right)_{4}$; 1.84-1.99 (m, 2H, $\mathbf{C H}_{2} \mathrm{CH}_{2} \mathrm{CH}_{2}-\mathrm{OH} \mathrm{H}_{3}$ ); $2.48\left(\mathrm{~m}, 2 \mathrm{H}, \mathrm{H}_{4}\right) ; 2.49\left(\mathrm{~m}, 1 \mathrm{H}, \mathrm{H}_{3}\right) ; 3.18\left(\mathrm{~m}, 2 \mathrm{H}, \mathrm{H}_{6}\right) ; 3.26\left(\mathrm{q}, 1 \mathrm{H}, J=7.8 \mathrm{~Hz}, \mathrm{H}_{5}\right) ; 3.48\left(\mathrm{~m}, 1 \mathrm{H}, \mathrm{H}_{5}\right) ; 3.62(\mathrm{t}, 2 \mathrm{H}$, $\left.J=6 ; 8 \mathrm{~Hz}, \mathrm{CH}_{2} \mathrm{CH}_{2} \mathbf{C H}_{2}-\mathrm{OH}\right) ; 3.78\left(\mathrm{dd}, 1 \mathrm{H}, J=5.118 \mathrm{~Hz}, \mathrm{NHCH}_{2} \mathrm{COO} t \mathrm{Bu}\right) ; 3.92(\mathrm{dd}, 1 \mathrm{H}, J=5.818 \mathrm{~Hz}$, $\left.\mathrm{NHCH}_{2} \mathrm{COO} t \mathrm{Bu}\right) ; 4.62\left(\mathrm{t}, 1 \mathrm{H}, \mathrm{J}=7.5 \mathrm{~Hz}, \mathrm{H}_{2}\right) ; 5.09$ (s, 2H, PhCH $) ; 5.29$ (t, 1H, J = 5.2 Hz, NHCOCbz); 7.05 (bt, $\left.1 \mathrm{H}, \mathbf{N H C O C H} \mathrm{NOOt}_{2} \mathrm{Bu}\right) ; 7.33(\mathrm{~m}, 5 \mathrm{H}, \mathrm{Ar}) . \mathrm{NMR}{ }^{13} \mathrm{C}\left(75 \mathrm{MHz}, \mathrm{CDCl}_{3}\right): \delta_{\mathrm{C}}: 23.0\left(\mathrm{C}_{4}\right) ; 25.1\left(\mathrm{C}_{4}\right) ; 27.1$ $\left(\mathbf{C H}_{2} \mathrm{CH}_{2} \mathrm{CH}_{2}-\mathrm{OH}\right) ; 27.6\left(\mathrm{C}_{3}\right) ; 28.0\left(\mathrm{C}_{\mathrm{tBu}}\right) ; 29.2\left(\mathrm{C}_{5}\right) ; 30.0\left(\mathrm{CH}_{2} \mathbf{C H}_{\mathbf{2}} \mathrm{CH}_{2}-\mathrm{OH}\right) ; 40.7\left(\mathrm{C}_{6}\right) ; 41.6\left(\mathrm{C}_{3}\right) ; 41.8$ $\left(\mathrm{NHCH}_{2} \mathrm{COO} t \mathrm{Bu}\right) ; 42.3\left(\mathrm{C}_{5}\right) ; 54.5\left(\mathrm{C}_{2}\right) ; 62.2\left(\mathrm{CH}_{2} \mathrm{CH}_{2} \mathbf{C H}_{2}-\mathrm{OH}\right) ; 66.5\left(\mathrm{PhCH}_{2}\right) ; 82.1\left(\mathrm{C}_{\mathrm{quattBu}}\right) ; 128.1-128.5$ $\left(\mathrm{C}_{\mathrm{Ar}}\right)$; $136.7\left(\mathrm{C}_{\text {Arquat }}\right)$; $156.6(\mathrm{CO})$; 168.7-170.4-178.0 (3 CO). $[\alpha]_{\mathrm{D}}{ }^{20}:-53.8\left(\mathrm{c}=1 ; \mathrm{CH}_{2} \mathrm{Cl}_{2}\right)$; IR (neat): $v_{\max } 3315$, 2934, 2867, 1660, 1530, 1367, 1250, 1154, 739, 698. HRMS (ES $\left.{ }^{+} \cdot[\mathrm{M}+\mathrm{H}]^{+}\right)$: Calcd for $\mathrm{C}_{27} \mathrm{H}_{42} \mathrm{~N}_{3} \mathrm{O}_{7} 520.3017$ Found 520.3015 .

4.1.25 (3S, 2S)-3-\{6-Benzyloxycarbonylamino-2-[3-(3-guanidin-diboc-propyl)-2-oxo-pyrrolidin-1-yl]hexanoylamino\}-acetic acid tert-butyl ester 13a

The same experimental procedure as described for 12a was applied to minor distereoisomer (115 mg; 0.22 mmol) using and 1,3-bis(tert-butoxycarbonyl) guanidine (115 mg, $0.44 \mathrm{mmol}, 2$ equiv), triphenylphosphine (116 $\mathrm{mg}, 0.44 \mathrm{mmol}, 2$ equiv), $40 \%$ solution of diethylazodicarboxylate (DEAD) in toluene $(0.2 \mathrm{~mL}, 0.44 \mathrm{mmol}, 2$ equiv). Stirring was continued for $44 \mathrm{~h}$. Flash chromatography on silica gel $\left(\mathrm{Et}_{2} \mathrm{O} /\right.$ cyclohexane $\left.9 / 1\right)$ allowed the isolation of 13a as a colourless oil (141 $\mathrm{mg}, 84 \%)$.

NMR ${ }^{1} \mathrm{H}\left(400 \mathrm{MHz}, \mathrm{CDCl}_{3}\right): \delta_{\mathrm{H}}: 1.28-1.39\left(\mathrm{~m}, 2 \mathrm{H}, \mathrm{H}_{4}\right) ; 1.46-1.50-1.54(3 \mathrm{~s}, 27 \mathrm{H}, t \mathrm{Bu}) ; 1.40-1.52(\mathrm{~m}, 1 \mathrm{H}$, $\left.\mathbf{C H}_{2} \mathrm{CH}_{2} \mathrm{CH}_{2}-\mathrm{NH}\right)$; $1.45-1.61\left(\mathrm{~m}, 2 \mathrm{H}, \mathrm{H}_{5}\right) ; 1.64-1.82\left(\mathrm{~m}, 4 \mathrm{H}, \mathrm{CH}_{2} \mathbf{C H}_{2} \mathrm{CH}_{2}-\mathrm{NH}_{3} \mathrm{H}_{4}\right) ; 1.90(\mathrm{~m}, 1 \mathrm{H}$, $\left.\mathbf{C H}_{2} \mathrm{CH}_{2} \mathrm{CH}_{2}-\mathrm{NH}\right) ; 2.03\left(\mathrm{~m}, 1 \mathrm{H}, \mathrm{H}_{3}\right) ; 2.35\left(\mathrm{~m}, 1 \mathrm{H}, \mathrm{H}_{4}\right) ; 2.54\left(\mathrm{~m}, 1 \mathrm{H}, \mathrm{H}_{3}\right) ; 3.20\left(\mathrm{~m}, 2 \mathrm{H}, \mathrm{H}_{6}\right) ; 3.25(\mathrm{q}, 1 \mathrm{H}, J=8.4$ $\left.\mathrm{Hz}, \mathrm{H}_{5}\right) ; 3.46\left(\mathrm{t}, 1 \mathrm{H}, J=8.5 \mathrm{~Hz}, \mathrm{H}_{5}\right) ; 3.79\left(\mathrm{~m}, 1 \mathrm{H}, \mathrm{CH}_{2} \mathrm{CH}_{2} \mathbf{C H}_{2}-\mathrm{NH}\right) ; 3.81(\mathrm{dd}, 1 \mathrm{H}, J=5.2,18.0 \mathrm{~Hz}$, 
$\left.\mathrm{NHCH}_{2} \mathrm{COO} t \mathrm{Bu}\right) ; 3.92\left(\mathrm{dd}, 1 \mathrm{H}, J=5.8,18.0 \mathrm{~Hz}, \mathrm{NHCH}_{2} \mathrm{COO} t \mathrm{Bu}\right) ; 4.01\left(\mathrm{~m}, 1 \mathrm{H}, \mathrm{CH}_{2} \mathrm{CH}_{2} \mathbf{C H}_{2}-\mathrm{NH}\right) ; 4.61(\mathrm{t}$, $1 \mathrm{H}, J=7.5 \mathrm{~Hz}, \mathrm{H}_{2}$ ); 5.07 (bt, $1 \mathrm{H}, \mathbf{N H C O C H}_{2} \mathrm{Ph}$ ); 5.11 (s, 2H, $\left.\mathrm{PhCH}_{2}\right) ; 6.67$ (bt, 1H, $\left.\mathbf{N H C H}_{2} \mathbf{C O O} \mathrm{Bu}\right) ; 7.34$ (m, $5 \mathrm{H}, \mathrm{Ar}) ; 9.24$ and 9.35 (bs, $2 \mathrm{H}, \mathrm{NHCNH}) . \mathrm{NMR}{ }^{13} \mathrm{C}\left(75 \mathrm{MHz}, \mathrm{CDCl}_{3}\right): \delta_{\mathrm{C}}: 23.1\left(\mathrm{C}_{4}\right) ; 25.1\left(\mathrm{C}_{4}\right) ; 26.1$ $\left(\mathrm{CH}_{2} \mathbf{C H}_{2} \mathrm{CH}_{2}-\mathrm{NH}\right) ; 26.9\left(\mathrm{C}_{3}\right) ; 27.7\left(\mathbf{C H}_{2} \mathrm{CH}_{2} \mathrm{CH}_{2}-\mathrm{NH}\right) ; 28.0-28.3\left(3 \mathrm{C}_{t \mathrm{Bu}}\right) ; 29.3\left(\mathrm{C}_{5}\right) ; 40.6\left(\mathrm{C}_{6}\right) ; 41.2\left(\mathrm{C}_{3}\right) ; 41.8$ $\left(\mathrm{NHCH}_{2} \mathrm{COO} t \mathrm{Bu}\right) ; 42.2\left(\mathrm{C}_{5}\right) ; 44.3\left(\mathrm{CH}_{2} \mathrm{CH}_{2} \mathbf{C H}_{2}-\mathrm{NH}\right) ; 54.6\left(\mathrm{C}_{2}\right) ; 66.5\left(\mathrm{PhCH}_{2}\right) ; 78.6-82.0-83.7\left(\mathrm{C}_{\text {quat } t \mathrm{Bu}}\right) ; 128.0-$ 128.1-128.5 $\left(\mathrm{C}_{\mathrm{Ar}}\right)$; $136.7\left(\mathrm{C}_{\text {Arquat }}\right) ; 155.0-156.5(\mathrm{CO} \mathrm{C}=\mathrm{N}) ; 160.5-163.8-168.5-170.4-177.7(5 \mathrm{CO}) .[\alpha]_{\mathrm{D}}{ }^{20}:-25.1$ $\left(\mathrm{c}=0.5 ; \mathrm{CH}_{2} \mathrm{Cl}_{2}\right)$. IR (neat): $v_{\max } 3319,2977,2933,1662,1525,1247,1153,737,697 . \mathrm{HRMS}_{(\mathrm{ES}}$. $\left.[\mathrm{M}+\mathrm{Na}]^{+}\right)$: Calcd for $\mathrm{C}_{38} \mathrm{H}_{60} \mathrm{~N}_{6} \mathrm{O}_{10} \mathrm{Na} 783.4285$ Found 783.4469 .

4.1.26 (3S,2S)(6-(((benzyloxy)carbonyl)amino)-2-(3-(3-guanidinopropyl)-2-oxopyrrolidin-1yl)hexanoyl)glycine 15a

The same protocol for deprotection with TFA was applied to compound described above (27 mg; 0.035 mmol). Guanidyl compound $\mathbf{1 5 a}$ was obtained as a foam in $80 \%$ yield (21 $\mathrm{mg})$.

NMR ${ }^{1} \mathrm{H}\left(400 \mathrm{MHz}, \mathrm{D}_{2} \mathrm{O}\right): \delta_{\mathrm{H}}: 0.95-1.15\left(\mathrm{~m}, 2 \mathrm{H}, \mathrm{H}_{4}\right) ; 1.25-1.46\left(\mathrm{~m}, 5 \mathrm{H}, \mathrm{H}_{5} \mathrm{CH}_{2} \mathbf{C H}_{2} \mathrm{CH}_{2}-\mathrm{NH}_{\mathbf{C H}} \mathrm{CH}_{2} \mathrm{CH}_{2}-\mathrm{NH}\right)$; 1.41-1.69 (m, 4H, H $\left.\mathbf{C H}_{2} \mathrm{CH}_{2} \mathrm{CH}_{2}-\mathrm{NH} \mathrm{H}_{4}\right) ; 2.03\left(\mathrm{~m}, 1 \mathrm{H}, \mathrm{H}_{4}\right) ; 2.35\left(\mathrm{~m}, 1 \mathrm{H}, \mathrm{H}_{3}\right) ; 2.96-3.03(\mathrm{~m}, 4 \mathrm{H}$, $\left.\left.\mathrm{CH}_{2} \mathrm{CH}_{2} \mathbf{C H}_{2}-\mathrm{NH} \mathrm{H}\right)_{6}\right) ; 3.20\left(\mathrm{~m}, 1 \mathrm{H}, \mathrm{H}_{5}\right) ; 3.28\left(\mathrm{~m}, 1 \mathrm{H}, \mathrm{H}_{5}\right) ; 3.80\left(\mathrm{~m}, 2 \mathrm{H}, \mathrm{NHCH}_{2} \mathrm{COO} t \mathrm{Bu}\right) ; 4.41\left(\mathrm{~m}, 1 \mathrm{H}, \mathrm{H}_{2}\right)$; 4.95 (s, 2H, PhCH $\left.\mathbf{C H}_{2}\right) ; 7.25$ (m, 5H, Ar). NMR ${ }^{13} \mathrm{C}\left(75 \mathrm{MHz}, \mathrm{D}_{2} \mathrm{O}\right): \delta_{\mathrm{C}}: 22.05\left(\mathrm{C}_{4}\right) ; 23.9\left(\mathrm{C}_{4}\right) ; 25.2\left(\mathrm{CH}_{2} \mathbf{C H}_{2} \mathrm{CH}_{2}-\right.$ $\mathrm{NH}) ; \quad 27.0 \quad\left(\mathrm{C}_{3}\right) ; \quad 27.05 \quad\left(\mathbf{C H}_{2} \mathrm{CH}_{2} \mathrm{CH}_{2}-\mathrm{NH}\right) ; \quad 28.0 \quad\left(\mathrm{C}_{5}\right) ; \quad 39.9 \quad\left(\mathrm{CH}_{2} \mathrm{CH}_{2} \mathbf{C H}_{2}-\mathrm{NH}\right) ; \quad 40.8 \quad\left(\mathrm{C}_{6}\right) ; \quad 40.9$ $\left(\mathrm{NHCH}_{2} \mathrm{COO} t \mathrm{Bu}\right) ; 41.4\left(\mathrm{C}_{3}\right) ; 42.9\left(\mathrm{C}_{5}\right) ; 54.8\left(\mathrm{C}_{2}\right) ; 66.6\left(\mathrm{PhCH}_{2}\right) ; 127.5-128.2-128.6\left(\mathrm{C}_{\mathrm{Ar}}\right) ; 136.6\left(\mathrm{C}_{\text {Arquat }}\right)$; 156.5-158.1 (CO C=N); 172.7-172.8-179.9 (3 CO). $[\alpha]_{\mathrm{D}}{ }^{20}:-26.6\left(\mathrm{c}=0.7 ; \mathrm{H}_{2} \mathrm{O}\right)$. IR (neat): $v_{\max } 3330,3192$, 2940, 1650, 1530, 1259, 1179, 1131, 720. HRMS $\left(\mathrm{ES}^{+} .[\mathrm{M}+\mathrm{H}]^{+}\right)$: Calcd for $\mathrm{C}_{24} \mathrm{H}_{37} \mathrm{~N}_{6} \mathrm{O}_{6} 505.2772$ Found 505.2775 .

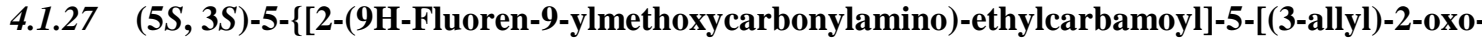
pyrrolidin-1-yl]-pentyl\}-carbamic acid benzyl ester 17

The same experimental procedure as described for peptide coupling was applied to carboxylic acid 9a (265 $\mathrm{mg}$; $0.68 \mathrm{mmol})$ using N-1-Fmoc-1,2-diaminoethane (0.75 mmol, 1.1 equiv), N-methylmorpholine (NMM) $(230 \mu \mathrm{L}, 2.1 \mathrm{mmol}, 3$ equiv), hydroxybenzotriazole (HOBt) (135 mg, $1 \mathrm{mmol}$, 1.5 equiv), then EDC (143mg, $0.75 \mathrm{mmol}, 1.1$ equiv). This allowed the isolation of a foam $(91 \%, 414 \mathrm{mg})$.

NMR ${ }^{1} \mathrm{H}\left(400 \mathrm{MHz}, \mathrm{CDCl}_{3}\right): \delta_{\mathrm{H}}: 1.29\left(\mathrm{~m}, 2 \mathrm{H}, \mathrm{H}_{3}\right) ; 1.55\left(\mathrm{~m}, 2 \mathrm{H}, \mathrm{H}_{2}\right) ; 1.63-1.87\left(\mathrm{~m}, 2 \mathrm{H}, \mathrm{H}_{3} \mathrm{H}_{4}\right) ; 1.99(\mathrm{~m}, 1 \mathrm{H}$, $\left.\mathrm{H}_{4}\right) ; 2.08-2.36\left(\mathrm{~m}, 2 \mathrm{H}, \mathbf{C H}_{2}-\mathrm{CH}=\mathrm{CH}_{2} \mathrm{H}_{4}\right) ; 2.58\left(\mathrm{~m}, 2 \mathrm{H}, \mathrm{H}_{3} \mathbf{C H}_{2}-\mathrm{CH}=\mathrm{CH}_{2}\right) ; 3.15-3.24\left(\mathrm{~m}, 2 \mathrm{H}, \mathrm{H}_{1}\right) ; 3.24-3.31$ $\left(\mathrm{m}, 6 \mathrm{H}, \mathrm{NHCH}_{2} \mathbf{C H}_{2} \mathrm{NH} \mathrm{H}_{5}\right) ; 4.23(\mathrm{t}, 1 \mathrm{H}, J=6.9 \mathrm{~Hz}, \mathbf{C H F m o c}) ; 4.61$ (m, 2H, $\left.\mathbf{C H}_{2} \mathrm{Fmoc}\right) ; 4.54$ (t, $1 \mathrm{H}, J=7.5$ $\left.\mathrm{Hz}, \mathrm{H}_{5}\right) ; 5.08$ (m, 5H, NHCbz $\left.\mathrm{PhCH}_{2} \mathbf{C H}=\mathbf{C H}_{2}\right) ; 5.55$ (bt, 1H, OCONH); 5.76 (m, 1H, CH=CH $) ; 6.92(\mathrm{bt}, 1 \mathrm{H}$, $\mathrm{NH}) ; 7.36(\mathrm{~m}, 7 \mathrm{H}, \mathrm{Ar}) ; 7.44$ (t, 2H,J=7.4 Hz, Ar); 7.63 (d, 2H, J=7.4 Hz, Ar); 7.80 (d, 2H, J = 7.5 Hz, Ar). $\mathrm{NMR}{ }^{13} \mathrm{C}\left(75 \mathrm{MHz}, \mathrm{CDCl}_{3}\right): \delta_{\mathrm{C}}: 23.1\left(\mathrm{C}_{3}\right) ; 24.2\left(\mathrm{C}_{4}\right) ; 27.5\left(\mathrm{C}_{4}\right) ; 29.3\left(\mathrm{C}_{2}\right) ; 35.1\left(\mathbf{C H}_{2}-\mathrm{CH}_{2} \mathrm{CH}_{2}\right) ; 39.9-41.0$ $\left(\mathrm{NHCH}_{2} \mathbf{C H}_{2} \mathrm{NH}\right) ; 40.6\left(\mathrm{C}_{1}\right) ; 41.4\left(\mathrm{C}_{3}\right) ; 42.4\left(\mathrm{C}_{5}\right) ; 47.2(\mathrm{CHFmoc}) ; 55.1\left(\mathrm{C}_{5}\right) ; 66.6\left(\mathrm{PhCH}_{2}\right) ; 66.9\left(\mathrm{CH}_{2} \mathrm{Fmoc}\right)$; $117.2\left(\mathbf{C H}=\mathbf{C H}_{2}\right) ; \quad 120.0-125.2-127.1-127.8-128.1-128.5 \quad\left(\mathrm{C}_{\mathrm{Ar}}\right) ; \quad 135.2 \quad\left(\mathbf{C H}=\mathrm{CH}_{2}\right) ; \quad 136.6-141.3-143.8-$ $143.9\left(\mathrm{C}_{\text {Arquat }}\right) ; 156.5-156.9(\mathrm{O}-\mathrm{CONH}), 170.8-177.2(\mathrm{CO}) .[\alpha]_{\mathrm{D}}{ }^{20}:-25.4\left(\mathrm{c}=0.4 ; \mathrm{CH}_{2} \mathrm{Cl}_{2}\right)$. IR (neat): $v_{\max } 3304$, 2923, 2853, 1654, 1523, 1449, 1247, 731, 696.

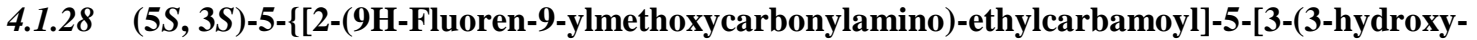
propyl)-2-oxo-pyrrolidin-1-yl]-pentyl\}-carbamic acid benzyl ester 18

The same experimental procedure as described for hydroboration was applied to alkene 17 (374 $\mathrm{mg}$; $0.56 \mathrm{mmol}$ ) using a $0.5 \mathrm{M}$ solution of 9-BBN in THF (3.4 mL; $1.7 \mathrm{mmol} ; 3$ equiv). Stirring was maintained for $16 \mathrm{~h}$ after addition of sodium acetate $5 \mathrm{M}\left(1.3 \mathrm{~mL}, 6.5 \mathrm{mmol}, 12\right.$ equiv) and a $30 \% \mathrm{H}_{2} \mathrm{O}_{2}$ solution $(0.9 \mathrm{~mL} ; 14$ equiv). Flash chromatography on silica gel (AcOEt/MeOH: 90/10) allowed the isolation of a yellow foam $(61 \%, 235$ $\mathrm{mg})$.

$\mathrm{R}_{\mathrm{f}}=0.05$ (AcOEt). NMR ${ }^{1} \mathrm{H}\left(400 \mathrm{MHz}, \mathrm{CDCl}_{3}\right): \delta_{\mathrm{H}}: 1.29\left(\mathrm{~m}, 2 \mathrm{H}, \mathrm{H}_{3}\right) ; 1.46-1.65\left(\mathrm{~m}, 5 \mathrm{H}, \mathbf{C H}_{2} \mathbf{C H}_{2} \mathrm{CH}_{2} \mathrm{OH} \mathrm{H}_{2}\right)$; 1.65-1.79 (m, 3H, $\left.\mathrm{H}_{4} \mathrm{H}_{4}\right) ; 1.80-2.04\left(\mathrm{~m}, 2 \mathrm{H}, \mathbf{C H}_{2} \mathrm{CH}_{2} \mathrm{CH}_{2} \mathrm{OH} \mathrm{H}\right) ; 2.50\left(\mathrm{~m}, 1 \mathrm{H}, \mathrm{H}_{3}\right) ; 3.18\left(\mathrm{~m}, 2 \mathrm{H}, \mathrm{H}_{1}\right) ; 3.22-3.53$ $\left(\mathrm{m}, 6 \mathrm{H}, \mathrm{NHCH}_{2} \mathbf{C H}_{2} \mathrm{NH} \mathrm{H}_{5}\right) ; 3.56-3.67\left(\mathrm{~m}, 2 \mathrm{H}, \mathrm{CH}_{2} \mathrm{CH}_{2} \mathbf{C H}_{2} \mathrm{OH}\right) ; 4.20$ (t, 1H, J = 6.8 Hz, CHFmoc); 4.39 (m, $2 \mathrm{H}, \mathbf{C H}_{2} \mathrm{Fmoc}$ ); 4.54 (t, 1H, J = 7.5 Hz, H ); 5.1 (bs, 2H, NHCbz PhCH $) ; 5.74$ (bt, 1H, OCONH); 7.13 (bt, $1 \mathrm{H}$, $\mathrm{NH}) ; 7.36(\mathrm{~m}, 7 \mathrm{H}, \mathrm{Ar}) ; 7.43(\mathrm{t}, 2 \mathrm{H}, . J=7.4 \mathrm{~Hz}, \mathrm{Ar}) ; 7.63(\mathrm{~d}, 2 \mathrm{H}, J=7.3 \mathrm{~Hz}, \mathrm{Ar}) ; 7.80(\mathrm{~d}, 2 \mathrm{H}, J=7.5 \mathrm{~Hz}, \mathrm{Ar})$. $\mathrm{NMR}{ }^{13} \mathrm{C}\left(75 \mathrm{MHz}, \mathrm{CDCl}_{3}\right): \delta_{\mathrm{C}}: 23.1\left(\mathrm{C}_{3}\right) ; 24.8\left(\mathrm{C}_{4}\right) ; 27.1\left(\mathbf{C H}_{2} \mathrm{CH}_{2} \mathrm{CH}_{2} \mathrm{OH}\right) ; 27.8\left(\mathrm{C}_{4}\right) ; 29.2\left(\mathrm{C}_{5}\right) ; 29.8$ $\left(\mathrm{CH}_{2} \mathbf{C H}_{2} \mathrm{CH}_{2} \mathrm{OH}\right)$; 39.6- $41.0\left(\mathrm{NHCH}_{2} \mathbf{C H}_{2} \mathrm{NH}\right) ; 40.6\left(\mathrm{C}_{1}\right) ; 41.5\left(\mathrm{C}_{3}\right) ; 42.4\left(\mathrm{C}_{5}\right) ; 47.1(\mathrm{CHFmoc}) ; 54.8\left(\mathrm{C}_{5}\right)$; $62.02\left(\mathrm{CH}_{2} \mathrm{CH}_{2} \mathbf{C H}_{2} \mathrm{OH}\right) ; 66.5\left(\mathrm{PhCH}_{2}\right) ; 66.8\left(\mathrm{CH}_{2} \mathrm{Fmoc}\right) ; 120.0-125.2-127.1-127.8-128.1-128.5\left(\mathrm{C}_{\mathrm{Ar}}\right)$; $136.7-$ 
141-3-143.8-143.9 $\left(\mathrm{C}_{\text {Arquat }}\right) ; 156.6-157.1(\mathrm{O}-\mathrm{CONH}), 170.8-178.1(\mathrm{CO}) .[\alpha]_{\mathrm{D}}^{20}:-25.5\left(\mathrm{c}=0.9 ; \mathrm{CH}_{2} \mathrm{Cl}_{2}\right)$. IR (neat): $v_{\max } 3308,2924,2854,1659,1531,1450,1252,734$.

\subsubsection{9 (3S, 5S)-3-(1-\{5-Benzyloxycarbonylamino-1-[2-(9H-fluoren-9-ylmethoxycarbonylamino)- ethylcarbamoyl]-pentyl\}-2-oxo-pyrrolidin-3-yl)-propionic acid 19}

To alcohol 18 (270 mg; $0.4 \mathrm{mmol})$ dissolved in $4 \mathrm{~mL}$ of acetone was added dropwise Jones reagent $2.67 \mathrm{M}$ $\left(0.22 \mathrm{~mL} ; 0.59 \mathrm{mmol} ; 1.5\right.$ equiv) at $0{ }^{\circ} \mathrm{C}$. Stirring was prolonged for $30 \mathrm{~min}$. Then $1.5 \mathrm{~mL}$ of isopropanol was added and the mixture was stirred for $20 \mathrm{~min}$ at $0{ }^{\circ} \mathrm{C}$. After addition of $5 \mathrm{~mL}$ of water, acetone was evaporated and the mixture was extracted 3 times with ethyl acetate. The organic layer was washed with 2 $\mathrm{mL}$ of water and then dried with $\mathrm{MgSO}_{4}$ and the solvent removed in vacuum. Flash chromatography performed on silica gel (AcOEt/MeOH/AcOH: 99/0.5/0.5) allowed the isolation of a white foam (64\%; 140 $\mathrm{mg})$.

$\mathrm{R}_{\mathrm{f}}=0.3$ (AcOEt/AcOH: 99/1). NMR ${ }^{1} \mathrm{H}\left(400 \mathrm{MHz}, \mathrm{CDCl}_{3}\right): \delta_{\mathrm{H}}: 1.24\left(\mathrm{~m}, 2 \mathrm{H}, \mathrm{H}_{3}\right) ; 1.45-1.59\left(\mathrm{~m}, 2 \mathrm{H}, \mathrm{H}_{2}\right) ; 1.60-$ $1.86\left(\mathrm{~m}, 3 \mathrm{H}, \mathbf{C H}_{2} \mathrm{CH}_{2} \mathrm{COOH} \mathrm{H} \mathrm{H}_{4}\right) ; 1.86-2.04\left(\mathrm{~m}, 1 \mathrm{H}, \mathrm{H}_{4}\right) ; 2.05-2.19\left(\mathrm{~m}, 2 \mathrm{H}, \mathbf{C H}_{2} \mathrm{CH}_{2} \mathrm{COOH} \mathrm{H}_{4}\right) ; 2.38-2.62$ $\left(\mathrm{m}, 3 \mathrm{H}, \mathrm{CH}_{\mathbf{2}} \mathbf{C H}_{2} \mathrm{COOH} \mathrm{H}\right) ; 3.09-3.21\left(\mathrm{~m}, 2 \mathrm{H}, \mathrm{H}_{1}\right) ; 3.21-3.53\left(\mathrm{~m}, 6 \mathrm{H}, \mathrm{NHCH}_{2} \mathbf{C H}_{2} \mathrm{NH} \mathrm{H}_{5}\right) ; 4.22(\mathrm{t}, 1 \mathrm{H}, J=7$ $\mathrm{Hz}, \mathbf{C H F m o c}) ; 4.38$ (m, 2H, CH $\left.\mathbf{H}_{2} \mathrm{Fmoc}\right) ; 4.46$ (bt, 1H, $\left.\mathrm{H}_{5}\right) ; 5.1$ (bs, 2H, PhCH $) ; 5.33(\mathrm{t}, 1 \mathrm{H}, J=5.4 \mathrm{~Hz}$, NHCbz); 5.91 (bt, 1H, OCONH); 7.35 (m, 7H, Ar); $7.42(\mathrm{t}, 2 \mathrm{H}, . J=7.4 \mathrm{~Hz}, \mathrm{Ar}) ; 7.61(\mathrm{t}, 2 \mathrm{H}, J=7.5 \mathrm{~Hz}, \mathrm{Ar})$; $7.78(\mathrm{~d}, 2 \mathrm{H}, J=7.3 \mathrm{~Hz}, \mathrm{Ar}) . \mathrm{NMR}{ }^{13} \mathrm{C}\left(100 \mathrm{MHz}, \mathrm{CDCl}_{3}\right): \delta_{\mathrm{C}}: 23.0\left(\mathrm{C}_{3}\right) ; 24.7\left(\mathrm{C}_{4}\right) ; 25.8\left(\mathbf{C H}_{2} \mathrm{CH}_{2} \mathrm{COOH}\right) ; 27.7$ $\left(\mathrm{C}_{4}\right) ; 29.2\left(\mathrm{C}_{2}\right) ; 31.3\left(\mathrm{CH}_{2} \mathbf{C H}_{2} \mathrm{COOH}\right) ; 39.7-40.9\left(\mathrm{NHCH}_{2} \mathbf{C H}_{2} \mathrm{NH}\right) ; 40.6\left(\mathrm{C}_{1}\right) ; 40.9\left(\mathrm{C}_{3}\right) ; 42.3\left(\mathrm{C}_{5}\right) ; 47.2$ (CHFmoc); $54.8\left(\mathrm{C}_{5}\right) ; 66.6\left(\mathrm{PhCH}_{2}\right) ; 66.9\left(\mathrm{CH}_{2} \mathrm{Fmoc}\right) ; 120.0-125.2-127.8-127.8-128.1-128.5\left(\mathrm{C}_{\mathrm{Ar}}\right)$; 136.7-1413-143.9-144.0 ( $\left.\mathrm{C}_{\text {Arquat }}\right)$; 156.7-157.1 (O-CONH), 170.8-177.5 (CO). [ $\left.\alpha\right]_{\mathrm{D}}{ }^{20}:-38.6\left(\mathrm{c}=0.9 ; \mathrm{CH}_{2} \mathrm{Cl}_{2}\right)$. IR (neat): $v_{\max } 3309,2925,2855,1659,1528,1450,1251,734 . \mathrm{MS}\left(\mathrm{ES}^{+}\right): m / z=707\left([\mathrm{MNa}]^{+}\right) . \mathrm{HRMS}\left(\mathrm{ES}^{+} \cdot[\mathrm{M}+\mathrm{H}]^{+}\right)$: Calcd for $\mathrm{C}_{38} \mathrm{H}_{45} \mathrm{~N}_{4} \mathrm{O}_{8} 685.3232$ Found 685.3225.

\subsubsection{3-(S)-\{1-[5-(S)-Benzyloxycarbonylamino-1-(2-(aminoethylamino)-pentyl]-2-oxo-pyrrolidin-3- yl\}-propionic acid 20}

Piperidine $(0.04 \mathrm{~mL} ; 0.37 \mathrm{mmol})$ was added to a solution of compound 19 (130 $\mathrm{mg} ; 0.19 \mathrm{mmol})$ dissolved in anhydrous DMF ( $3 \mathrm{~mL}$ ). The mixture was stirred at room temperature for $2 \mathrm{~h}$. DMF was evaporated. The residue was taken off with $30 \mathrm{~mL}$ of dichloromethane, extracted with $\mathrm{HCl} 1 \mathrm{M}$. The aqueous phase was lyophilised to leave $\mathbf{2 0}$ as a foam in a quantitative yield $(95 \mathrm{mg})$.

NMR ${ }^{1} \mathrm{H}(400 \mathrm{MHz}, \mathrm{MeOD}): \delta_{\mathrm{H}}: 1.20-1.39\left(\mathrm{~m}, 2 \mathrm{H}, \mathrm{H}_{3}\right) ; 1.46-1.63\left(\mathrm{~m}, 2 \mathrm{H}, \mathrm{H}_{2}\right) ; 1.63-1.86\left(\mathrm{~m}, 3 \mathrm{H}, \mathbf{C H}_{2} \mathrm{CH}_{2} \mathrm{COOH} \mathrm{H}_{4}\right.$ $\left.\mathrm{H}_{4}\right)$; 1.86-2.00 (m, $\left.1 \mathrm{H}, \mathrm{H}_{4}\right) ; 2.00-2.14\left(\mathrm{~m}, 1 \mathrm{H}, \mathbf{C H}_{2} \mathrm{CH}_{2} \mathrm{COOH}\right) ; 2.14-2.30\left(\mathrm{~m}, 1 \mathrm{H}, \mathrm{H}_{4}\right) ; 2.38-2.62(\mathrm{~m}, 3 \mathrm{H}$, $\mathrm{CH}_{2} \mathbf{C H}_{2} \mathrm{COOH} \mathrm{H}$ ); 3.03-3.20 (m, 4H, NHCH $\left.\mathbf{C H}_{2} \mathrm{NH} \mathrm{H}_{1}\right) ; 3.27-3.42\left(\mathrm{~m}, 1 \mathrm{H}, \mathrm{H}_{5}\right) ; 3.42-3.51\left(\mathrm{~m}, 3 \mathrm{H}, \mathrm{NHCH}_{\mathbf{2}} \mathbf{C H}_{2} \mathrm{NH}\right.$ $\left.\mathrm{H}_{5}\right) ; 4.50\left(\mathrm{q}, 1 \mathrm{H}, J=5.0 \mathrm{~Hz}, \mathrm{H}_{5}\right) ; 5.1\left(\mathrm{~m}, 2 \mathrm{H}, \mathrm{PhCH} \mathbf{H}_{2}\right) ; 7.34$ (m, 5H, Ar). NMR ${ }^{13} \mathrm{C}(100 \mathrm{MHz}, \mathrm{MeOD}): \delta_{\mathrm{C}}: 23.0\left(\mathrm{C}_{3}\right)$; $24.5\left(\mathrm{C}_{4}\right) ; 25.8\left(\mathbf{C H}_{2} \mathrm{CH}_{2} \mathrm{COOH}\right) ; 27.9\left(\mathrm{C}_{4}\right) ; 28.9\left(\mathrm{C}_{2}\right) ; 30.9\left(\mathrm{CH}_{2} \mathbf{C H}_{2} \mathrm{COOH}\right) ; 36.9-40.1\left(\mathrm{NHCH}_{2} \mathbf{C H}_{2} \mathrm{NH}\right) ; 39.3\left(\mathrm{C}_{1}\right)$; $41.1\left(\mathrm{C}_{3}\right) ; 42.8\left(\mathrm{C}_{5}\right) ; 55.2\left(\mathrm{C}_{5}\right) ; 65.9\left(\mathrm{PhCH}_{2}\right) ; 127.4-127.6-128.1\left(\mathrm{C}_{\mathrm{Ar}}\right) ; 137.1\left(\mathrm{C}_{\text {Arquat }}\right)$; $157.5(\mathrm{O}-\mathrm{CONH}), 172.4-$ 174.0-178.2 (CO). $[\alpha]_{\mathrm{D}}{ }^{20}:-24.5\left(\mathrm{c}=0.2 ; \mathrm{D}_{2} \mathrm{O}\right) . \mathrm{MS}\left(\mathrm{ES}^{+}\right): \mathrm{m} / z=463\left([\mathrm{MH}]^{+}\right)$. IR (neat): $v_{\max } 3310,3032,2934,1651$, 1525, 1455, 1253, 1147, 698. HRMS (ES $\left.{ }^{+} .[\mathrm{M}+\mathrm{H}]+\right)$ : Calcd for $\mathrm{C}_{23} \mathrm{H}_{34} \mathrm{~N}_{4} \mathrm{O}_{6} 463.2551$ Found 463.2532.

\subsubsection{3-(S)-\{1-[5-(S)-Benzyloxycarbonylamino-1-(2-(guanidin-diboc)-ethylcarbamoyl)-pentyl]-2- oxo-pyrrolidin-3-yl\}-propionic acid 21}

$\mathrm{N}$-methylmorpholine $(9 \mathrm{~mL} ; 0.08 \mathrm{mmol})$ was added to a solution of compound 20 (40 $\mathrm{mg} ; 0.08 \mathrm{mmol})$ dissolved in anhydrous DMF $(2.5 \mathrm{~mL})$ under argon, then $75 \mathrm{mg}(0.24 \mathrm{mmol}, 3$ equiv) of N-N'-bis-(tertbutoxycarbonyl)-1H-pyrazole-1-carboxamidine was added. The mixture was stirred at room temperature for $18 \mathrm{~h}$. DMF was evaporated The residue was taken off with $30 \mathrm{~mL}$ of ethylacetate, The organic phase was washed with $4 \mathrm{~mL}$ of $\mathrm{HCl} 1 \mathrm{M}$ and then dried with $\mathrm{MgSO}_{4}$ and the solvent removed in vacuum. Flash chromatography performed on silica gel (AcOEt/AcOH: 98.5/1.5) allowed the isolation of an oil (54\%; 30 $\mathrm{mg})$.

$\mathrm{R}_{\mathrm{f}}=0.2(\mathrm{AcOEt} / \mathrm{AcOH}: 98.5 / 1.5) . \mathrm{NMR}{ }^{1} \mathrm{H}\left(400 \mathrm{MHz}, \mathrm{CDCl}_{3}\right): \delta_{\mathrm{H}}: 1.24\left(\mathrm{~m}, 2 \mathrm{H}, \mathrm{H}_{3}\right) ; 1.48(\mathrm{~s}, 9 \mathrm{H}, t \mathrm{Bu}) ;$ 1.38-1.54 (m, 2H, $\left.\mathrm{H}_{2}\right)$; 1.60-1.80 (m, 2H, $\left.\mathrm{H}_{4} \mathrm{H}_{4}\right) ; 1.80-2.05\left(\mathrm{~m}, 3 \mathrm{H}, \mathrm{H}_{4} \mathbf{C H}_{2} \mathrm{CH}_{2} \mathrm{COOH}\right) ; 2.14-2.16(\mathrm{~m}, 1 \mathrm{H}$, $\left.\mathrm{H}_{4}\right)$; 2.42-2.59 (m, 3H, $\left.\mathrm{CH}_{2} \mathbf{C H}_{2} \mathrm{COOH} \mathrm{H}\right) ; 3.17\left(\mathrm{~m}, 2 \mathrm{H}, \mathrm{H}_{1}\right) ; 3.25\left(\mathrm{~m}, 1 \mathrm{H}, \mathrm{H}_{5}\right) ; 3.32-3.62(\mathrm{~m}, 5 \mathrm{H}$, $\left.\mathrm{NHCH}_{2} \mathbf{C H}_{2} \mathrm{NH} \mathrm{H}_{5}\right) ; 4.55$ (bt, $\left.1 \mathrm{H}, J=6.3 \mathrm{~Hz}, \mathrm{H}_{5}\right) ; 5.0$ (bt, 1H, NHCbz); 5.1 (m, 2H, PhCH $) ; 7.2(\mathrm{bt}, 1 \mathrm{H}$, $\mathrm{NH}) ; 7.34(\mathrm{~m}, 5 \mathrm{H}, \mathrm{Ar}) ; 8.51(\mathrm{bs}, 1 \mathrm{H}, \mathrm{NH}) . \mathrm{NMR}{ }^{13} \mathrm{C}\left(75 \mathrm{MHz}, \mathrm{CDCl}_{3}\right): \delta_{\mathrm{C}}: 23.0\left(\mathrm{C}_{3}\right) ; 24.8\left(\mathrm{C}_{4}\right) ; 25.5$ $\left(\mathbf{C H}_{2} \mathrm{CH}_{2} \mathrm{COOH}\right) ; \quad 27.5 \quad\left(\mathrm{C}_{4}\right) ; \quad 25.1-28.2(\mathrm{~s}, \quad t \mathrm{Bu}) ; \quad 29.3 \quad\left(\mathrm{C}_{2}\right) ; \quad 31.1 \quad\left(\mathrm{CH}_{2} \mathbf{C H}_{2} \mathrm{COOH}\right) ; \quad 39.4-40.1$ 
$\left(\mathrm{NHCH}_{2} \mathbf{C H}_{2} \mathrm{NH}\right) ; 40.7\left(\mathrm{C}_{1} / \mathrm{C}_{3}\right) ; 42.0\left(\mathrm{C}_{5}\right) ; 54.6\left(\mathrm{C}_{5}\right) ; 66.6\left(\mathrm{PhCH}_{2}\right) ; 79.7\left(\mathrm{C}_{\mathrm{quat} t \mathrm{Bu}}\right) ; 83.6\left(\mathrm{C}_{\mathrm{q}} t \mathrm{Bu}\right) ; 128.1-$ $128.5\left(\mathrm{C}_{\mathrm{Ar}}\right) ; 137.1\left(\mathrm{C}_{\text {Arquat }}\right) ; 153.1-156.6(\mathrm{O}-\mathrm{CONH}), 163.2(\mathrm{C}=\mathrm{N}) ; 170.4-176.4-177.2(\mathrm{CO}) .[\alpha]_{\mathrm{D}}{ }^{20}:-14.3$ $\left(\mathrm{c}=1 ; \mathrm{CH}_{2} \mathrm{Cl}_{2}\right)$. MS $\left(\mathrm{ES}^{+}\right): \mathrm{m} / z=727\left([\mathrm{MNa}]^{+}\right)$. IR (neat): $v_{\max } 3322,2934,1720,1639,1328,1251,1136$ $\mathrm{cm}^{-1}$. HRMS $\left(\mathrm{ES}^{+}\right.$. [M + H]+): Calcd for $\mathrm{C}_{34} \mathrm{H}_{52} \mathrm{~N}_{6} \mathrm{O}_{10} 705.3818$ Found 705.3827.

\subsubsection{3-(S)-\{1-[5-(S)-Benzyloxycarbonylamino-1-(2-guanidino-ethylcarbamoyl)-pentyl]-2-oxo- pyrrolidin-3-yl\}-propionic acid 22}

The same protocol for deprotection with TFA was applied to compound described above (15 mg; $0.021 \mathrm{mmol}$ ). Guanidyl compound $\mathbf{2 2}$ was obtained as a foam in a quantitative yield $(11 \mathrm{mg})$.

NMR ${ }^{1} \mathrm{H}\left(400 \mathrm{MHz}, \mathrm{D}_{2} \mathrm{O}\right): \delta_{\mathrm{H}}: 1.05-1.16\left(\mathrm{~m}, 2 \mathrm{H}, \mathrm{H}_{3}\right) ; 1.42\left(\mathrm{~m}, 2 \mathrm{H}, \mathrm{H}_{2}\right) ; 1.51-1.75\left(\mathrm{~m}, 4 \mathrm{H}, \mathbf{C H}_{2} \mathrm{CH}_{2} \mathrm{COOH} \mathrm{H}_{4}\right.$ $\mathrm{H}_{4}$ ); 1.94 (dddd, $\left.1 \mathrm{H}, J=7.57 .513 .1 \mathrm{~Hz}, \mathbf{C H}_{2} \mathrm{CH}_{2} \mathrm{COOH}\right) ; 2.11\left(\mathrm{~m}, 1 \mathrm{H}, \mathrm{H}_{4}\right) ; 2.33(\mathrm{t}, 2 \mathrm{H}, J=7.3 \mathrm{~Hz}$, $\left.\mathrm{CH}_{\mathbf{2}} \mathbf{C H}_{2} \mathrm{COOH}\right) ; 2.44\left(\mathrm{~m}, 1 \mathrm{H}, \mathrm{H}_{3}\right) ; 3.04\left(\mathrm{~m}, 2 \mathrm{H}, \mathrm{H}_{1}\right) ; 3.21-3.35\left(\mathrm{~m}, 6 \mathrm{H}, \mathrm{NHCH}_{2} \mathbf{C H}_{2} \mathrm{NH} \mathrm{H}\right.$ ); 4.37 (bt, $1 \mathrm{H}, J=$ $\left.7.3 \mathrm{~Hz}, \mathrm{H}_{5}\right) ; 5.01\left(\mathrm{~m}, 2 \mathrm{H}, \mathrm{Ph} \mathbf{C H}_{2}\right) ; 7.33$ (m, 5H, Ar); 8.03 (bs, 1H, NH). NMR ${ }^{13} \mathrm{C}\left(100 \mathrm{MHz}, \mathrm{D}_{2} \mathrm{O}\right): \delta_{\mathrm{C}}: 22.1$ $\left(\mathrm{C}_{3}\right) ; \quad 24.1 \quad\left(\mathrm{C}_{4}\right) ; \quad 25.4 \quad\left(\mathbf{C H}_{2} \mathrm{CH}_{2} \mathrm{COOH}\right) ; \quad 27.3 \quad\left(\mathrm{C}_{4}\right) ; \quad 28.1 \quad\left(\mathrm{C}_{2}\right) ; \quad 31.2 \quad\left(\mathrm{CH}_{2} \mathbf{C H}_{2} \mathrm{COOH}\right) ; \quad 38.0-40.4$ $\left(\mathrm{NHCH}_{2} \mathbf{C H}_{2} \mathrm{NH}\right) ; 39.9\left(\mathrm{C}_{1}\right) ; 43.1\left(\mathrm{C}_{5}\right) ; 55.3\left(\mathrm{C}_{5}\right)$; $66.7\left(\mathrm{PhCH}_{2}\right) ; 127.5-128.3-128.8\left(\mathrm{C}_{\mathrm{Ar}}\right) ; 136.6\left(\mathrm{C}_{\text {Arquat }}\right)$; 157.0$158.4(\mathrm{O}-\mathrm{CONH} \mathrm{C}=\mathrm{N}) ; 172.8-178.0-179.5(\mathrm{CO}) .[\alpha]_{\mathrm{D}}{ }^{20}:-21.0\left(\mathrm{c}=0.5 ; \mathrm{H}_{2} \mathrm{O}\right) .2638$. IR (neat): $v_{\max } 3328,3179$, 2939, 1645, 1532, 1328, 1254, 1136, $1025 \mathrm{~cm}^{-1}$. HRMS $\left(\mathrm{ES}^{+} .[\mathrm{M}+\mathrm{H}]^{+}\right)$: Calcd for $\mathrm{C}_{24} \mathrm{H}_{36} \mathrm{~N}_{6} \mathrm{O}_{6} 505.2769$ Found 505.2638 .

\subsection{Docking analysis}

The crystal structure of the extracellular segment of human integrin alpha $\mathrm{V}$ beta 3 in complex with a cyclic pentapeptide ligand Arg-Gly-Asp-\{d-Phe $\}-\{N$-methyl-Val- $\}$, called cyclo(RGDF=N $\{\mathrm{Me}\} \mathrm{V}) \quad$ (PDB Accession code $1 \mathrm{~L} 5 \mathrm{G}$ ) was retrieved from protein data bank and used for docking analysis. [18]

Ligands were built with Marvin software considering a $\mathrm{pH}$ value of 7.4 and minimized using calculator plugins[32]. To avoid wrong way calculations and emphasize the right binding mode, ligands were constructed with a simplified linker, but also without any. Herein, results are considered for molecules without any linker.

The protein file has been corrected before use : hydrogen atoms have been added, bond order were adjusted, initial complexed ligand has been deleted. Correct protonation states have been assigned to the residues.

Then, docking calculations using genetic algorithm search were performed with the minimized conformations using the GOLD suite version 5.1[24, 25] into the active site initially containing the ligand cyclo $(\mathrm{RGDF}=\mathrm{N}\{\mathrm{Me}\} \mathrm{V})$.

The cavity was detected with an active site radius of $10 \AA$ from the ligand. The chemPLP fitness function was chosen to evaluate the quality of the results. In the same run, the redocking of the ligand cyclo $(\mathrm{RGDF}=\mathrm{N}\{\mathrm{Me}\} \mathrm{V})$ gave us a reference chemPLP fitness score of 79.5 with a RMSD superposition of $0.96 \AA$ on heavy atoms of complexed initial ligand. Constraints based upon hydrogen-bonds involving two of the three point pharmacophoric functions described by Marinelli[19] and Moitessier[20] were used to favor a similar binding mode. The 10 resulting poses for each compound were clustered by RMSD up to $1.5 \AA$.

The best clusters of poses docking solutions were selected, first of all, on the basis of the averaged attained fitness score values of poses within the clusters and finally, after verification of the binding mode's preservation. Pymol sofware was used for overlays graphical representations.

\subsection{X-ray data collection and refinement}

Small single crystal of $\mathbf{9}$ suitable for X-ray diffraction studies was obtained by using acetonitrile solvent. Single crystal XRD data collection was performed at ambient temperature on a Rigaku RAPID II RAXIS large area curved imaging plate detector diffractometer with graphite monochromated $\mathrm{Cu} \operatorname{K} \alpha$ radiation $(\lambda=1.54184 \AA)$. Cell refinement, data reduction, and scaling were performed using the CrystalClear SM Expert 2.0 r4 package.[33]

The crystal structure was solved with direct methods using SHELXS-97 and final refinement, based on $\mathrm{F}^{2}$, was carried out by full matrix least squares with SHELXL-97 software [34-36]. Refinement was performed anisotropically for all non-hydrogen atoms. Mainly, in the final stages of least-squares refinement, hydrogen atoms were assigned to idealized positions and were allowed to ride with thermal parameters fixed at $1.2 \mathrm{Ueq}$ of the parent atom. The residual electron densities were of no chemical significance.

Relevant crystallographic datas are given in Table S1. Preparation of the material for publication was done 
with the PLATON package with the help of the WinGX gui. [33,37]

CCDC-1015520 record contains the supplementary crystallographic data for this paper. These data can be obtained free of charge from the Cambridge Crystallographic Data Centre via www.ccdc.cam.ac.uk/data_raquest/cif.

\section{$4.4 \alpha_{v} \beta_{3}$ Targeting Efficiency by Solid Phase Receptor Binding Assay}

The receptor binding assays were performed as previously described.[28, 29] $\alpha_{\mathrm{v}} \beta_{3}$ was diluted at $500 \mathrm{ng} / \mathrm{mL}$ in coating Buffer $\left(20 \mathrm{mM}\right.$ tris, pH 7.4, $\left.150 \mathrm{mM} \mathrm{NaCl}, 2 \mathrm{mM} \mathrm{CaCl}_{2}, 1 \mathrm{mM} \mathrm{MgCl}_{2}, 1 \mathrm{mM} \mathrm{MnCl} 2\right)$ and an aliquot of $100 \mu \mathrm{L} /$ well was added to a 96-well microtiter plate (Microlite 2+) and incubated overnight at $4^{\circ} \mathrm{C}$. The plate was washed once with blocking/binding buffer $(20 \mathrm{mM}$ tris, $\mathrm{pH} 7.4,150 \mathrm{mM} \mathrm{NaCl}, 2 \mathrm{mM}$ $\mathrm{CaCl}_{2}, 1 \mathrm{mM} \mathrm{MgCl}, 1 \mathrm{mM} \mathrm{MnCl}, 1 \%$ Bovine Serum Albumine) and incubated an additional $2 \mathrm{~h}$ at room temperature. The plate was rinsed twice with the same buffer and incubated with the radiolabeled ligand at the indicated concentrations for $3 \mathrm{~h}$ at room temperature. For co-incubations, unlabeled competitor was included at the concentrations described. After an additional three washes with blocking/binding buffer, counts were solubilized with boiling $2 \mathrm{~N} \mathrm{NaOH}$ and subjected to $\gamma$-counting. Non specific binding of ligand to the receptor was determined with molar excess (200-fold) of the unlabeled ligand. Each data point is a result of the average of triplicate wells.

\section{Acknowledgements}

This work was supported by ANR 2010-BLAN-1007-1 funding. We are grateful to Dr Pascal Retailleau from ICSN, Gif sur Yvette for X-Ray data collection. The authors thank Dr Erwann Guenin from CSPBAT, Bobigny and Dr Serge Perard for rereading and advices.

\section{Supplementary files}

Figures S1 to S4, table S1 and RMN spectra for synthesis schemes 1 to 3 are available as supplementary files.

[1] F. Danhier, A. Le Breton, V. Preat, RGD-based strategies to target alpha(v) beta(3) integrin in cancer therapy and diagnosis, Molecular pharmaceutics, 9 (2012) 2961-2973.

[2] J.S. Bennett, Structure and function of the platelet integrin $\alpha \operatorname{Ilb} \beta 3$, The Journal of Clinical Investigation, 115 (2005) 3363-3369.

[3] K.-E. Gottschalk, H. Kessler, The Structures of Integrins and Integrin-Ligand Complexes: Implications for Drug Design and Signal Transduction, Angewandte Chemie International Edition, 41 (2002) 3767-3774.

[4] M. Barczyk, S. Carracedo, D. Gullberg, Integrins, Cell Tissue Res, 339 (2010) 269-280.

[5] A. Enns, T. Korb, K. Schlüter, P. Gassmann, H.-U. Spiegel, N. Senninger, F. Mitjans, J. Haier, av $\beta 5$-Integrins mediate early steps of metastasis formation, European Journal of Cancer, 41 (2005) 1065-1072.

[6] A. Meyer, J. Auernheimer, A. Modlinger, H. Kessler, Targeting RGD Recognizing Integrins: Drug Development, Biomaterial Research, Tumor Imaging and Targeting, Current Pharmaceutical Design, 12 (2006) 2723-2747.

[7] M.A. Dechantsreiter, E. Planker, B. Matha, E. Lohof, G. Holzemann, A. Jonczyk, S.L. Goodman, H. Kessler, N-Methylated cyclic RGD peptides as highly active and selective alpha(V)beta(3) integrin antagonists, Journal of medicinal chemistry, 42 (1999) 3033-3040.

[8] C. Mas-Moruno, F. Rechenmacher, H. Kessler, Cilengitide: The First Anti-Angiogenic Small Molecule Drug Candidate. Design, Synthesis and Clinical Evaluation, Anticancer Agents Med Chem, 10 (2010) 753-768.

[9] G. Eisele, A. Wick, A.-C. Eisele, P. Clément, J. Tonn, G. Tabatabai, A. Ochsenbein, U. Schlegel, B. Neyns, D. Krex, M. Simon, G. Nikkhah, M. Picard, R. Stupp, W. Wick, M. Weller, Cilengitide treatment of newly diagnosed glioblastoma patients does not alter patterns of progression, J Neurooncol, 117 (2014) 141-145.

[10] V. Rerat, S. Laurent, C. Burtea, B. Driesschaert, V. Pourcelle, L. Vander Elst, R.N. Muller, J. Marchand-Brynaert, Ultrasmall particle of iron oxide--RGD peptidomimetic conjugate: synthesis and characterisation, Bioorganic \& medicinal chemistry letters, 20 (2010) 1861-1865. 
[11] A. Trabocchi, G. Menchi, N. Cini, F. Bianchini, S. Raspanti, A. Bottoncetti, A. Pupi, L. Calorini, A. Guarna, Click-chemistry-derived triazole ligands of arginine-glycine-aspartate (RGD) integrins with a broad capacity to inhibit adhesion of melanoma cells and both in vitro and in vivo angiogenesis, Journal of medicinal chemistry, 53 (2010) 7119-7128.

[12] M. Marchini, M. Mingozzi, R. Colombo, I. Guzzetti, L. Belvisi, F. Vasile, D. Potenza, U. Piarulli, D. Arosio, C. Gennari, Cyclic RGD peptidomimetics containing bifunctional diketopiperazine scaffolds as new potent integrin ligands, Chemistry, 18 (2012) 6195-6207.

[13] A. Tolomelli, M. Baiula, L. Belvisi, A. Viola, L. Gentilucci, S. Troisi, S.D. Dattoli, S. Spampinato, M. Civera, E. Juaristi, M. Escudero, Modulation of $\alpha v \beta 3$ - and $\alpha 5 \beta 1$-integrinmediated adhesion by dehydro- $\beta$-amino acids containing peptidomimetics, European Journal of Medicinal Chemistry, 66 (2013) 258-268.

[14] S. Neubauer, F. Rechenmacher, R. Brimioulle, F.S. Di Leva, A. Bochen, T.R. Sobahi, M. Schottelius, E. Novellino, C. Mas-Moruno, L. Marinelli, H. Kessler, Pharmacophoric modifications lead to superpotent alphavbeta3 integrin ligands with suppressed alpha5beta1 activity, Journal of medicinal chemistry, 57 (2014) 3410-3417.

[15] P. Galletti, R. Soldati, M. Pori, M. Durso, A. Tolomelli, L. Gentilucci, S.D. Dattoli, M. Baiula, S. Spampinato, D. Giacomini, Targeting integrins alphavbeta3 and alpha5beta1 with new beta-lactam derivatives, Eur J Med Chem, 83 (2014) 284-293.

[16] P. Fabbrizzi, G. Menchi, S. Raspanti, A. Guarna, A. Trabocchi, Role of Side-Chain Bioisosteres in Determining the Binding Affinity of Click Chemistry Derived RGD Peptidomimetics to avß3Integrin, European Journal of Organic Chemistry, (2014) n/a-n/a.

[17] D. Halie, J. Pérard-Viret, S. Dufour, J. Royer, Synthesis and evaluation of substituted indolizidines as peptidomimetics of RGD tripeptide sequence, Tetrahedron, 65 (2009) 14021414.

[18] J.P. Xiong, T. Stehle, R. Zhang, A. Joachimiak, M. Frech, S.L. Goodman, M.A. Arnaout, Crystal structure of the extracellular segment of integrin alpha Vbeta3 in complex with an Arg-Gly-Asp ligand, Science, 296 (2002) 151-155.

[19] L. Marinelli, A. Lavecchia, K.E. Gottschalk, E. Novellino, H. Kessler, Docking studies on alphavbeta 3 integrin ligands: pharmacophore refinement and implications for drug design, Journal of medicinal chemistry, 46 (2003) 4393-4404.

[20] N. Moitessier, C. Henry, B. Maigret, Y. Chapleur, Combining Pharmacophore Search, Automated Docking, and Molecular Dynamics Simulations as a Novel Strategy for Flexible Docking. Proof of Concept: Docking of Arginine-Glycine-Aspartic Acid-like Compounds into the $\alpha v \beta 3$ Binding Site, Journal of medicinal chemistry, 47 (2004) 4178-4187.

[21] A.M. Clark, P. Labute, 2D Depiction of Protein-Ligand Complexes, Journal of Chemical Information and Modeling, 47 (2007) 1933-1944.

[22] M. Pfaff, K. Tangemann, B. Müller, M. Gurrath, G. Müller, H. Kessler, R. Timpl, J. Engel, Selective recognition of cyclic RGD peptides of NMR defined conformation by alpha IIb beta 3, alpha V beta 3, and alpha 5 beta 1 integrins, Journal of Biological Chemistry, 269 (1994) 20233-20238.

[23] R. Haubner, D. Finsinger, H. Kessler, Stereoisomeric Peptide Libraries and Peptidomimetics for Designing Selective Inhibitors of the $\alpha v \beta 3$ Integrin for a New Cancer Therapy, Angewandte Chemie International Edition in English, 36 (1997) 1374-1389.

[24] G. Jones, P. Willett, R.C. Glen, Molecular recognition of receptor sites using a genetic algorithm with a description of desolvation, Journal of molecular biology, 245 (1995) 43-53.

[25] Gold Suite 5.1, in, Cambridge Crystallographic Data Centre (http://www.ccdc.cam.ac.uk/Solutions/GoldSuite/Pages/GOLD.aspx), Cambridge, UK, 2012.

[26] H. Sajiki, K. Hattori, K. Hirota, Highly Chemoselective Hydrogenation with Retention of the Epoxide Function Using a Heterogeneous $\mathrm{Pd} / \mathrm{C}$-Ethylenediamine Catalyst and THF, Chemistry - A European Journal, 6 (2000) 2200-2204. 
[27] D. Misiti, G. Zappia, G. Delle Monache, Selective Catalytic Hydrogenation of $\gamma$-Amino $\alpha, \beta$-Unsaturated Esters in the Presence of Hydrogenable Protecting Groups, Synthesis, 1999 (1999) 873-877.

[28] C.C. Kumar, H. Nie, C.P. Rogers, M. Malkowski, E. Maxwell, J.J. Catino, L. Armstrong, Biochemical characterization of the binding of echistatin to integrin alphavbeta3 receptor, The Journal of pharmacology and experimental therapeutics, 283 (1997) 843-853.

[29] R.A. Orlando, D.A. Cheresh, Arginine-glycine-aspartic acid binding leading to molecular stabilization between integrin alpha $\mathrm{v}$ beta 3 and its ligand, The Journal of biological chemistry, 266 (1991) 19543-19550.

[30] V. Rerat, G. Dive, A.A. Cordi, G.C. Tucker, R. Bareille, J.l. Amédée, L. Bordenave, J. Marchand-Brynaert, $\alpha v \beta 3$ Integrin-Targeting Arg-Gly-Asp (RGD) Peptidomimetics Containing Oligoethylene Glycol (OEG) Spacers, Journal of medicinal chemistry, 52 (2009) 7029-7043.

[31] J. Bolley, Y. Lalatonne, O. Haddad, D. Letourneur, M. Soussan, J. Perard-Viret, L. Motte, Optimized multimodal nanoplatforms for targeting alpha(v)beta3 integrins, Nanoscale, 5 (2013) 11478-11489.

[32] Marvin 6.0.0, in, ChemAxon (http://www.chemaxon.com), 2013.

[33] A.L. Spek, Structure validation in chemical crystallography, Acta crystallographica. Section D, Biological crystallography, 65 (2009) 148-155.

[34] G.M. Sheldrick, A short history of SHELX, Acta crystallographica. Section A, Foundations of crystallography, 64 (2008) 112-122.

[35] G.M. Sheldrick, T.R. Schneider, SHELXL: high-resolution refinement, Methods in enzymology, 277 (1997) 319-343.

[36] G.M. Sheldrick, SHELXL-97, in, University of Göttingen, Germany, 1997.

[37] L. Farrugia, WinGX suite for small-molecule single-crystal crystallography, J Appl Crystallogr, 32 (1999) 837-838. 